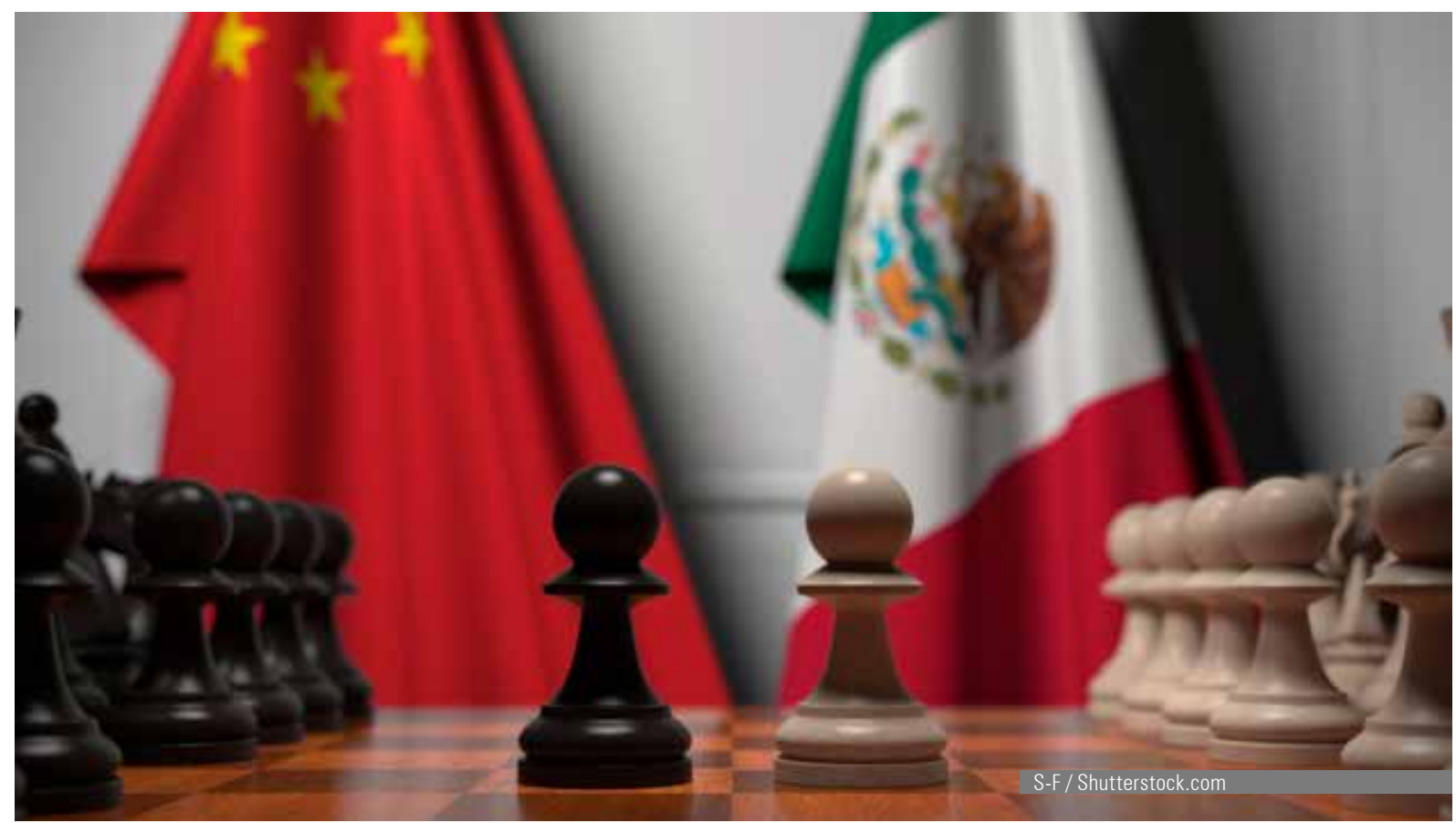

\title{
Asia, la Cuarta Transformación y el cambio de poder global
}

\section{Asia, The Fourth Transformation and the Global Change of Power}

\section{Adolfo Alberto Laborde Carranco*}

Universidad Anáhuac, México

adolfo.labordec@anahuac.mx

https://orcid.org/0000-0002-4925-5229

\section{Marcela Maldonado Bodart**}

Universidad Autónoma de Baja California, México

bodart@uabc.edu.mx

https://orcid.org/0000-0001-7218-1590

Recibido: 29 de enero 2020

Aprobado: 6 de abril 2020

Publicado: 15 de junio 2020

\section{Resumen}

El presente trabajo tiene como objetivo principal ubicar los intereses nacionales mexicanos dentro de su política exterior, en el contexto de la transformación que hoy se experimenta en México, denominada la Cuarta Transformación —4T-, considerando los cambios en el equilibrio de poder global, así como exponer alternativas en la materia que coadyuven a cumplirlos. Partiendo de la importancia de la diversificación de las relaciones económicas comerciales con el exterior como elemento clave para dejar de depender del mercado de Norte América, que de acuerdo a la Secretaría de Economía (2019) en México, las exportaciones mexicanas hacia el mercado estadounidense representaron 76\% del total en el año 2018. De ahí que el presente trabajo parte del supuesto de que a pesar de que la diversificación política y económica del país es una necesidad, aún no hay estrategias claras frente a las propuestas vertidas por nuestros principales socios en el mundo, especialmente los de Asia (China, Corea del Sur y Japón), que recientemente han mostrado un interés en profundizar sus lazos con México. Para ello, se realizará un análisis bajo el enfoque neorrealista de las relaciones internacionales, de las fuentes del poder de Joseph S. Nye Jr. (2011), así como de la teoría de la transición de poder Tammen (2000).

\section{Palabras clave}

México, política exterior, Asia, 4T, transición de poder, globalización. 


\section{Abstract}

This paper mainly places Mexico's national interests within its foreign policy, as part of the transformation context that Mexico is currently undergoing, known as The Fourth Transformation - 4T. It takes into account changes in the global balance of power and presents alternatives in this area, which will contribute to their accomplishment. Based on the importance of diversifying international economic trade relationships, as a key factor to eliminate dependence on the North American market, Mexican exports to the American market accounted for $76 \%$ of the total exports in 2018 according to the Secretariat of Economy (2019). Consequently, this paper is based on the assumption that "while the country's political and economic diversification is necessary, there are still no clear strategies, as opposed to the proposals made by our main partners in the world, especially those in Asia (China, South Korea, and Japan), which have recently shown interest in strengthening their ties with Mexico." To this end, an analysis is conducted using the neorealist approach of international relationships, of the sources of power by Joseph S. Nye Jr. (2011), and of the power transition theory by Tammen (2000).

\section{Keywords:}

Mexico, Foreign Policy, Asia, 4T, Power Transition, Globalization

\section{La Política Exterior. Un enfoque teórico}

Para entender la política exterior de México en el contexto de la 4T es preciso describir la política exterior enmarcada en su historia diplomática reciente. De la misma manera, es necesario entender cuáles son los componentes que integran al Estado-Nación mexicano. Para ello, se exponen los estudios de algunos autores fundamentales que abordan el tema del contenido de la política exterior y de los elementos que la constituyen.

En este sentido, John Stoessinger (1994) afirma que el hombre ha construido un entorno para hacer frente a la vergüenza y la desesperación, pero también para fundamentar su orgullo y esperanza; de ahí la anatomía que presenta del Estado-Nación. Describe cómo el mundo está dividido en estas unidades, que tienen el poder para decretar la muerte, el asilo o la ciudadanía. Rescata el concepto que Jean Bodin propuso en el siglo XVI, para señalar que los hombres son los que lo dotan de su soberanía. Aporta la idea de que la soberanía del Estado se mantiene en tiempo de paz, no de guerra, por lo que se pregunta sobre la validez o los cambios que ha sufrido con la llegada de la era atómica. John Stoessinger concluye que se ha vuelto ambivalente, ya que las organizaciones supranacionales la fortalecen en algunos aspectos, mientras que, en otros, la debilitan. Sobre el nacionalismo se pregunta acerca de su origen y sobre sus aspectos positivos y negativos (Stoessinger,1994, p. 21) para argumentar que el matiz que adopta depende del contexto de desarrollo histórico de cada nación. Los elementos objetivos de una nación, según el autor, son la base geográfica, económica, lingüística y cultural. Sobre el poder, sostiene que es un concepto vago, que no incorpora la suma de las capacidades sociales; el poder es relativo, la capacidad no, concluye.

Al respecto, John A. Vásquez (1992), en su obra El poder de la política del poder, se inserta en este debate, con la pregunta sobre ¿cuál es la política del poder? En sus planteamientos retoma el enfoque realista para desarrollar un análisis en cinco campos diferentes: 
1. Política exterior

2. Procesos sistémicos

3. Causas de guerra

4. Disuasión y negociación

5. Supranacionalismo

En el tema de la política exterior, explica que esta materia tiene una serie de ramificaciones, que se sintetizan en tres aspectos:

1. El interés nacional

2. El grado de poder nacional

3. Desarrollo de una perspectiva de toma de decisiones y evaluación de las posibilidades de que su ejecución provoque una crisis dinámica que pudiera conducir a la guerra. Es decir, primero se determina el interés nacional, se evalúa el poder nacional y, por último, se contempla la perspectiva de la toma de decisiones.

Por otra parte, respecto al tema del interés nacional, Morgenthau (1948), señala que existen diversos intereses nacionales, como son:

1. La integridad territorial

2. La soberanía nacional

3. La integridad cultural, que aporta los elementos esenciales para que el Estado-Nación sobreviva.

Asimismo, según este autor, cualquier otro interés que aparezca puede clasificarse como subnacional o supranacional, es decir, el interés nacional permanece constante. Sobre esta base, los hombres de Estado desarrollan objetivos "lógicamente compatibles" con el mantenimiento de la integridad territorial, la soberanía nacional y la integridad cultural, Morgenthau (1948), en este sentido, indica que la política exterior contrasta con la noción idealista de las relaciones internacionales como la búsqueda de la cooperación internacional en los ámbitos legal y moral. En este sentido y analizando seriamente la política exterior se puede llegar a una evaluación de las razones por las que un Estado adopta ciertas conductas; no toda la políica puede clasificarse por sí misma como un error o un acierto, sino que el juicio que de ella se haga debe considerarse en función del interés nacional.

Wolfers (1962) destaca que el concepto de interés nacional no es sinónimo del término seguridad nacional. Para él, el concepto de seguridad nacional es tan amplio que incluye múltiples aspectos que hacen que resulte muy difícil definir expresamente lo que incluye, por eso, opina que el concepto de Morgenthau de seguridad nacional se limitaba a la actitud defensiva que el Estado debía asumir de modo constante frente a la amenaza del exterior.

Por su parte, Frederic S. Pearson (2003) sostiene que no todos los países observan el mismo comportamiento, los hay injerencistas, aislacionistas, activos y pasivos. Toda su conducta está guiada en función de determinar el interés nacional para proceder a realizar un análisis comparativo de la política exterior acorde con una serie de factores internos y externos. El concepto de intereses nacionales desde el punto de vista realista, expresa que los Estados buscan maximizar sus ventajas frente a otros, en función del interés nacional. Para hacerlo, según el autor, existen tres intereses fundamentales, que a veces son incompatibles entre ellos:

1. Asegurar la supervivencia física de la patria

2. Promover el bienestar económico de sus habitantes

3. Preservar la autodeterminación nacional en lo que respecta a la naturaleza del sistema gubernamental del país 
En este sentido, Pearson (2003, p. 171) elabora un marco explicativo del tema que implica abordar otros aspectos, que son:

1. Los factores sistémicos (la geografía, las interacciones y vínculos internacionales y la estructura del sistema internacional)

2. Los atributos nacionales

3. Las características demográficas

4. Las cualidades económicas

5. Los atributos gubernamentales

6. La opinión pública, que suele ser cambiante y un factor decisivo en el futuro de un líder o un país

7. Los factores de idiosincrasia

En cuanto a los objetivos que persigue la política exterior, Karl W. Deutsch (1990) aporta elementos que contribuyen a determinar el campo de la política exterior;

1. Preservar la independencia

2. La seguridad

3. Mantener y proteger sus intereses económicos (en particular los de los grupos más poderosos)

Igualmente, sostiene que la política exterior también busca defenderse de las intromisiones externas, ya sean de tipo ideológico o político. Asegura que las organizaciones de seguridad nacional y la protección de sus intereses son los aspectos principales de la política exterior de toda gran nación. Finalmente, menciona que las implicaciones psicológicas que se utilizan en el discurso de la política exterior son parte de un diseño estratégico de la misma.

En el caso específico de la política exterior de México, puede afirmarse que los planteamientos de John A. Vásquez (1992, p. 55) describen la situación del país en el contexto internacional actual. En cuanto a los análisis sobre el interés nacional, los planteamientos de Frederic S. Pearson (2003, p. 66) y de Karl Deutsch (1990, p. 67) ayudarán a precisar las prioridades de la política exterior mexicana en el contexto de la 4T, así como también los sucesivos cambios que experimentará en el ámbito internacional y, especialmente, con respecto en las regiones donde México planteó sus intereses nacionales.

En cuanto a las modalidades de poder, Josep Nye Jr. (2011) plantea que existen "tres grandes tipos de poderes: poder duro (hard power), basado en los recursos militares y económicos; poder suave (soft power), basado en factores como instituciones, ideas, valores, cultura y legitimidad de las acciones, y el poder inteligente (smart power), que integra elementos como diplomacia, defensa, desarrollo y demás herramientas de los otros dos tipos de poderes".

En este sentido, Nye (2011) "señala que la situación ideal para cualquier país es la estratégica combinación de los tres, aunque claramente no todos los países cuentan con fuentes de poder, como los recursos militares y económicos, así como no todos los recursos de poder de un país son efectivos en todo momento y su acumulación no tiene mayor utilidad si los resultados de sus acciones no corresponden a los objetivos planteados".

Por su parte, y de manera adicional, la teoría de la transición de poder, identifica y define al poder, como la combinación de los siguientes elementos: el número de personas que pueden trabajar y pelear; la productividad de la economía y la efectividad del sistema político en la extracción y contribución de los ciudadanos para avanzar en los objetivos nacionales (Tammen, 2000, p. 8). 


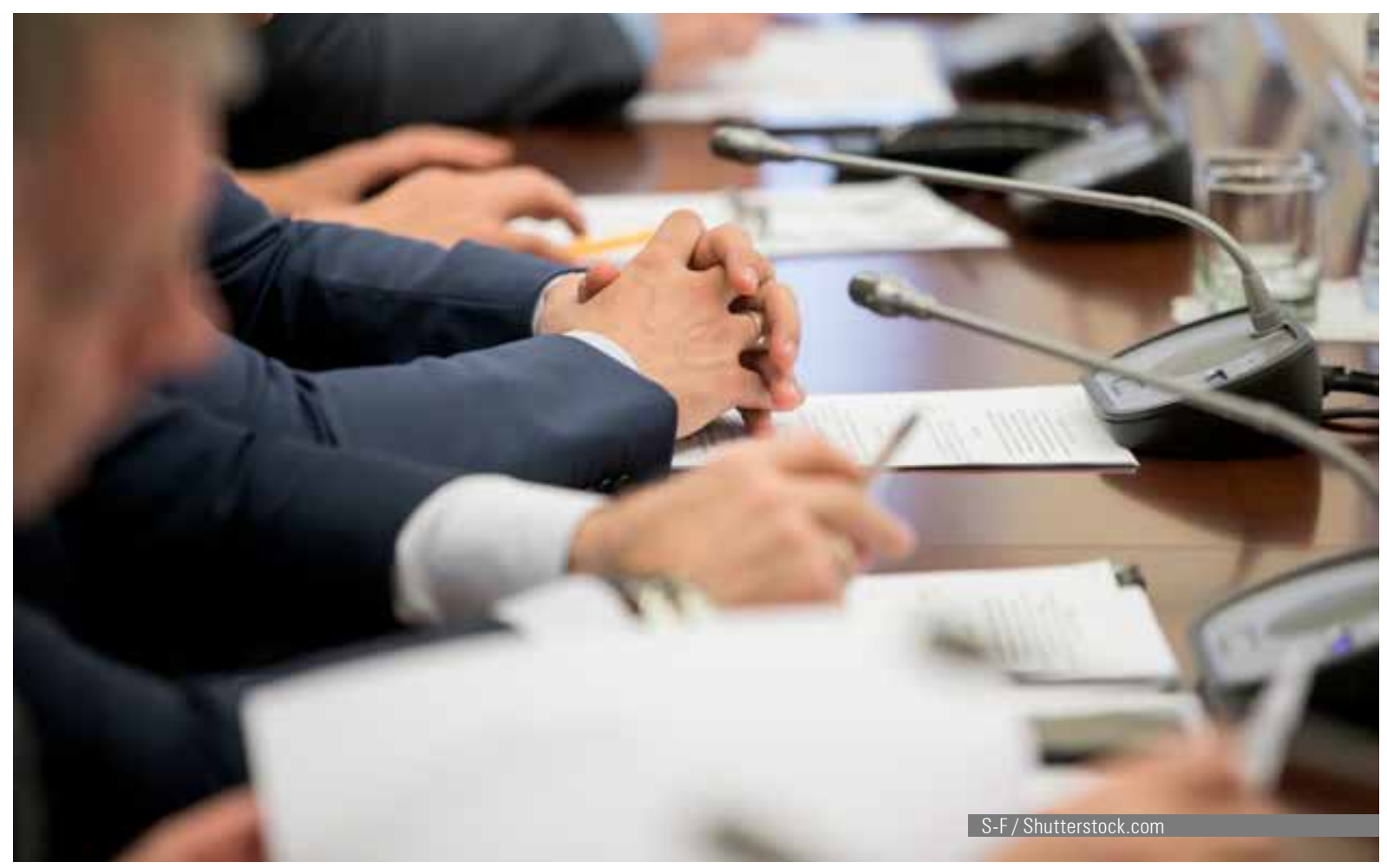

\section{Asia, política exterior y la 4T}

La vinculación entre la 4T y la política exterior de México puede identificarse, en una primera instancia, con el posicionamiento del canciller mexicano Marcelo Ebrard, a partir de su participación en la $74^{\circ}$ Asamblea General de las Naciones Unidas (ONU) el pasado 28 de septiembre de 2019. El canciller Ebrard expuso ante el mundo la Cuarta Transformación (4T) que México está experimentando. Desde esta perspectiva, señaló que los principales objetivos del gobierno del presidente Andrés Manuel López Obrador son terminar con la corrupción, reducir la desigualdad, acelerar el crecimiento de la economía y que México sea una sociedad segura. De igual forma, dejó claros los principios de la política exterior de México que radican en los principios de "no intervención, autodeterminación de los pueblos y la solución pacífica de las controversias", así como también que el gobierno mexicano se considera feminista, con equidad de género, definido como fundamento de la equidad. Asimismo, aseguró que México respaldará todos los esfuerzos del Beijing más 25, que es el programa de la ONU más ambicioso para empoderar a las niñas y mujeres de todo el mundo, en el año 2020 cumplirá 25 años de la conferencia en esa ciudad donde se establecieron estos objetivos (ONU, 2019). Paralelamente, se estableció que el gobierno de México seguirá luchando contra el cambio climático, la solución de los flujos migratorios y en las desigualdades, enfatizando que entre los principales intereses del país se incluye reforzar, ampliar y profundizar la adhesión al sistema multilateral y a un multilateralismo eficaz (Newsweek en español, 28 de septiembre de 2019).

A pesar de lo anteriormente planteado, los principios, bases y fundamentos de la política exterior de México se enmarcan en el artículo 89 fracción X de la Constitución Política de los Estados Unidos Mexicanos (Constitución Política de los Estados Unidos Mexicanos, 2019), que textualmente indica lo siguiente: 
Dirigir la política exterior y celebrar tratados internacionales, así como terminar, denunciar, suspender, modificar, enmendar, retirar reservas y formular declaraciones interpretativas sobre los mismos, sometiéndolos a la aprobación del Senado. En la conducción de tal política, el titular del poder ejecutivo observará los siguientes principios normativos: la autodeterminación de los pueblos, la no intervención, la solución pacífica de controversias, la proscripción de la amenaza o el uso de la fuerza en las relaciones internacionales, la igualdad jurídica de los Estados, la cooperación internacional para el desarrollo, el respeto, la protección y promoción de los derechos humanos y la lucha por la paz y la seguridad internacionales.

Dentro de los mismos, salvo en las alianzas internacionales en el seno de los organismos globales, donde caben todos, es difícil descifrar cómo estos principios se podrían ver reflejados en el contexto de la 4T y la política exterior hacia Asia, independientemente de que en múltiples ocasiones se ha pensado en esta región como una alternativa —real o no- para la diversificación de las relaciones exteriores — políticas, económicas principalmente-. Antes de entrar en detalle de las recomendaciones para implementar una política exterior de mayor calado con los países en cuestión, es necesario ubicar los intereses nacionales el contexto y la coyuntura de la 4T.

El Plan Nacional de Desarrollo (PND) (Gobierno de México, 2019) es un documento de suma importancia que plasma los objetivos de desarrollo de la administración en turno. Es, en otras palabras, una ruta crítica para alcanzar los objetivos planteados en la materia. Ya se ha hablado hasta el cansancio de este, de hecho, muchos han afirmado que es un bosquejo de lo que debería ser un PND. Toca ahora a ambas cámaras analizarlo y aprobarlo en su caso, sin embargo, antes de que eso suceda, sería conveniente, en materia de política exterior, robustecer lo que ahí se ha planteado. Si bien es cierto, la vecindad con los Estados Unidos ha sido un factor fundamental en la definición de los intereses nacionales que se defenderán o buscarán cumplirse mediante el diseño de una política exterior basada en ellos, tradicionalmente se habían considerado a otras regiones como punta de lanza del desarrollo nacional a través de su incorporación al PND. En este caso, no ha sido así. La presente propuesta establece a Norteamérica como una región prioritaria para México; Centroamérica como parte de una tradición y zona de influencia y la región de América Latina, como parte de nuestra naturaleza diplomática desde una perspectiva histórica. El fenómeno migratorio se toca en un apartado posterior al de la política exterior. En el documento no se profundiza en regiones que en los próximos años serán factor importante de la dinámica de las relaciones internacionales, tal es el caso de Asia, o bien, Medio Oriente, sin mencionar a Europa con quien recientemente acabamos de relanzar una nueva relación estratégica a través del Tratado de Libre Comercio entre México y la Unión Europea (TLCUM) próximo a ratificarse. África ni si quiera fue mencionada.

Si bien es cierto, se ha declarado que, en el presente gobierno, la mejor política exterior será la continuación de la política interna, debemos considerar que México no es una isla; de hecho, la interdependencia económica o globalización (económica, política y social) impactarán a nuestro país de una manera u otra. Desde el alza de los precios de los hidrocarburos por los conflictos latentes en Venezuela o Medio Oriente, hasta la reorientación de los procesos productivos (cadenas de valor) derivadas de las modificaciones a la naturaleza del nuevo T-MEC (nuevas reglas de origen), o bien, por la guerra comercial entre Estados Unidos y sus socios comerciales, pasando por los problemas migratorios de carácter global, sin mencionar los efectos de la crisis sanitaria causada por el COVID-19 que azota el mundo desde principios del año 2020 y que traerá consecuencias negativas para el país.

Los pronósticos de este año, de acuerdo a las calificadoras Standard \& Poor's y J.P. Morgan pronostican una fuerte caída del PIB de entre $-5 \%$ 
y el $-7 \% \%$ en este 2020 , lo cual bajó la calificación soberana de México a "BBB", lo que significa que México está a dos escalones de convertirse en riesgo de inversión "especulativo" (El Universal, 27 de marzo de 2020). Si a esto le sumamos que uno de los rubros que serán más afectados por el COVID-19, además del comercio exterior, que representó para 2018 alrededor de 77,6\% del PIB (Santander, 2020), será el turismo, que guarda una proporción de 8,7\% del PIB para el mismo año (INEGI, 2020) la situación es más compleja de lo que parece.

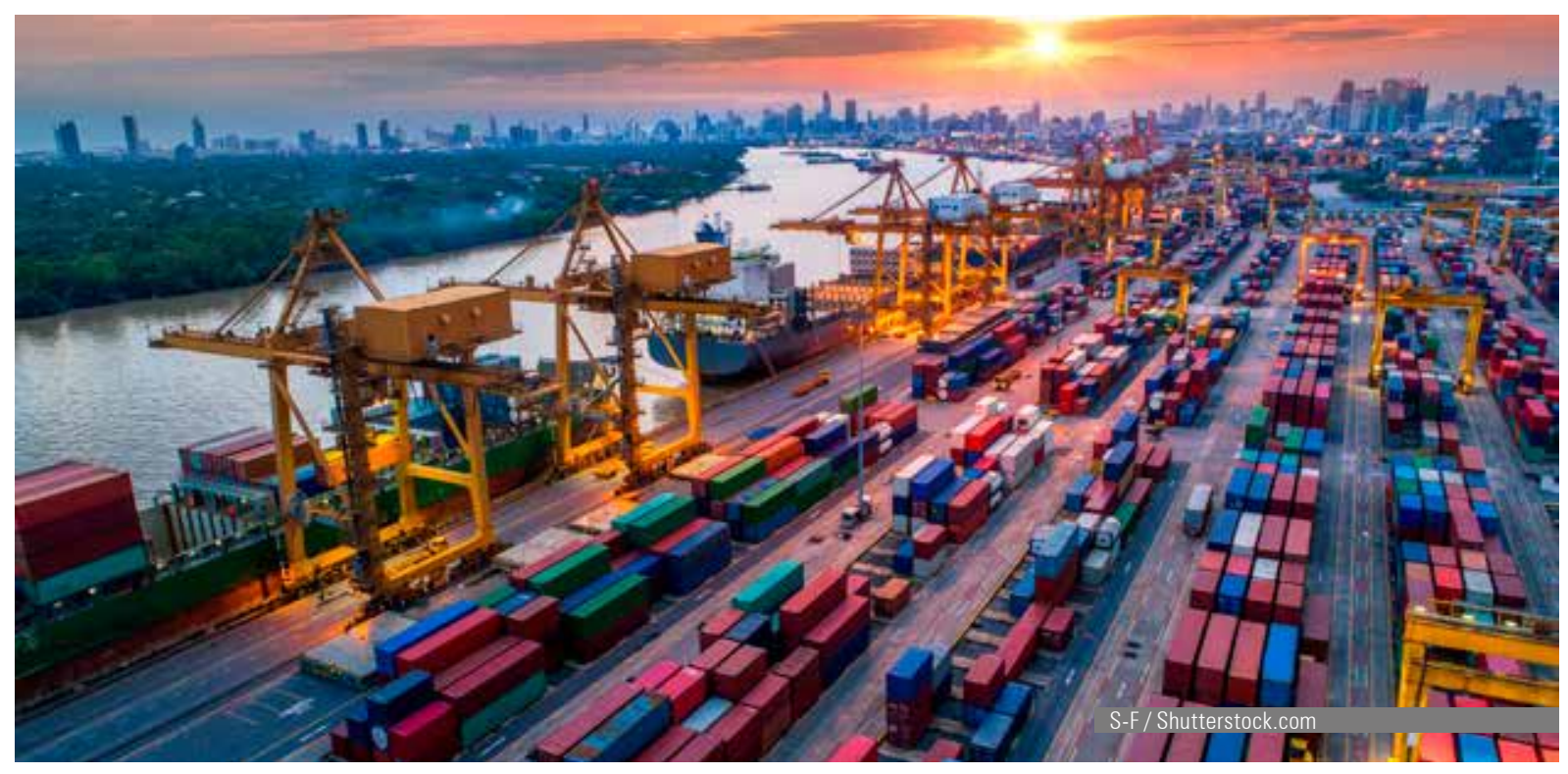

Como se mencionó anteriormente, México no es país aislado de la economía internacional y lo que ha acontecido en materia económica en Asia será una constante en nuestro país. Los datos no mienten. China, Japón y en menor medida Corea, son nuestros principales socios comerciales en Asia y dependemos de ellos en gran cantidad de insumos (por ejemplo, autopartes, eléctricos, manufacturas, químicos) y de bienes de capital necesarios para una gran parte de la producción nacional. Si bien es cierto existe un déficit comercial con Asia de alrededor de USD 140.713.823 millones (Banco de México, 2020), mismo que se compensa con nuestro superávit con América del Norte de USD 169.786.685 millones (Banco de México, 2020), la lógica de nuestra estrategia económica-comercial y de inversiones se tendrá que modificar debido a lo expuesto anteriormente.

\subsection{China}

Este país, además de mantener una expansión económica y militar en el mundo, comenzó a usar su poder suave a través de un hecho histórico rescatado en el año 2013 denominado la Nueva Ruta de la Seda (OBOR por sus siglas en inglés). Este proyecto, que ya se instrumentaliza en varios países de Asia y Europa ha sido ofrecido a otras regiones, entre ellas, América Latina, sobre todo en el contexto del 40 aniversario del establecimiento de las reformas económicas y apertura al exterior de ese país. Los resultados están a la vista. Por ejemplo, en el terreno comercial, cabe destacar que las importaciones provenientes de China para el año de 2019 alcanzaron un valor de USD 83.052.518 millones y las exportaciones mexicanas USD 7.130.476 millones. El saldo favorable es para China con USD 75.922.042 millones. Esto es una muestra de la 
naturaleza deficitaria del comercio exterior de México con ese país que desde el año de 1993 al primer trimestre del 2020 acumuló un déficit comercial de alrededor USD -779.683.916 millones, como se aprecia en la Tabla 1.

Tabla1. Balanza comercial de México con China 1993 - 2020 (*millones de dólares)

\begin{tabular}{|c|c|c|c|c|}
\hline Año & *Exportaciones & *Importaciones & $\begin{array}{c}\text { *Comercio } \\
\text { Total }\end{array}$ & $\begin{array}{l}\text { *Balanza } \\
\text { Comercial }\end{array}$ \\
\hline 1993 & 44.777 & 386.442 & 431.219 & -341.665 \\
\hline 1994 & 42.162 & 499.655 & 541.817 & -457.493 \\
\hline 1995 & 37.002 & 520.580 & 557.582 & -483.578 \\
\hline 1996 & 38.277 & 759.704 & 797.981 & -721.427 \\
\hline 1997 & 45.882 & 1.247.376 & 1.293 .258 & -1.201 .494 \\
\hline 1998 & 105.977 & 1.616 .494 & 1.722 .471 & -1.510 .517 \\
\hline 1999 & 126.338 & 1.921 .057 & 2.047 .395 & -1.794 .719 \\
\hline 2000 & 203.586 & 2.879 .620 & 3.083 .206 & -2.676 .034 \\
\hline 2001 & 281.774 & 4.027 .253 & 4.309 .027 & -3.745 .479 \\
\hline 2002 & 653.913 & 6.274 .381 & 6.928 .294 & $-5.620,468$ \\
\hline 2003 & 974.369 & 9.400 .591 & 10.374 .960 & -8.426 .222 \\
\hline 2004 & 986.304 & 14.373 .843 & 15.360 .147 & -13.387 .539 \\
\hline 2005 & 1.135 .544 & 17.696.338 & 18.831 .882 & -16.560 .794 \\
\hline 2006 & 1.688 .107 & 24.438 .279 & 26.126 .386 & -22.750 .172 \\
\hline 2007 & 1.895 .338 & 29.743 .656 & 31.638 .994 & -27.848 .318 \\
\hline 2008 & 2.044 .750 & 34.690 .310 & 36.735 .060 & -32.645 .560 \\
\hline 2009 & 2.207 .788 & 32.528 .967 & 34.736 .755 & -30.321 .179 \\
\hline 2010 & 4.182 .842 & 45.607 .551 & 49.790 .393 & -41.424 .709 \\
\hline 2011 & 5.964 .225 & 52.248 .003 & 58.212 .228 & -46.283 .778 \\
\hline 2012 & 5.720 .732 & 56.936 .129 & 62.656 .861 & -51.215 .397 \\
\hline 2013 & 6.468 .508 & 61.321 .376 & 67.789 .884 & -54.852 .868 \\
\hline 2014 & 5.964 .143 & 66.257 .292 & 72.221 .435 & -60.293 .149 \\
\hline 2015 & 4.873 .152 & 69.988 .130 & 74.861 .282 & -65.114 .978 \\
\hline 2016 & 5.411 .256 & 69.521 .795 & 74.933 .051 & -64.110 .539 \\
\hline 2017 & 6.712 .580 & 74.150 .446 & 80.863 .026 & -67.437 .866 \\
\hline 2018 & 7.428.917 & 83.510 .571 & 90.939 .488 & -76.081 .654 \\
\hline 2019 & 7.130 .476 & 83.052 .518 & 90.182 .994 & -75.922 .042 \\
\hline $2020 / 1$ & 485.625 & 6.939 .902 & 7.425 .527 & -6.454 .277 \\
\hline Total & 72.854 .344 & 852.538 .259 & 925.392 .603 & -779.683 .915 \\
\hline
\end{tabular}

Fuente: Elaboración propia, con datos del Sistema de Consulta de Información Estadística (Secretaría de Economía, 2020)

Nota 1: Las estadísticas están sujetas a cambio, en particular las más recientes.

Nota 2: Las exportaciones de 1993 a 2001 la atribución de país sigue el criterio de país comprador. A partir de 2002 el criterio utilizado es el de país destino. Nota 3: /1 enero 
Cabe destacar que dentro del universo de los productos que se comercializan entre ambos países destacan, por parte de China las 99 principales fracciones arancelarias, los siguientes: circuitos, electrodomésticos, conductores, maquinaria-equipo (bienes de capital) y manufactura en general. Ver Tabla 2 en anexos. En el caso de México, dentro de las principales 99 fracciones arancelarias, se destacan: minerales de cobre y sus derivados, motores, vidrio, carne de res, carne de puerco, moras, aguacate, cerveza, tequila, mezcal, plátanos, camarones, langostinos, aparatos eléctricos, autopartes y manufactura en general (Secretaría de Economía, 2020). Ver Tabla 3 en anexos.

\subsection{Japón}

Las relaciones bilaterales con el país del sol naciente son fuertes, sin embargo, en materia comercial no es un secreto que ha sido desplazado por China. A pesar de ello, la relación comercial en el año 2019 fue significativa con un valor de USD 17.963.780 millones en importaciones y USD 4.102.349 millones en exportaciones mexicanas. El saldo comercial es desfavorable para México con un déficit comercial de USD 13.861.431 millones y el saldo negativo acumulado desde el año de 1993 para México es de USD -268.511.221 millones (Secretaría de Economía, 2020). Ver Tabla 4.

Tabla 4. Balanza comercial de México con Japón, 1993 - 2020 ( ${ }^{*}$ millones de dólares)

\begin{tabular}{|c|c|c|c|c|}
\hline Año & *Exportaciones & *Importaciones & *Comercio Total & $\begin{array}{c}\text { *Balanza } \\
\text { Comercial }\end{array}$ \\
\hline 1993 & 706.551 & 3.928 .743 & 4.635 .294 & -3.222 .192 \\
\hline 1994 & 1.007 .042 & 4.780 .541 & 5.787 .583 & -3.773 .499 \\
\hline 1995 & 979.312 & 3.952 .099 & 4.931 .411 & -2.972 .787 \\
\hline 1996 & 1.393 .404 & 4.132 .093 & 5.525 .497 & -2.738 .689 \\
\hline 1997 & 1.156 .428 & 4.333 .619 & 5.490 .047 & -3.177 .191 \\
\hline 1998 & 851.235 & 4.537 .043 & 5.388 .278 & -3.685 .808 \\
\hline 1999 & 776.093 & 5.083 .124 & 5.859 .217 & -4.307 .031 \\
\hline 2000 & 930.535 & 6.465 .683 & 7.396 .218 & -5.535 .148 \\
\hline 2001 & 620.550 & 8.085 .693 & 8.706 .243 & -7.465 .143 \\
\hline 2002 & 1.194 .206 & 9.348 .549 & 10.542 .755 & -8.154 .343 \\
\hline 2003 & 1.172 .583 & 7.595 .048 & 8.767 .631 & -6.422 .465 \\
\hline 2004 & 1.190 .497 & 10.583 .397 & 11.773 .894 & -9.392 .900 \\
\hline 2005 & 1.470 .012 & 13.077 .780 & 14.547 .792 & -11.607 .768 \\
\hline 2006 & 1.594 .038 & 15.295 .157 & 16.889 .195 & -13.701 .119 \\
\hline 2007 & 1.912 .637 & 16.342 .979 & 18.255 .616 & -14.430 .342 \\
\hline 2008 & 2.046 .035 & 16.282 .450 & 18.328 .485 & -14.236 .415 \\
\hline 2009 & 1.600 .591 & 11.397 .105 & 12.997 .696 & -9.796 .514 \\
\hline 2010 & 1.925 .554 & 15.014 .685 & 16.940 .239 & -13.089 .131 \\
\hline 2011 & 2.252 .287 & 16.493 .493 & 18.745 .780 & -14.241 .206 \\
\hline 2012 & 2.610 .742 & 17.655 .200 & 20.265 .942 & -15.044 .458 \\
\hline 2013 & 2.244 .050 & 17.076 .109 & 19.320 .159 & -14.832 .059 \\
\hline 2014 & 2.608 .494 & 17.544 .918 & 20.153 .412 & -14.936 .424 \\
\hline 2015 & 3.017 .510 & 17.368 .269 & 20.385 .779 & -14.350 .759 \\
\hline
\end{tabular}




\begin{tabular}{|c|c|c|c|c|}
\hline 2016 & 3.778 .863 & 17.751 .398 & 21.530 .261 & -13.972 .535 \\
\hline 2017 & 4.038 .396 & 18.186 .030 & 22.224 .426 & -14.147 .634 \\
\hline 2018 & 3.865 .652 & 18.194 .456 & 22.060 .108 & -14.328 .804 \\
\hline 2019 & 4.102 .349 & 17.963 .780 & 22.066 .129 & -13.861 .431 \\
\hline $\begin{array}{c}2020 \\
/ 1\end{array}$ & 311.695 & 1.399 .121 & 1.710 .816 & -1.087 .426 \\
\hline
\end{tabular}

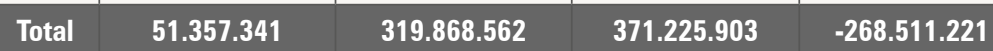

\begin{tabular}{|c|c|c|c|c|}
\hline Año & ${ }^{*}$ Exportaciones & *Importaciones & $\begin{array}{c}\text { *Comercio } \\
\text { Total }\end{array}$ & $\begin{array}{l}\text { *Balanza } \\
\text { Comercial }\end{array}$ \\
\hline 1993 & 706.551 & 3.928 .743 & 4.635 .294 & -3.222 .192 \\
\hline 1994 & 1.007 .042 & 4.780 .541 & 5.787 .583 & -3.773 .499 \\
\hline 1995 & 979.312 & 3.952 .099 & 4.931 .411 & -2.972 .787 \\
\hline 1996 & 1.393 .404 & 4.132 .093 & 5.525 .497 & -2.738 .689 \\
\hline 1997 & 1.156 .428 & 4.333.619 & 5.490 .047 & -3.177 .191 \\
\hline 1998 & 851.235 & 4.537 .043 & 5.388 .278 & -3.685 .808 \\
\hline 1999 & 776.093 & 5.083 .124 & 5.859 .217 & -4.307 .031 \\
\hline 2000 & 930.535 & 6.465 .683 & 7.396.218 & -5.535 .148 \\
\hline 2001 & 620.550 & 8.085 .693 & 8.706 .243 & -7.465 .143 \\
\hline 2002 & 1.194 .206 & 9.348 .549 & 10.542 .755 & -8.154 .343 \\
\hline 2003 & 1.172 .583 & 7.595 .048 & 8.767 .631 & -6.422 .465 \\
\hline 2004 & 1.190 .497 & 10.583 .397 & 11.773 .894 & -9.392 .900 \\
\hline 2005 & 1.470 .012 & 13.077 .780 & 14.547 .792 & -11.607 .768 \\
\hline 2006 & 1.594 .038 & 15.295 .157 & 16.889 .195 & -13.701 .119 \\
\hline 2007 & 1.912 .637 & 16.342 .979 & 18.255.616 & -14.430 .342 \\
\hline 2008 & 2.046 .035 & 16.282 .450 & 18.328 .485 & -14.236 .415 \\
\hline 2009 & 1.600 .591 & 11.397.105 & 12.997 .696 & -9.796 .514 \\
\hline 2010 & 1.925.554 & 15.014 .685 & 16.940.239 & -13.089 .131 \\
\hline 2011 & 2.252.287 & 16.493 .493 & 18.745 .780 & -14.241 .206 \\
\hline 2012 & 2.610 .742 & 17.655 .200 & 20.265 .942 & -15.044 .458 \\
\hline 2013 & 2.244 .050 & 17.076.109 & 19.320 .159 & -14.832 .059 \\
\hline 2014 & 2.608 .494 & 17.544 .918 & 20.153 .412 & -14.936 .424 \\
\hline 2015 & 3.017 .510 & 17.368 .269 & 20.385 .779 & -14.350 .759 \\
\hline 2016 & 3.778 .863 & 17.751 .398 & 21.530 .261 & -13.972 .535 \\
\hline 2017 & 4.038.396 & 18.186 .030 & 22.224 .426 & -14.147 .634 \\
\hline 2018 & 3.865 .652 & 18.194.456 & 22.060 .108 & -14.328 .804 \\
\hline 2019 & 4.102.349 & 17.963 .780 & 22.066.129 & -13.861 .431 \\
\hline $2020 / 1$ & 311.695 & 1.399 .121 & 1.710 .816 & -1.087 .426 \\
\hline Total & 51.357 .341 & 319.868 .562 & 371.225 .903 & -268.511 .221 \\
\hline
\end{tabular}

Fuente: Elaboración propia, con datos del Sistema de Consulta de Información Estadística (Secretaría de Economía, 2020a)

Nota 1: Las estadísticas están sujetas a cambio, en particular las más recientes.

Nota 2: Las exportaciones de 1993 a 2001 la atribución de país sigue el criterio de país comprador. A partir de 2002 el criterio utilizado es el de país destino. Nota 3: / 1 enero 
En el universo comercial, dentro de las 99 fracciones arancelarias más dinámicas en la relación comercial, México importa de Japón: vehículos, camiones, motores, autopartes, circuitos integrados, dispositivos semiconductores, entre otros. Ver Tabla 5 en Anexos.

Por su parte, dentro de las 99 fracciones arancelarias más importantes, México exporta a Japón: productos agroindustriales como aguacate, mineral de cobre y plata, moras, naranja, fresas, carne de res y puerco, tequila, mezcal, cerveza y autopartes y manufacturas en general (Secretaría de Economía, 2020). Ver Tabla 6 en anexos.

Independientemente de esto, Japón ha pasado a un segundo término en cuanto al interés que despierta a los mexicanos. Una política cultural agresiva para recuperar su lugar podría ayudar a la reactivación de la relación bilateral; esto, acompañado de un nuevo modelo de negocios a través de las coinversiones méxico-japonesas es el modelo innovador a seguir. Japón tiene muchos retos por delante y México es una pieza importante en su posicionamiento en América del Norte y América Latina. El reto es grande, empero a ello, existen las condiciones de amistad reflejadas en una imagen positiva en la opinión pública entre la población de ambas naciones.

\subsection{Corea del Sur}

Si hay un país con el que México podría avanzar y dar paso a una relación más estratégica es con Corea del Sur. No se ha podido cuajar un Acuerdo de Libre Comercio (TLC) entre los dos países y desafortunadamente el país asiático quedó fuera de la lógica del Tratado Integral y Progresista de la Asociación Transpacífico (CPTPP por sus siglas en inglés). Como en el caso de China, explorar un Acuerdo de Complementación Económica (AAE) antes de un TLC con Corea del Sur, podría ser la salida para evitar desviar el comercio, o bien, enfriar las relaciones económicas con ellos. Se integre o no Corea del Sur al CPTPP, el comercio bilateral con ellos va en aumento y se ubicó en el año de 2019 en USD 17.649.234 millones en cuanto a las importaciones y en USD 4.948.805 millones de exportaciones mexicanas dejando como saldo desfavorable para nuestro país en un monto de USD -12.700.429 millones. El déficit acumulado desde el año de 1993 con Corea del Sur es de USD -201.137.718 millones (Secretaría de Economía, 2020). Ver Tabla 7.

Tabla 7. Balanza comercial de México con Corea del Sur, 1993-2020 (*millones de dólares)

\begin{tabular}{|c|c|c|c|c|}
\hline Año & *Exportaciones & *Importaciones & $\begin{array}{c}\text { *Comercio } \\
\text { Total }\end{array}$ & $\begin{array}{c}\text { *Balanza Comer- } \\
\text { cial }\end{array}$ \\
\hline 1993 & 27.137 & 837.470 & 864.607 & -810.333 \\
\hline 1994 & 37.848 & 938.401 & 976.249 & -900.553 \\
\hline 1995 & 88.334 & 770.871 & 859.205 & -682.537 \\
\hline 1996 & 193.851 & 1.059 .422 & 1.253 .273 & -865.571 \\
\hline 1997 & 66.241 & 1.584 .290 & 1.650 .531 & -1.518 .049 \\
\hline 1998 & 68.366 & 1.823 .086 & 1.891 .452 & -1.754 .720 \\
\hline 1999 & 150.313 & 2.780 .761 & 2.931 .074 & -2.630 .448 \\
\hline 2000 & 179.205 & 3.690 .374 & 3.869 .579 & -3.511 .169 \\
\hline 2001 & 293.052 & 3.531 .743 & 3.824 .795 & -3.238 .691 \\
\hline 2002 & 161.915 & 3.909 .960 & 4.071 .875 & -3.748 .045 \\
\hline 2003 & 181.460 & 4.112 .879 & 4.294 .339 & -3.931 .419 \\
\hline
\end{tabular}




\begin{tabular}{|c|c|c|c|c|}
\hline 2004 & 218.947 & 5.227 .820 & 5.446 .767 & -5.008 .873 \\
\hline 2005 & 241.835 & 6.495 .904 & 6.737 .739 & -6.254 .069 \\
\hline 2006 & 457.488 & 10.621 .404 & 11.078 .892 & -10.163 .916 \\
\hline 2007 & 680.562 & 12.613 .695 & 13.294 .257 & -11.933 .133 \\
\hline 2008 & 537.599 & 13.527 .280 & 14.064 .879 & -12.989 .681 \\
\hline 2009 & 498.746 & 10.946 .188 & 11.444 .934 & -10.447 .442 \\
\hline 2010 & 928.788 & 12.730 .673 & 13.659 .461 & -11.801 .885 \\
\hline 2011 & 1.521 .776 & 13.663 .751 & 15.185 .527 & -12.141 .975 \\
\hline 2012 & 1.726 .585 & 13.340 .961 & 15.067 .546 & -11.614 .376 \\
\hline 2013 & 1.525 .333 & 13.492 .964 & 15.018 .297 & -11.967 .631 \\
\hline 2014 & 2.027 .375 & 13.771 .630 & 15.799 .005 & -11.744 .255 \\
\hline 2015 & 2.815 .469 & 14.618 .879 & 17.434 .348 & -11.803 .410 \\
\hline 2016 & 2.507 .147 & 13.612 .327 & 16.119 .474 & -11.105 .180 \\
\hline 2017 & 3.428 .269 & 15.756 .819 & 19.185 .088 & -12.328 .550 \\
\hline 2018 & 4.145 .156 & 16.727 .396 & 20.872 .552 & -12.582 .240 \\
\hline 2019 & 4.948 .805 & 17.649 .234 & 22.598 .039 & -12.700 .429 \\
\hline $2020 / 1$ & 348.611 & 1.307 .749 & 1.656 .360 & -959.138 \\
\hline Total & 30.006 .213 & 231.143 .931 & 261.150 .144 & -201.137 .718 \\
\hline
\end{tabular}

Fuente: Elaboración propia. con datos del Sistema de Consulta de Información Estadística (Secretaría de Economía, 2020b)

Nota 1: Las estadísticas están sujetas a cambio, en particular las más recientes.

Nota 2: Las exportaciones de 1993 a 2001 la atribución de país sigue el criterio de país comprador. A partir de 2002 el criterio utilizado es el de país destino. Nota 3: /1 enero

Los productos que México más importa de Corea del Sur están en las primeras 99 fracciones arancelarias y se destacan: circuitos modulares híbridos, automóviles, televisiones, motocompesores, autopartes (ver Tabla 8 en Anexos). Por lo que se refiere a México, dentro de las 99 fracciones más representativas del comercio bilateral, nuestro país exporta mayoritariamente los siguientes productos: minerales de plomo, cinc, plata cobre, automóviles, camiones, autopartes, motores, circuitos modulares, barcos de motor, carne, atún, entre otros productos agroindustriales (Secretaría de Economía, 2020). (Ver Tabla 9 en Anexos).

Bajo este escenario y considerando los candados que se le impusieron a México en el contexto de la renegociación del T-MEC el capítulo 32 del nuevo tratado, específicamente en lo referente a exenciones y provisiones generales, en su artículo 32.10 estipula que si uno de los tres socios quiere entrar en un acuerdo comercial con un país que no practique una economía de mercado deberá avisar a los socios tres meses antes de iniciar la negociación (Gobierno de México, 2019a), cabe entonces la pregunta: ¿qué hacer con China?, quizá la respuesta es nada y buscar alternativas que no pongan en peligro el T-MEC con Corea del Sur y Japón, con quienes se debe, en un primer momento, transitar de una relación de cooperación cerrada y administrada, hacia un esquema de cooperación abierto y democratizado entre los actores de la misma, es decir, darles cabida a los especialistas del tema en todos los ámbitos, que por una u otra razón han quedado fuera de la lógica de la relación de cooperación por los que tradicionalmente la han adminis- 
trado. Estas dinámicas cerradas y monopolizadas en la cooperación bilateral solo han dado como resultado un enfoque de ganancias nulo, en el que ninguna de las partes puede vislumbrar algún tipo de ganancia real, ya sea en el corto o largo plazo, como resultado de la cooperación. Esto debe cambiar, de lo contrario, no se refrescará la dinámica de la relación y las temáticas continuarán siendo las del interés del grupo cerrado, sin considerar las nuevas tendencias, enfoques y prácticas que ya se realizan en el plano internacional.

Después de que se pase a la cooperación de tipo bottom-up, democratizada e incluyente entre los actores, se debe avanzar hacia una coordinación binacional donde a través de la Agencia Mexicana de Cooperación Internacional para el Desarrollo (Amexcid) y la Agencia de Cooperación Internacional de Japón (Jica, por sus siglas en inglés) y la Agencia de Cooperación Internacional de Corea (Koica por sus siglas en inglés) se establezcan los nuevos criterios de cooperación e intercambio. Aquí deberá estar presente Jetro (Japan External Trade Organization, por sus siglas en inglés) y la Agencia Coreana de Promoción Comercial y de Inversiones (Kotra por sus siglas en inglés), quienes juntamente con los funcionarios de la Cancillería y Secretaría de Economía asesorarán la parte comercial. En ello, los consejos empresariales, como la Cámara Japonesa de Comercio e Industria, la Cámara de Comercio e Industria de Corea del Sur, así como el Consejo Coordinador Empresarial (CCE), tendrán un rol importante en la implementación de los nuevos modelos de negocios, en las dinámicas de los esquemas de cooperación e intercambio comercial. Aquí también la experiencia de las empresas mexicanas que han operado negocios en Japón y Corea del Sur, serán de gran valor.

Además de todo ello y para que realmente pueda dar comienzo una nueva etapa, la visión de México como una plataforma para los intereses empresariales japoneses y coreanos, tendrán que trascender, de lo contrario, la relación comercial no tendrá mayores modificaciones, al contrario, se profundizará el déficit comercial que México tiene con Japón -ya mencionado con anterioridad-, y se continuará con un enfoque de ganancias nulas. Aquí una opción es explorar la coinversión binacional de tipo "japomexicana" y "coreano-mexicana". Así, la repatriación de capitales, independientemente de que se trate de firmas mexicanas con apellido japonés o coreano, se desalentará o un parte importante de la inversión y las ganancias generadas se quedarán en México.

Todo parece indicar que los acuerdos en torno a la renegociación trilateral vía T-MEC (Canadá, Estados Unidos y México) del antiguo Tratado de Libre Comercio de Norteamérica ya tienen rumbo. Una vez que entren en vigor los nuevos acuerdos referentes al sector automotriz, será muy complicado que la cadena de valor de las empresas del sector asiáticas establecidas en México puedan cumplir con las siguientes condiciones para obtener los certificados de origen correspondientes y gozar de los beneficios del nuevo acuerdo: que $40 \%$ - 45\% de la producción de los vehículos deberá hacerse en un país con un salario no menor de 16 dólares como Estados Unidos o Canadá; que 55\% - 60\% de la producción automotriz podrá realizarse con un costo de mano de obra inferior a los 16 dólares como salario mínimo como lo es el caso de México (Gobierno de México, 2019a).

En caso de que las compañías del ramo lo puedan cumplir desde el inicio, el arancel que se impondrá será de tasa 0 . Las que no cumplan con esto, podrán exportar con una tasa del 2,5\% mientras se acoplan a las nuevas disposiciones. En cuanto a las reglas de origen, hay un requerimiento de contenido regional que establece que $75 \%$ del contenido automotriz tendrá que estar fabricado en Estados Unidos y México. Quizá esto en el largo plazo revierta el superávit que se tiene con Norteamérica que para el año de 2018 ascendió a USD 131.707,40 millones (Gobierno de México, 2019a), lo cual 
traería un grave problema con nuestra relación comercial con Asia que de alguna manera ha cubierto el déficit comercial que esto ocasiona por medio del saldo comercial favorable con Estados Unidos y Canadá.

Para ilustrar la importancia del sector automotriz para las exportaciones mexicanas, cabe señalar que, de acuerdo con el Instituto Nacional de Estadística y Geografía (INEGI), este sector representó el 25,5\% del valor agregado de la exportación de la manufactura global para el año de 2018, lo que implica para el sector manufacturero dedicado a la fabricación de equipo de transporte un valor de USD 164.739.540 millones (INEGI, 2020).

A los ojos de la industria automotriz procedente de Asia (Japón, Corea y en menor medida China) esto podría desalentar las inversiones en el sector, mismas que en los recientes años han incrementado en el centro y norte del país; lo que tendría que modificar las estrategias de atracción de este tipo de recursos del exterior que, de alguna manera, complementan los esfuerzos de los gobiernos estatales y municipales de promover el desarrollo a través de la creación del empleo en los famosos ecosistemas industriales, o lo que en su momento Michael Porter (1999) llamó los clúster económicos que maximizan las ventajas comparativas de las naciones.

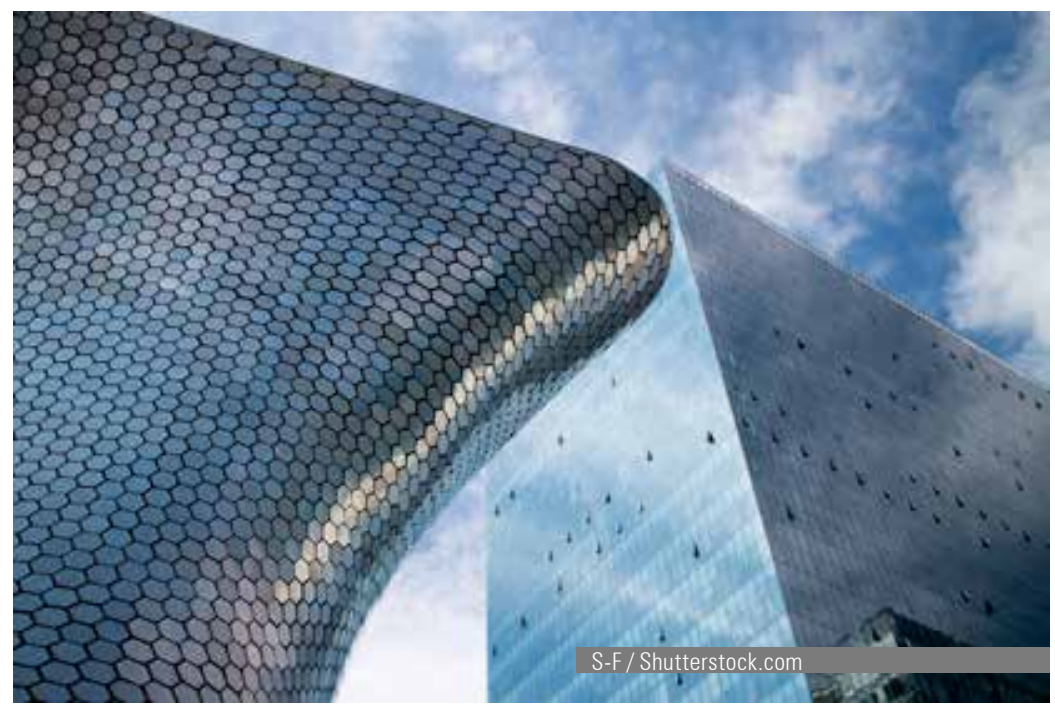

\section{Política exterior de México en el contexto de la transición de poder en el mundo y su repercusión en Asia}

En los apartados anteriores se abordó la formulación de la política exterior de México en Asia y cómo esta se ha concentrado básicamente en tres países: China, Corea del Sur y Japón. De la misma manera, se ubicaron los intereses de México en estas naciones, así como se ubicó la situación que guarda la diplomacia de México con cada uno de ellos. Ahora resulta de utilidad ubicar cómo la transición de poder que experimenta el mundo, especialmente la propuesta por China en el terreno de la gobernanza global, afecta la diplomacia, marcada, sin lugar a dudas, por lo que se denomina la "Cuarta Transformación" del país. 
En entrevista con Wang Lei, ${ }^{1}$ académico de origen chino, explica su concepción de la gobernanza global:

La forma en que la comunidad internacional se organiza para atender los grandes retos del mundo, tales como la paz y estabilidad internacional; las finanzas internacionales; el comercio internacional; el cambio climático; el movimiento de la población global (migración internacional); salud y epidemias globales y el desarrollo global, así como lucha contra la pobreza, entre otros.

De acuerdo al mencionado autor, la naturaleza de estos temas radica en la cooperación (negociación, reglas y regulaciones), temas orientados (transnacionalismo y globalismo) y los actores múltiples (estados nacionales, multinacionales, movimientos civiles y la gente). Todo esto, enmarcado en un contexto globalizado e interdependiente, que, en palabras de Wang Lei, "está sustentado bajo una organización internacional de tres fuentes de poder: el G7, los BRICS y el G20. De estos tres pilares, el G20 es la plataforma para la gobernanza económica global".

Los conceptos de Wang Lei, se contraponen con los principios e instituciones de la arquitectura económica y financiera de la posguerra (Banco Mundial, Fondo Monetario Internacional, GATT, hoy Organización Mundial del Comercio). Wang Lei, enfatizó el papel de su país en el cambio de poder global: "China desde hace diez años ha cambiado su narrativa; pasamos de una visión idealista a una realista, bueno, neorrealista del mundo, sin embargo, seguimos creyendo en la gobernanza global a través de esquemas de cooperación sur-sur".

Esta interpretación de lo que acontece en el mundo, es sin duda, una concepción y práctica de la gobernanza global híbrida. Esto es, desde un enfoque teórico, las prácticas y la concepción de la gobernanza económica global china se llevan a cabo a través de un enfoque neorealista, utilizando estructuras de poder que no cuentan con un alto grado o nivel de institucionalización, y que por lo tanto, conllevan hacia un enfoque negativo de la cooperación, en el que esperan a través de esas estructuras de poder, obtener ganancias relativas, es decir, en el corto plazo. Por el otro lado, la visión china de la gobernanza global a través de la cooperación, para atender los retos o problemáticas mundiales, en sí misma contempla una visión neoliberal, pretendiendo como objetivo principal la búsqueda del desarrollo o un mayor bienestar. Esto tiene implicaciones importantes para el sistema internacional, principalmente en cómo está organizado el sistema y cómo está distribuido el poder, desde el enfoque chino. Así, la gobernanza global desde la perspectiva china se puede entender como híbrida, en un concepto que mezcla, de acuerdo a sus prácticas y ganancias esperadas, dinámicas de cooperación a través de estructuras de poder, que con el tiempo se irán institucionalizando e impactando dentro del sistema internacional. Bueno de Mesquita (2006) lo esquematiza con claridad cuando señala que para los neorealistas el sistema internacional es anárquico y no jerárquico, mientras que para los neoliberales la distribución del poder se basa en la existencia de hegemonías regionales y no en un desbalance o balance de poder. Para los neorrealistas el comportamiento de los estados es equiparable a la naturaleza y estructura del sistema internacional. Entendiendo por estructura el reparto de poder entre los estados, lo cual explica el comportamiento de los Estados (Del Arenal, 2002).

En la práctica, esto es lo que dicta el pragmatismo chino reflejado en su política económica y comercial: se es neoliberal cuando es necesario, o mercantilista cuando la situación lo amerita. Asimismo, apuestan al multilateralismo con insumos propios, tal es el caso los instrumentos financieros de los BRICS (Brasil, Rusia, India, China y Sudáfrica) como el Nuevo Banco de Desarrollo (NBD) o su programa llamado la "Nueva ruta de la seda", que pre-

\footnotetext{
1 Entrevista realizada en Beijín, China, el 20 de septiembre de 2018.
} 


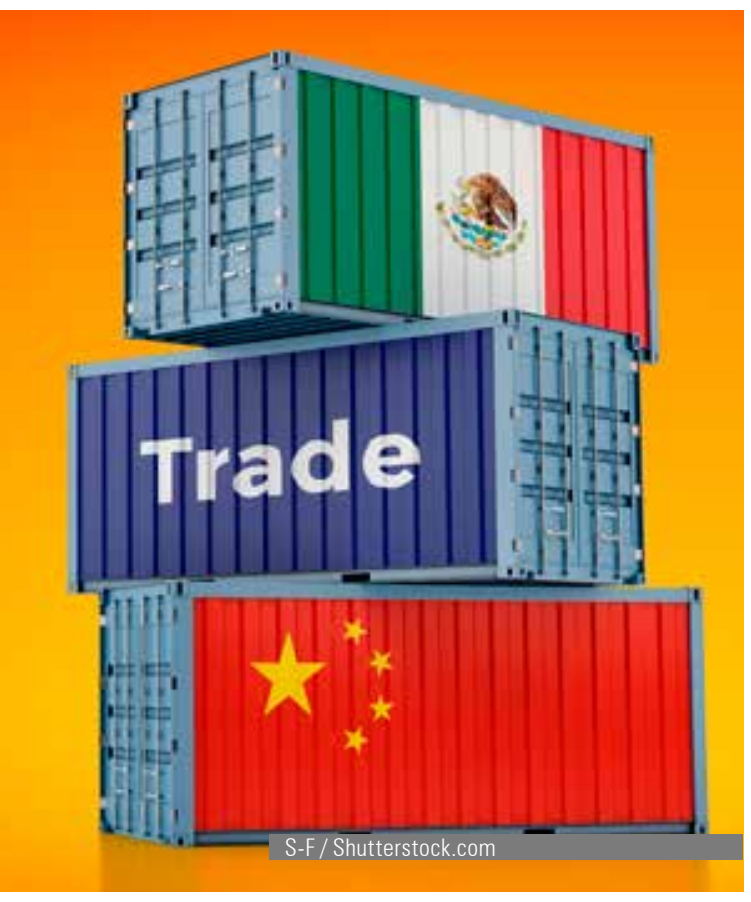

tende dotar de recursos económicos e infraestructura terrestre y marítima a países de Asia y Europa Central (Stevenson-Yang, 2013). Esto, en síntesis, es lo que denominamos el nuevo orden internacional, y en el que China pretende continuar como el hegemónico dentro del continente asiático para proyectarlo al mundo entero (Martínez, 2020).

La lección en este contexto es que China, a través de sus capacidades, está adaptándose a una transición de poder global en donde las reglas del juego y los intereses nacionales de los principales actores globales han cambiado. Para este motivo, están pavimentando el camino con una propuesta de un nuevo orden internacional, donde insertarán no solo instituciones a la nueva arquitectura internacional, sino que abogarán por un mundo desde una perspectiva china, misma que debemos conocer, más aún cuando se ha pensado en este país como una opción real para lograr la tan anhelada diversificación comercial de México. Se destaca la importancia de conocer a la naturaleza pragmática de China, que va más allá de los libros y de interpretaciones idealistas. En este sentido, la diplomacia mexicana permeada de la denominada Cuarta Transformación tendrá que adaptar el interés nacional en la región considerando estas variables.

\section{La 4T y la diversificación comercial de México}

Antes de finalizar este trabajo, es preciso señalar que, al momento de la construcción de conclusiones solo faltaba que los gobiernos de los países miembros del T-MEC notificaran a sus socios que están listos para su implementación, que deberán hacer antes del 30 de abril del 2020 y entre en vigor el 1 de julio de este mismo año (El Financiero, 4 de abril de 2020). Independientemente que se hayan eliminado los aranceles al acero y al aluminio procedentes de México y Canadá a principios de mayo de 2019, tal y como lo anunció la Secretaría de Economía de México (2019), en su comunicado número 56 de fecha 20 de mayo de 2019, esto desde una perspectiva estratégica y geoeconómica responde a otras razones, y no precisamente al T-MEC. Obedece, desde nuestro punto de vista, a una estrategia comercial para respaldar las cadenas de valor y proveeduría de las empresas de los Estados Unidos que necesitarán insumos competitivos en precio para sus procesos productivos ante la guerra comercial con China. La tasa impositiva de $15 \%$ y $20 \%$ respectivamente saca de mercado a la proveeduría canadiense y mexicana. Los efectos de esto ya los hemos observado con las represalias de ese país por las sanciones (suspendidas por tres meses) al gigante tecnológico Huawei impuestas por Donald Trump (BBC, 2019). Las repercusiones globales de este anuncio ya surtieron efecto con la cancelación de contratos millonarios por parte de empresas globales de compra de teléfonos y abastecimiento de componentes electrónicos a la firma china.

Una vez que se notifique la implementación del T-MEC por parte de los tres socios, la estrategia mexicana debería estar encaminada a explotar los beneficios del mismo para paliar la crisis que el año 2020 traerá a la economía mexicana, más aún ante una amenaza de decrecimiento de la economía global debido a la crisis sanitaria (COVID-19) del coronavirus que azota al mundo y que podría disminuir su crecimiento en este 2020 a una tasa de 1,5\% anual aproximadamente (BBC, 20 de marzo del 2020).

De la misma manera, resulta recomendable compaginar las agendas locales trasnacionales (seguro médico, seguridad, educación, servicios públicos, por ejemplo) con la lógica de una Norteamérica sólida a través del intercambio comercial vía el nuevo T-MEC. Esto, sin olvidar la cooperación en materia de seguridad fronteriza y migratoria, que deberá estar presente en la estrategia integral para despejar dudas y críticas sobre la inacción de México en estos temas.

El éxito del T-MEC no se dará de manera inercial o gracias a lo que se ha hecho hasta ahora. Es tarea de los miembros del servicio exterior mexicano 
comunicar adecuadamente la importancia del Tratado, resaltando la interdependencia y complementación entre sus tres socios ante los representantes de la Cámara Baja de ambos partidos mediante una estrategia alineada, coordinada y consensada partiendo de los intereses nacionales de México. Aunado a ello, una campaña de información sobre la importancia comercial de México en medios de comunicación del otro lado de la frontera respaldaría las labores de lobby. El departamento de prensa de la Embajada de México en Washington y de los consulados tienen una tarea titánica, pero no imposible, de comunicar esto. Nada está asegurado, más aún cuando se dieron los enfrentamientos entre ambos países por la política migratoria de puertas abiertas de México y las amenazas del presidente estadounidense de imponer aranceles extraordinarios a México si cambiaba dicha política. El resultado fue el envío de 27 mil miembros de la Guardia Nacional que lograron reducir en $56 \%$ los flujos migratorios en el periodo acordado (BBC News, 2019).

En este escenario adverso y de incertidumbre, además de la opción que ofrecen China, Japón y Corea del Sur para la diversificación, no hay que olvidar que México cuenta con una gran gama de Tratados de Libre Comercio - TLC_que se compone de 13 Acuerdos de Libre Comercio con 50 países (Secretaría de Economía, 2019a), empero, el cambio de la política comercial de Estados Unidos y los contextos políticos en el mundo dejan claro que estas estrategias ya no alcanzan y no garantizan los mercados para las exportaciones mexicanas. Todo se tiene que replantear. Las dificultades de renegociación del TLCAN, hoy T-MEC nos obligan a buscar la diversificación comercial y la respuesta está precisamente en el Acuerdo Integral y Progresivo de Asociación Transpacífico (CPTPP) en dónde la estrategia de oferta y demanda exportable tendrán que estar presentes. Asia es de suma importancia; sin embargo, pensamos que aún se debe formular una diplomacia dinámica en la región considerando variables como el cambio de la balanza de poder en el mundo, así como las capacidades reales con las que cuenta nuestro país para llevar a cabo esa diversificación con Asia dentro de una perspectiva integral y de largo plazo. Esto en una época de cambio en el país, en donde la austeridad es el eje de la política pública, no hay mucho que hacer en el terreno diplomático, menos aún en una región tan lejana, desconocida y en donde además de recursos humanos, se requieren presupuestos económicos para labores de promoción comercial y turística.

Esta postura debe entenderes en el marco de la coyuntura de México y el contexto de sus relaciones internacionales y por lo establecido en materia de política exterior en el Plan Nacional de Desarrollo (2019) que fijó la relación con Estados Unidos como una región prioritaria y un regreso a la región latinoamericana con la que tenemos profundos lazos históricos. No es fortuito que México en el 2020, por un año, presidirá la presidencia de la Comunidad de Estados Latinoamericanos y Caribeños (Celac), que desde la presente coyuntura abonará a equilibrar y compensar nuestra profunda relación asimétrica (económica y política) con los Estados Unidos (Secretaría de Relaciones Exteriores, 2019).

Los conflictos electorales y sanitarios coyunturales por los que atraviesa el presidente Donald Trump en el proceso electoral en 2020 (Restrepo, 2020), auguran una campaña compleja que seguramente embestirá a México con temas tan sensibles como el migratorio y el de seguridad fronteriza, lo cual traerá consigo de nuevo mayor incertidumbre que afectará, sin duda, la continuidad y éxito de la 4T. Aquí no cabe la frase de que "la mejor política exterior es la interior". Esto demuestra que México no es un país aislado y lo que acontece en el terreno global y regional tiene repercusiones. ¿No sería mejor que México enfocara sus esfuerzos de diversificación política y económica con países con los que somos complementarios en términos comerciales y aliados en agendas globales comunes? La idea de voltear a América Latina y el Caribe, con quien hay una integración espiritual, pero no real, tampoco es mala. Al respecto, se debería replantear si América Latina y el Caribe podrán aportar a cambiar la ecuación 
comercial que, de acuerdo con el Santander Trade Markets (2019), 80\% del comercio exterior mexicano está concentrado con Estados Unidos. Desafortunadamente el comercio con la región no es muy representativo ya que son solo dos países con quienes tenemos una mayor relación comercial: Brasil con 0,9\% y Colombia con el $0,8 \%$ del total de nuestras exportaciones. En la estrategia de diversificación deberían estar países como Canadá (2,8\%), Alemania (1,7\%), China (1,6\%), Japón (1\%), España (1\%), Corea del Sur (0,8\%) e India (0,8\%).

México se encuentra en una importante coyuntura que le dará la pauta de establecer una estrategia en materia de política exterior apegada a una realidad que nadie puede negar. En este sentido, se espera que el posicionamiento de México en la Asamblea General de las Naciones Unidas, así como el activismo internacional de México y la alianza y firma de convenio de promoción comercial entre la Secretaría de Relaciones Exteriores con la Secretaría de Economía a principios de 2019, lo mismo que la incorporación de su nuevo Centro Internacional de Negocios (CINSE) en septiembre del mismo año, colaboren en ello.

\section{Conclusiones}

En alusión a la teoría de transición de poder (Tammen, 2000), se puede identificar que México, en su búsqueda de la tan anhelada diversificación, ha integrado en sus acciones de política exterior actuales — para su relación con China, Corea del Sur y Japón- la combinación de sus elementos de análisis, es decir, el número de personas que pueden trabajar, así como los recursos y capacidades para ejecutar y cumplir los objetivos de la misma. En este punto, a pesar de que México ha emprendido acciones que reflejan una visión nueva de política exterior, también existen esfuerzos para diversificar las relaciones económicas, mediante la alianza entre la Secretaría de Economía y la CanciIlería. Asimismo, la productividad de la economía y la efectividad del sistema político, para avanzar en los objetivos nacionales, está enfocado en continuar con la visión de los procesos de transformación conforme a la perspectiva de la 4T, y mediante la política económica interna y externa, a través del libre comercio, utilizando la red de los trece acuerdos de Libre Comercio con cincuenta países, y mediante la cruzada para finalizar con la pobreza y dotar de capacidades económicas a través de programas sociales y de empleo a la población más vulnerable del país.

De esta manera, la transformación de México, dentro del contexto de la $4 \mathrm{~T}$, puede explicarse a través de la interpretación de la teoría de la transición de poder en el mundo, en donde México, a pesar de que su presidente haya decidido mantener una posición donde prevalece su visión nacionalista, ha generado una estrategia global considerando los cambios repentinos en la arena internacional, mediante el fortalecimiento de la Secretaría de Relaciones Exteriores, a través de su Canciller Marcelo Ebrard, quien se ha convertido en pieza clave del gabinete ejecutivo, y posible candidato a sucederlo en el cargo. Las consecuencias económicas-políticas, externas e internas, para México del COVID-19 serán de suma importancia y se tendrán que considerar en un análisis que vaya más allá de la coyuntura por parte de la 4T. Ejemplo de ello, es el papel que jugó recientemente en la negociación con Estados Unidos en materia comercial, arancelaria, migratoria y de seguridad, así como su asistencia a distintas reuniones de alto nivel en los Estados Unidos y participación como actor global en espacios de tanta importancia como la reunión del Grupo de los 20 en Osaka, Japón y la Asamblea General de la Organización de las Naciones Unidas (Expansión, 26 de noviembre de 2019). La posición de México ante el concierto internacional es multilateral y eso, desde nuestra perspectiva, obedece a una transición de poder en el mundo actual. 


\section{Referencias}

- Ariste, L. (2019). "AMLO cierra su primer año de gobierno sin viajar al extranjero". Expansión Política. Consultado en línea el 10 de diciembre de 2019. https://politica.expansion.mx/presidencia/2019/11/26/ amlo-cierra-su-primer-ano-de-gobierno-sin-viajar-al-extranjero

- Banco de México. Sistema de Información Económica. Consultado en línea el 7 de abril de 2020. https:/l www.banxico.org.mx/Sielnternet/consultarDirectorioInternetAction.do?sector $=1$ gaccion $=$ consultarCuad roAnaliticogidCuadro $=$ CA8glocale $=e s$

- $\quad$ Banco Santander (2020). Cifras del Comercio Exterior de México. Consultado en línea el 7 de abril de 2020. https://santandertrade.com/es/portal/analizar-mercados/mexico/cifras-comercio-exterior

- $\quad$ BBC (2019). Sanciones contra Huawei: Estados Unidos extiende otros 90 días la moratoria para la firma china. Consultado en línea el 15 de diciembre de 2019. https://www.bbc.com/mundo/noticias-49395770

- BBC News (2019). “Crisis migratoria: México asegura que redujo el flujo de inmigrantes un $56 \%$ desde que Trump amenazó con imponer aranceles a sus productos". Consultado en línea el 14 de septiembre de 2019. https://www.bbc.com/mundo/noticias-america-latina-49616051

- BBC News (2020). Coronavirus: 10 gráficos que muestran el impacto económico en el mundo que causa el Covid-19. Consultado en línea el 7 de abril de 2020. https://www.bbc.com/mundo/noticias-51971991

- Bueno de Mesquita, B.B. (2006). Principles of International Politics. People's power, preferences and perceptions. Third edition. Washington:COPress.

- Capital Economics (2020). “The COVID-19 Coronavirus and its economic impact ". Consultado en línea el 12 de febrero de 2020. https://www.capitaleconomics.com/the-economic-effects-of-the-coronavirus/

- Constitución Política de los Estados Unidos Mexicanos (2019). México: Cámara de Diputados. Consultado en línea, el 10 de enero de 2020. http://www.diputados.gob.mx/LeyesBiblio/pdf mov/Constitucion Politica.pdf

- Del Arenal, C. (2002). Apuntes de clase "Teoría de las Relaciones Internacionales", posgrado en Derecho Internacional y Relaciones Internacionales, Madrid: Instituto Ortega y Gasset.

- $\quad$ Deutsch, K. W.(1990). Análisis de las Relaciones Internacionales. México: Gernika.

- Gobierno de México (2019). Plan Nacional de Desarrollo 2019-2024. Gobierno de México. Consultado en línea el 10 de diciembre de 2019. https://framework-gb.cdn.gob.mx/landing/documentos/PND.pdf

- El Financiero (2020). "México notifica que está listo para implementar el T-MEC". Consultado en línea el 7 de abril de 2020 https://www.elfinanciero.com.mx/economia/mexico-notifica-que-esta-listo-paraimplementar-el-t-mec-es-una-buena-senal-ante-covid-19-dice-seade

- El Universal (2020). "SצP rebaja calificaciones de Pemex y México". Consultado en línea el 7 de abril de 2020 https://www.eluniversal.com.mx/cartera/flaquea-grado-de-inversion

- Gobierno de México (2019a). TMEC. Consulta y descarga las publicaciones de los reportes TMEC. Consultado en línea el 15 de diciembre. https://www.gob.mx/t-mec/acciones-y-programas/boletines-tmec?state $=$ published

- INEGI (2019). Balanza comercial de México. Información general. Consultado en línea el 15 de diciembre de 2019 https://www.inegi.org.mx/temas/balanza/

- INEGI (2020). "Valor agregado de exportación de la manufactura global". Consultado en línea 18 de enero de 2020. https://www.inegi.org.mx/temas/pibval/

- Martínez, J.I. (coord.) (2020). América Latina y el Caribe - China, Relaciones Políticas e Internacionales 2019, México: Unión de Universidades de América Latina y El Caribe. Consultado en línea, el 25 de enero de 2020. https://dusselpeters.com/CECHIMEX/20200120 REDALC CECHIMEX Relaciones politicas e internacionales_2019_Jose_lgnacio Martinez_Cortes.pdf

- Morguenthau, H.J. (1948). Politics Among Nations. The struggle for power and peace. Quinta edición revisada.

- Newsweek México (2019). “Ebrard dice que México tiene un gobierno feminista y rechaza bloquea a Cuba en la ONU". Consultado en línea el 29 de septiembre de 2019 https://newsweekespanol.com/2019/09/ mexico-marcelo-ebrard-onu/

- Nye, J. (2011). The Future of Power. New York, USA: Perseus book group.

- $\quad$ Organski, A.F.K \& Kugler, J. (1980). The War Ledger. Chicago, USA: University of Chicago Press.

- Pearson, F. S. (2003). Relaciones Internacionales. Situación global en el siglo XXI. México: Mc Graw Hill.

- $\quad$ Porter, M. E. (1999). Ser competitivo. Boston: The Harvard Business Review.

- Restrepo, D. (2020). "Los balances partidistas en tiempos de la campaña de Trump". Opinión. El País. Consultado en línea el 12 de febrero de 2020. https://elpais.com/elpais/2020/02/12/ opinion/1581469223 306811.html

- Santander Trade Markets (2019). "Cifras de comercio exterior en México". Consultado en línea el 29 de septiembre de 2019. https://es.portal.santandertrade.com/analizar-mercados/mexico/cifras-comercioexterior\#classification by country

- Secretaría de Economía (2019). "La SE se congratula por la proclamación hecha por el Presidente de EEUU que elimina aranceles a importaciones de acero y aluminio de México", Comunicado No. 56. Consultado en 
línea el 15 de diciembre de 2019. https://www.gob.mx/se/articulos/la-se-se-congratula-por-la-proclamacionhecha-por-el-presidente-de-eeuu-que-elimina-aranceles-a-importaciones-de-acero-y-aluminio-de-mexico

- Secretaría de Economía (2019a). "Libros blancos". Archivos. Consultado en línea el 15 de diciembre de 2019. https://www.gob.mx/cms/uploads/attachment/file/474566/Indice_libros_blancos.pdf

- Secretaría de Economía (2020). “Balanza comercial de México con China 1993-2020". Sistema de Consulta de Información Estadística por País. Consultado en Línea el 12 de abril de 2020. http://187.191.71.239/ sic php/pages/estadisticas/mexico/Z3bc e.html

- Secretaría de Economía (2020a). "Balanza comercial de México con Japón 1993-2020". Sistema de Consulta de Información Estadística por País. Consultado en Línea el 12 de abril de 2020. http://187.191.71.239/ sic_php/pages/estadisticas/mexico/Kgbc_e.html

- Secretaría de Economía (2020b). "Balanza comercial de México con Corea del Sur 1993-2020". Sistema de Consulta de Información Estadística por País. Consultado en Línea el 12 de abril de 2020. http://187.191.71.239/sic_php/pages/estadisticas/mexico/E8bc_e.html

- Secretaría de Economía (2020c). "Principales productos importados por México procedentes de China, 2008-2020" Sistema de Consulta de Información Estadística por País. Consultado en Línea el 12 de abril de 2020. http://187.191.71.239/sic_php/pages/estadisticas/mexico/Z3ppm_e.html

- Secretaría de Economía (2020d). "Principales productos exportados por México a China, 2008-2020" Sistema de Consulta de Información Estadística por País. Consultado en Línea el 12 de abril de 2020. http://187.191.71.239/sic_php/pages/estadisticas/mexico/Z3ppx_e.html

- Secretaría de Economía (2020e). "Principales productos importados por México procedentes de Japón, 2008-2020" Sistema de Consulta de Información Estadística por País. Consultado en Línea el 12 de abril de 2020. http://187.191.71.239/sic php/pages/estadisticas/mexico/K9ppm e.html

- Secretaría de Economía (2020f). "Principales productos exportados por México a Japón, 2008-2020" Sistema de Consulta de Información Estadística por País. Consultado en Línea el 12 de abril de 2020. http://187.191.71.239/sic_php/pages/estadisticas/mexico/K9ppx_e.html

- Secretaría de Economía (2020g). "Principales productos importados por México procedentes de Corea del Sur, 2008-2020" Sistema de Consulta de Información Estadística por País. Consultado en Línea el 12 de abril de 2020. http://187.191.71.239/sic_php/pages/estadisticas/mexico/E8ppm_e.html

- Secretaría de Economía (2020h). "Principales productos exportados por México a Corea del Sur, 20082020" Sistema de Consulta de Información Estadística por País. Consultado en Línea el 12 de abril de 2020. http://187.191.71.239/sic_php/pages/estadisticas/mexico/E8ppx_e.html

- Secretaría de Relaciones Exteriores (2019). "México presenta propuesta de plan de trabajo para la presidencia de la CELAC 2020". Consultado en línea el 12 de febrero de 2020. https://www.gob.mx/sre/es/articulos/ mexico-presenta-propuesta-de-plan-de-trabajo-para-la-presidencia-de-celac-2020-228366?idiom=es

- Stevenson-Yang, A. (2013). China alone, The emergence from, and potential return to insolation, UNAMCátedra China-México México:CECHIMEX. Consultado en línea, el 5 de enero de 2020. https://dusselpeters. com/CECHIMEX/libroChinaAlone.pdf

- Stoessinger, J. (1994). El poderío de las naciones. Política mundial de nuestro tiempo. Tercera ed. en español. México: Gernika.

- Tammen, R. L. (2000). Power Transitions. Strategies for the 21 st Century. Washington:CQ Press.

- Vásquez, A. J. (1992). El poder de la política del poder. México: Gernika.

- Wolfers, A. (1962). Discord and Collaboration: Essays on International Politics. Chapter Five, "The Goals of Foreign Policy," pp. 67- 80. Baltimore: The Johns Hopkins Press. 


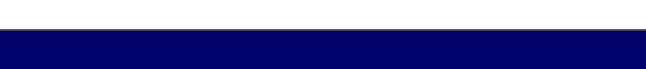

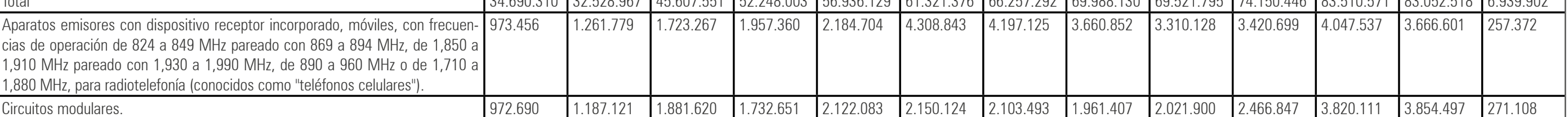

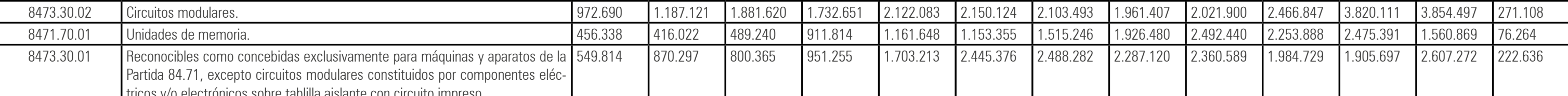

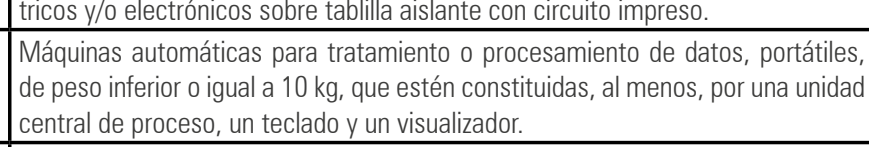

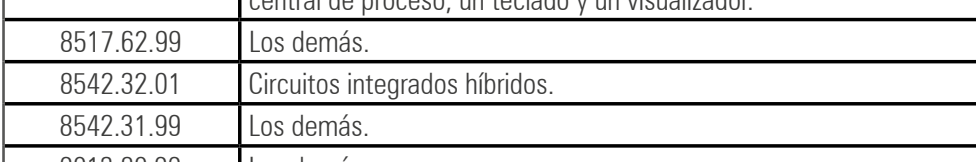

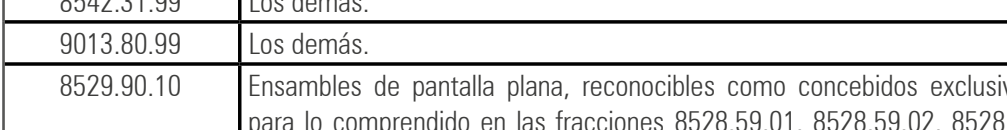

\begin{tabular}{|l|l|}
\hline 8517.12 .99 \\
\hline 9802.00 .02 \\
\hline
\end{tabular}

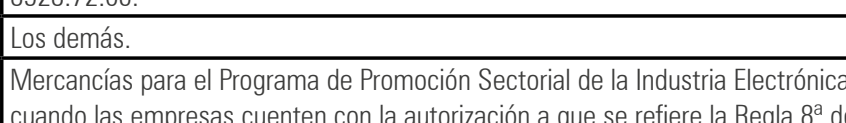

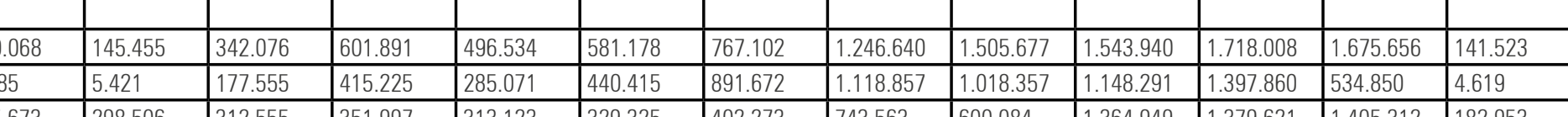

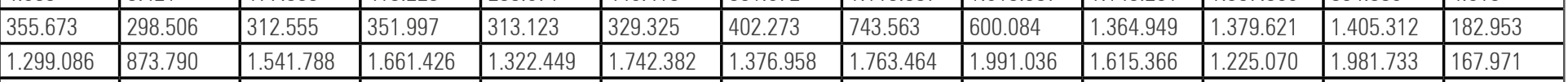

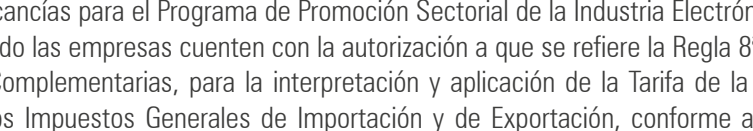

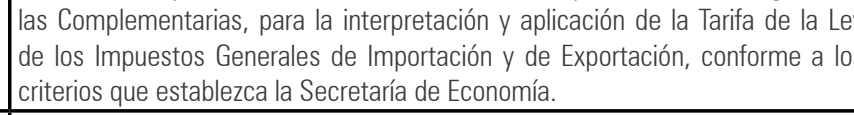

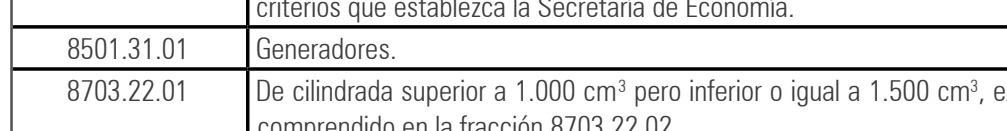

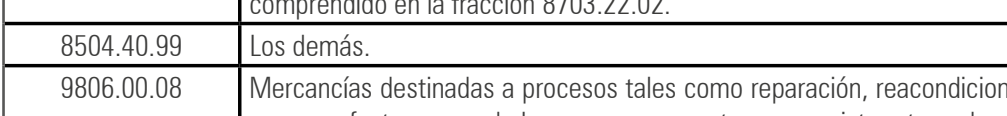

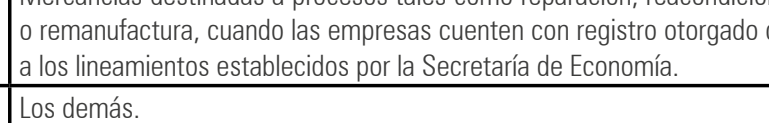

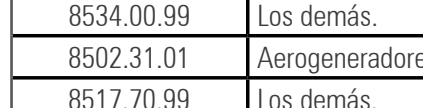

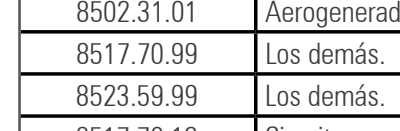

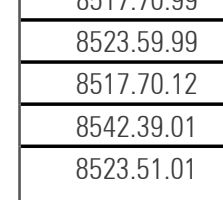

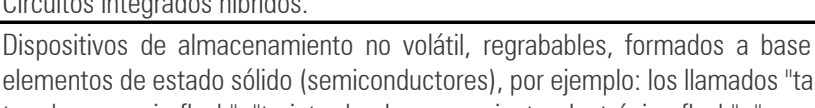

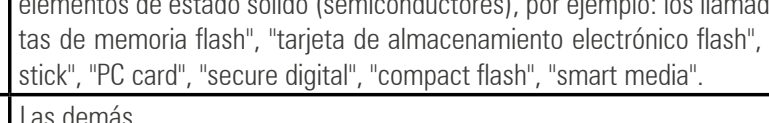

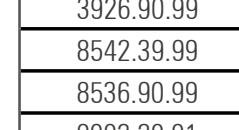

$\frac{9002.20 .01}{8415.10 .01}$

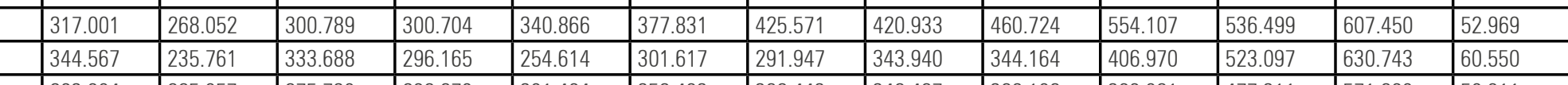

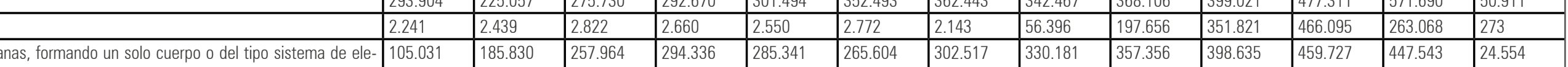

\begin{tabular}{|l|l|}
\hline 8415.10 .01 \\
\hline 270.12 .09 \\
\hline 8534.00 .02 \\
\hline
\end{tabular}

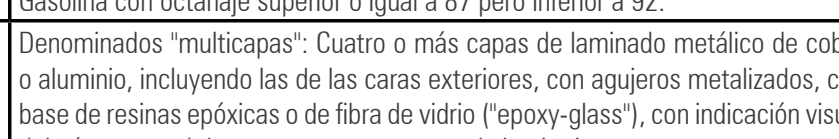

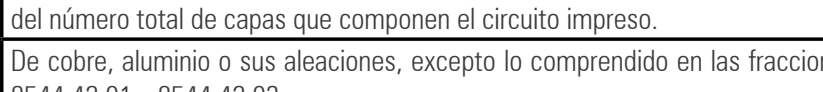

$\frac{8547.7099}{3052029}$

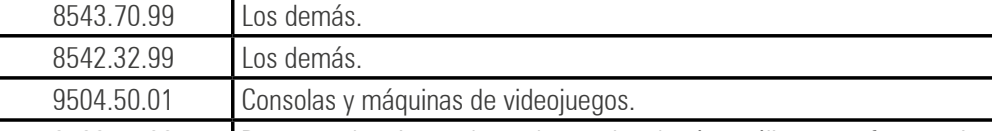

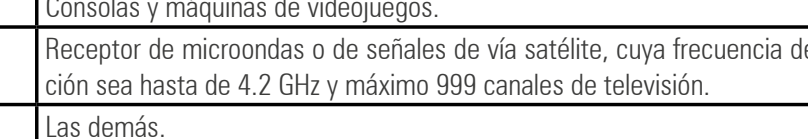

\begin{tabular}{|l|l|}
\hline 8529.9099 \\
\hline 8980.199 \\
\hline 8541.190 .01 \\
\hline
\end{tabular}

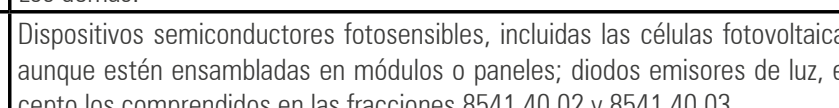

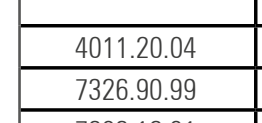

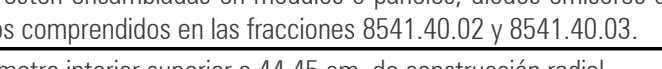

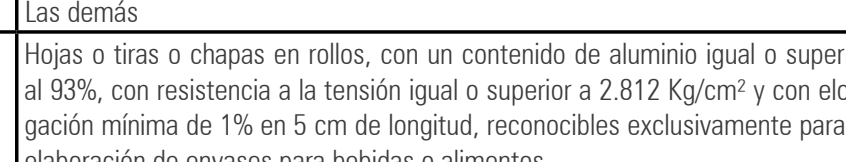

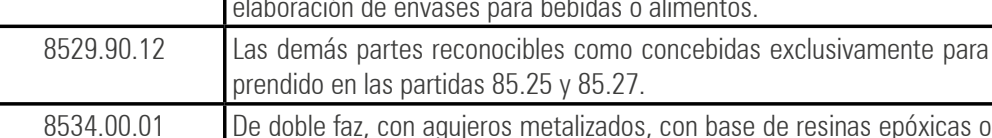

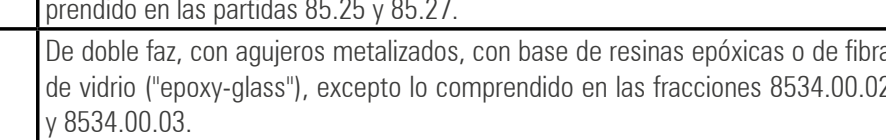

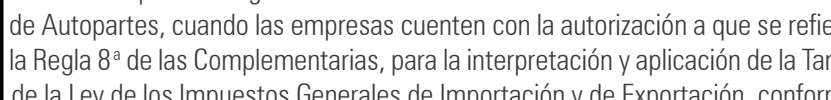

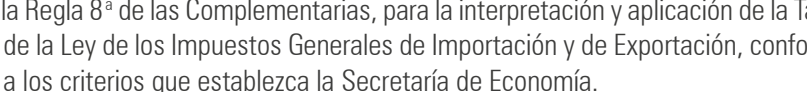

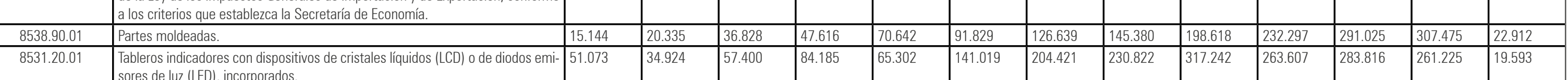

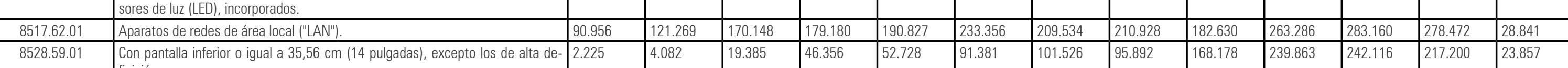

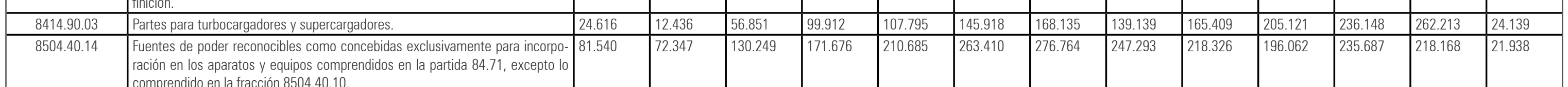

8517.62 .06
8433.990 .01

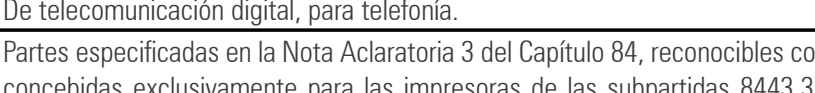

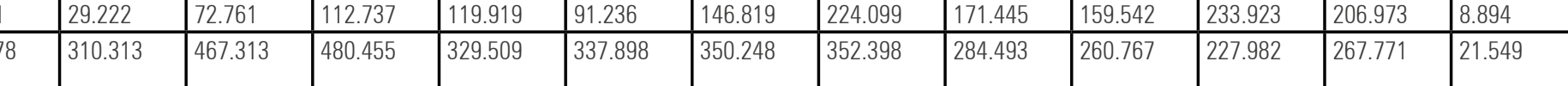

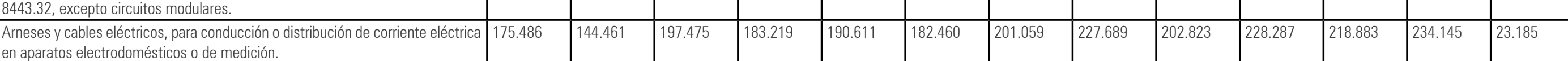

9802.00 .01

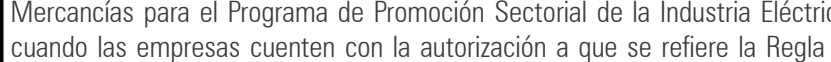

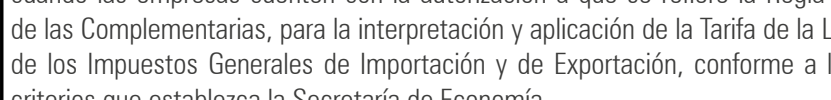
Los demás.

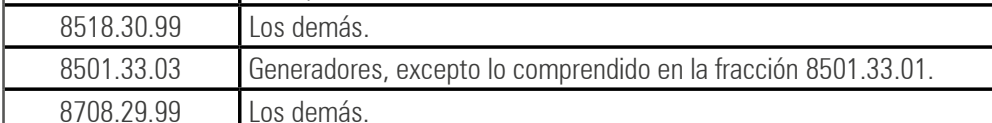

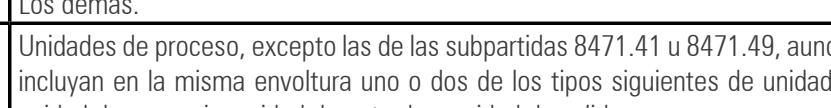

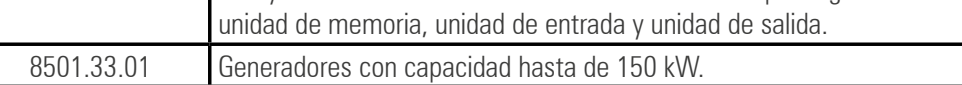

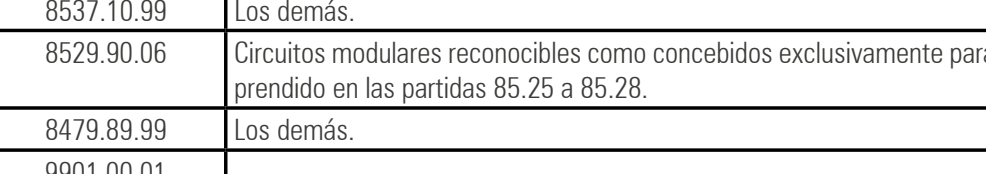

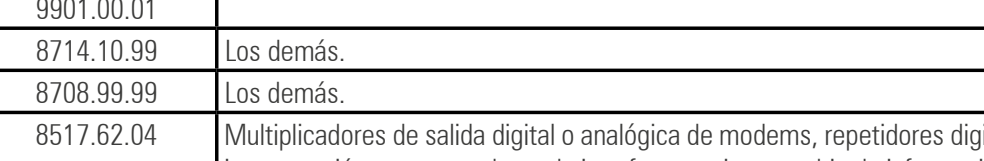

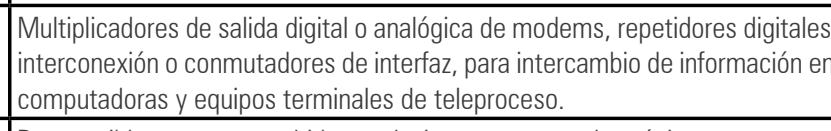

\begin{tabular}{|c|l|l}
\hline 8504.50.02 & Reconocoibles \\
\hline 8517.18 .99 & Los demas. \\
\hline 8482.10.99 & Los demás. \\
\hline
\end{tabular}

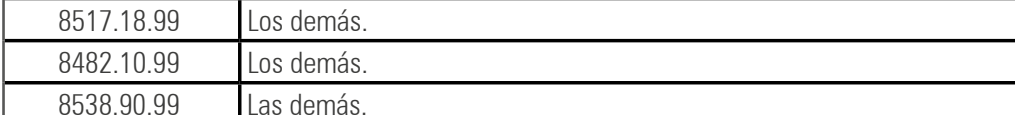

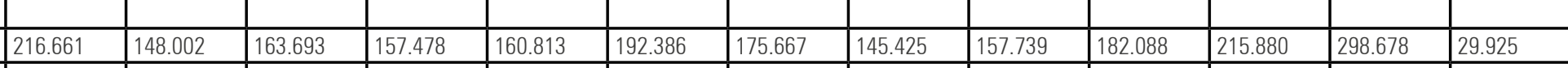

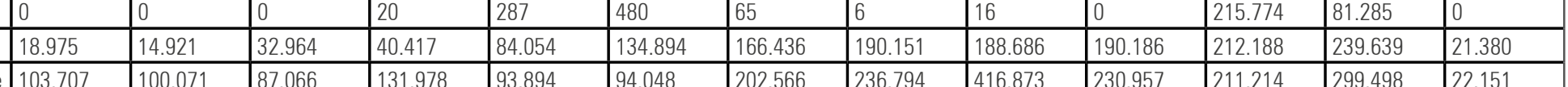

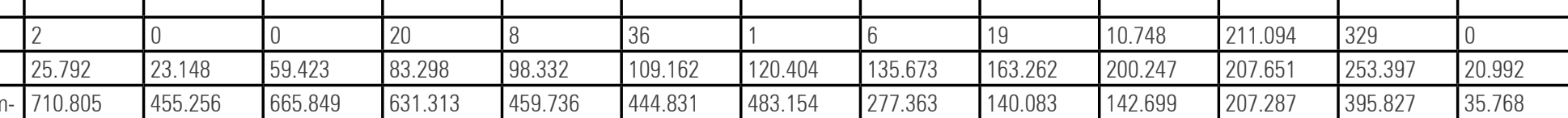

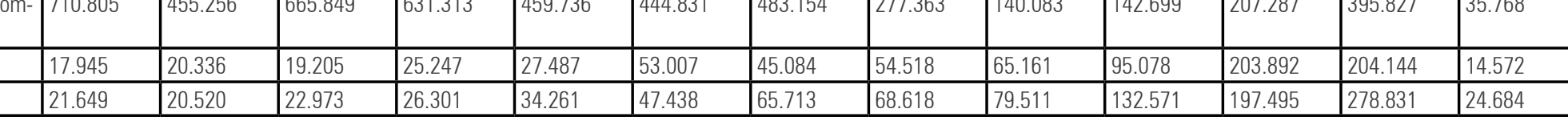

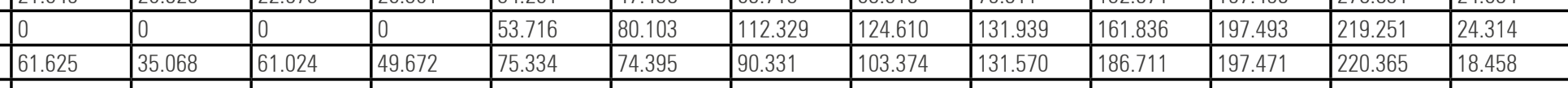

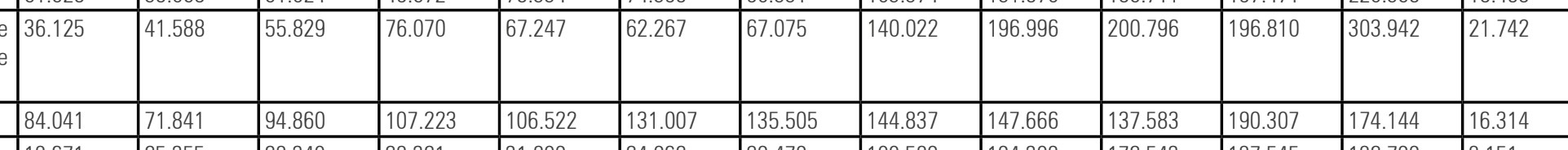

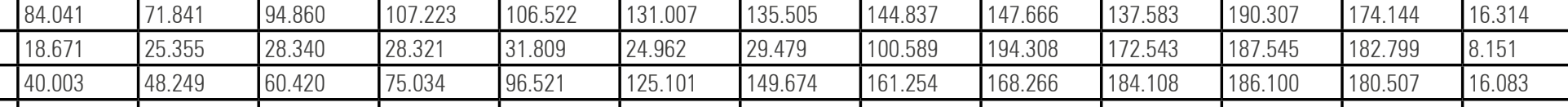

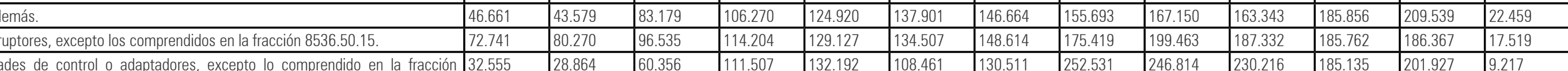

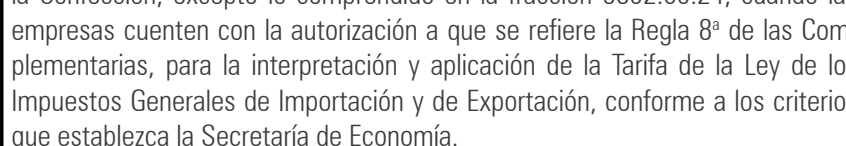

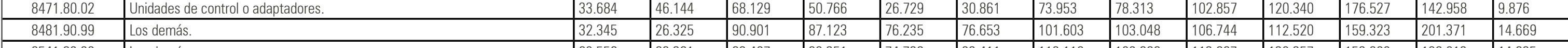

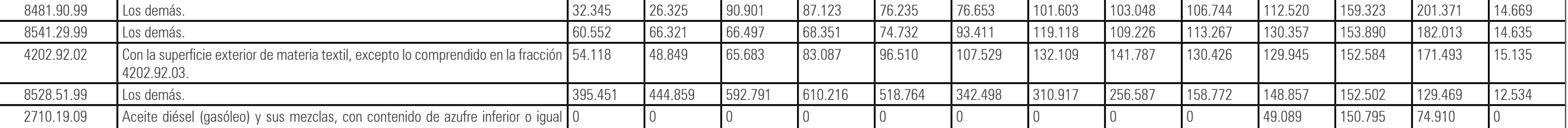

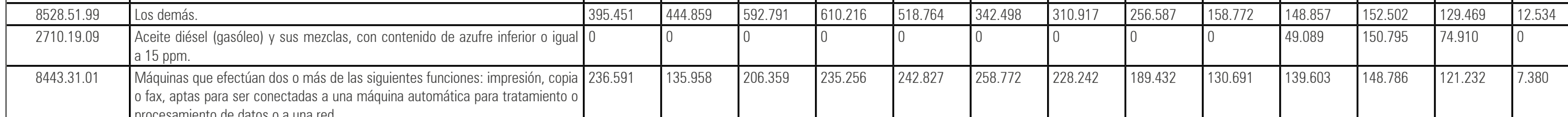

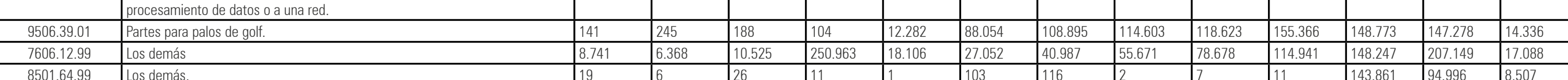

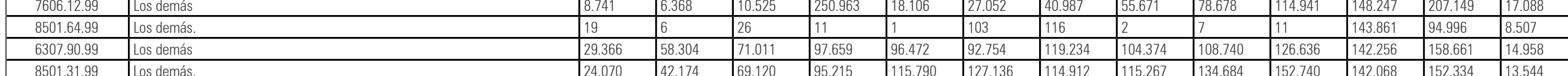

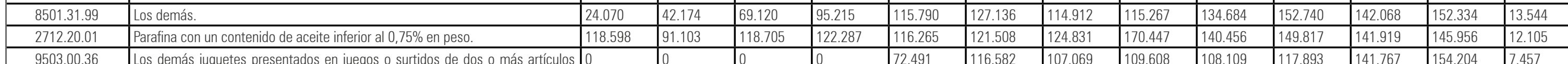

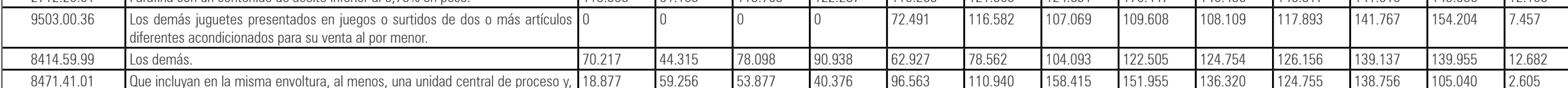

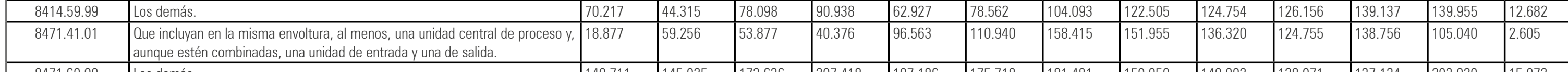

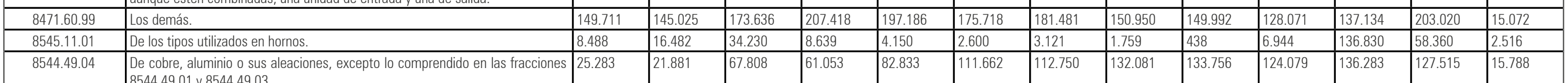

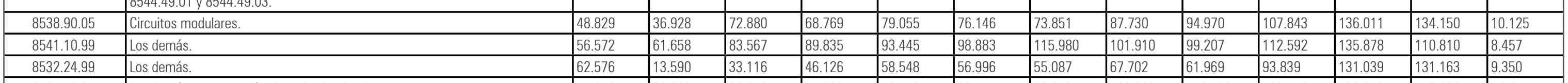

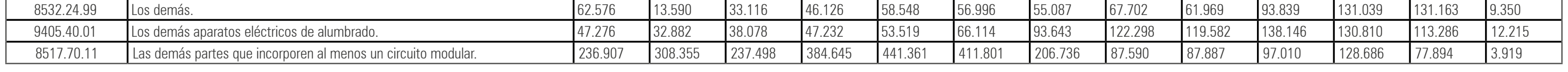




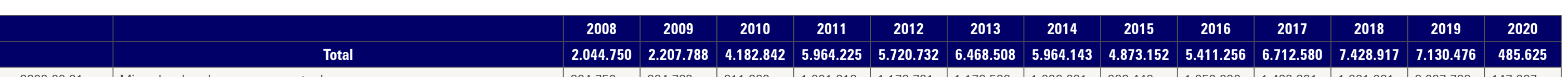

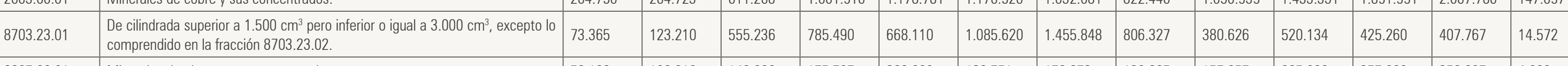

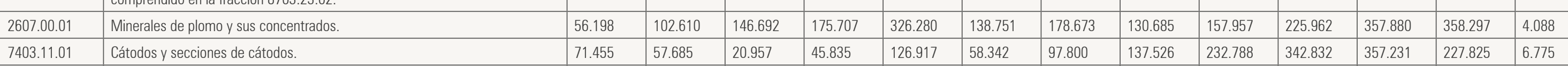

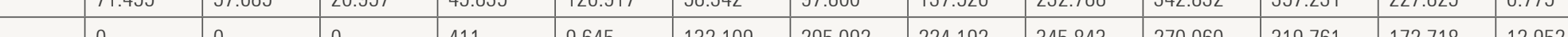

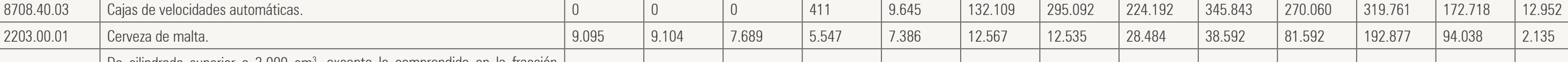

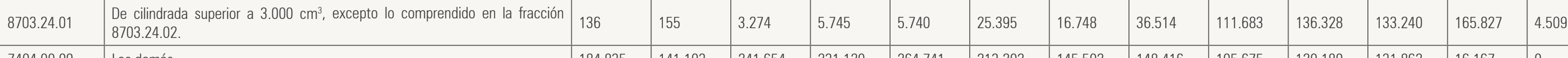

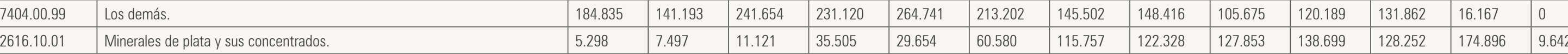

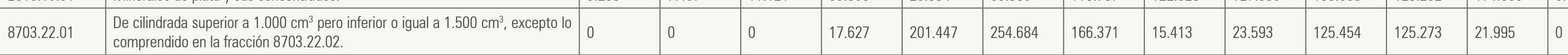

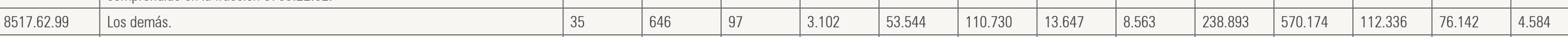

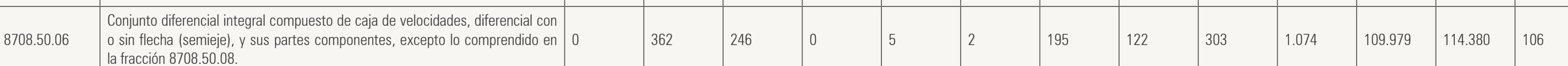

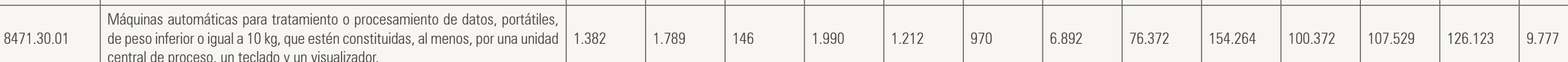

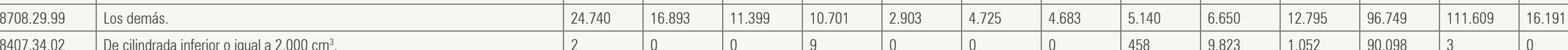

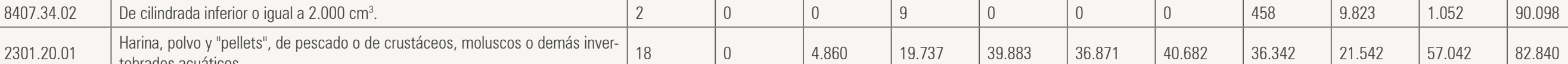

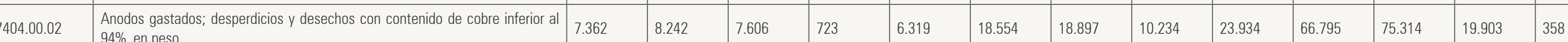

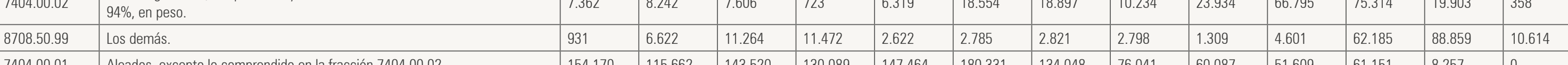

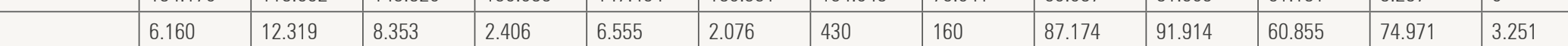

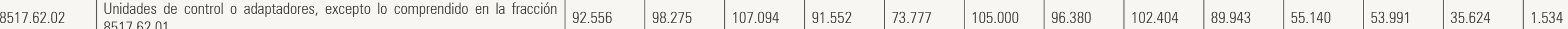
\begin{tabular}{|l|l|l|l}
21.528 & 52.460 & 52.206 & 0
\end{tabular}

2517.12.1.

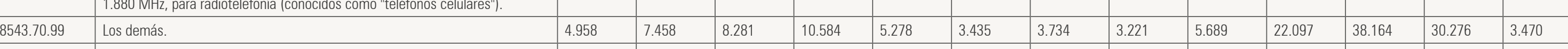
\begin{tabular}{|l|l|lll|l|l|l|l|l}
\hline & 0 & 31.45 & 29.466 & 161.369 & 15.662 & 17.134 & 38.159 & 31.42 & 0
\end{tabular}

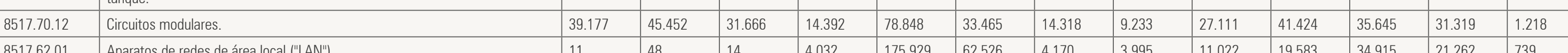

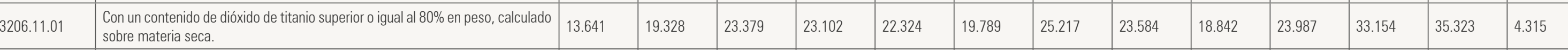

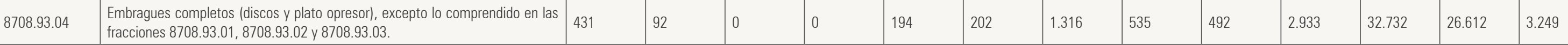
$\begin{array}{lllllllllllll}402 & 2.407 & 23.643 & 12.124 & 19.092 & 19.366 & 20.241 & 31.145 & 32.352 & 40.35 & 1769\end{array}$

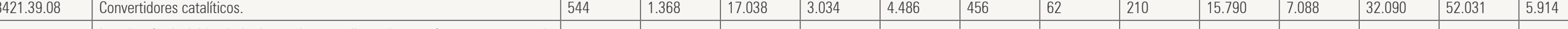

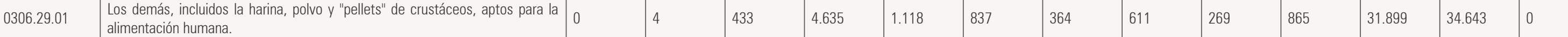

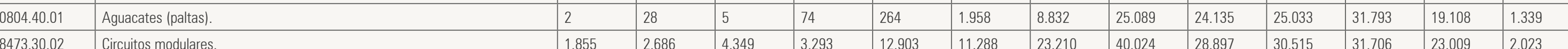

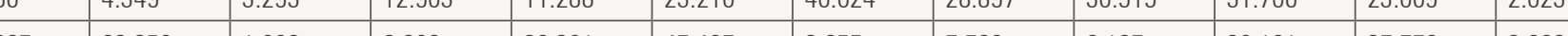
87089999 Los denán.

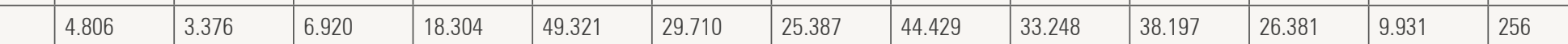

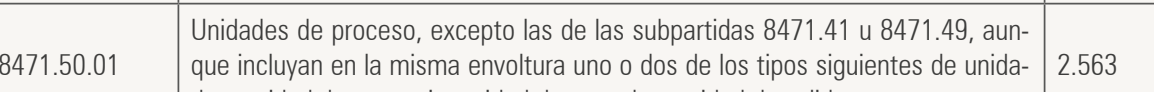

$87085004 \quad$ Fies

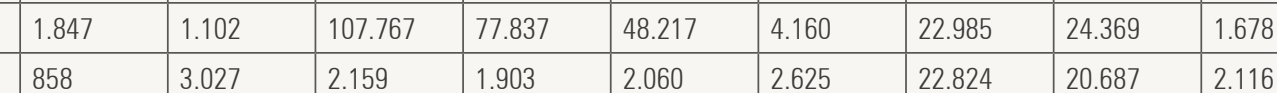

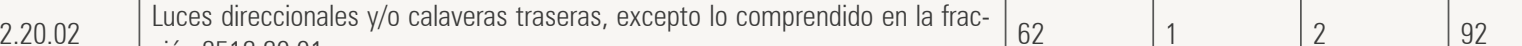

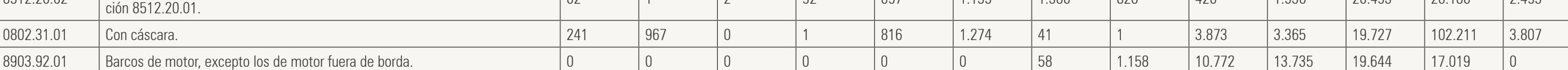

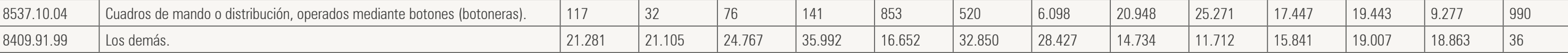

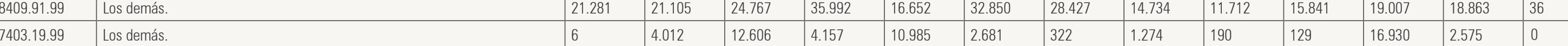

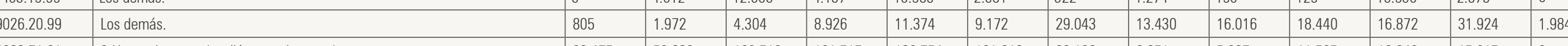

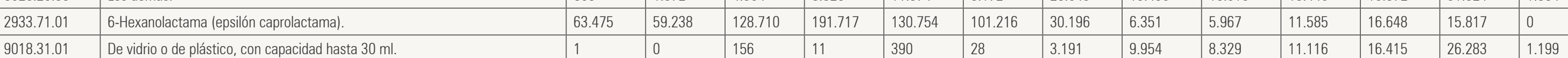

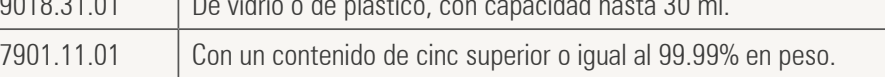

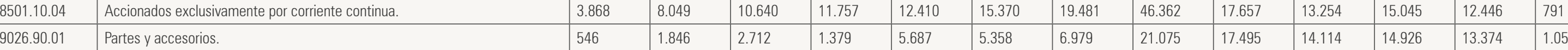

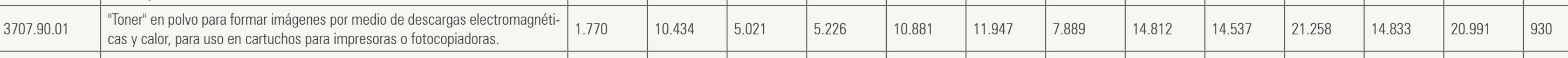

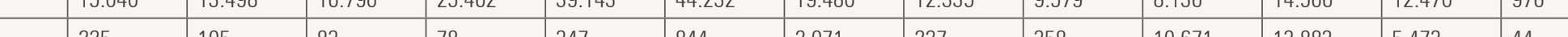

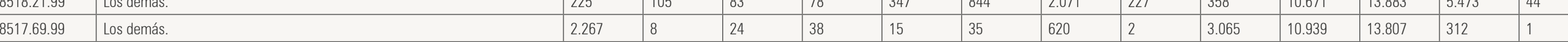

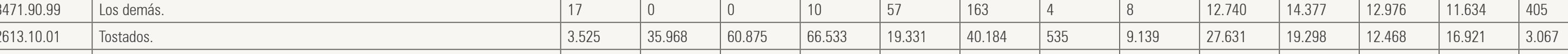

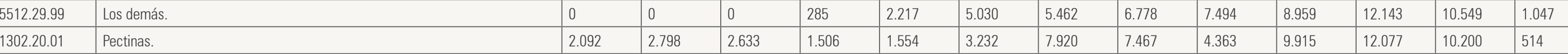

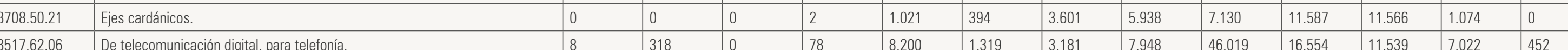

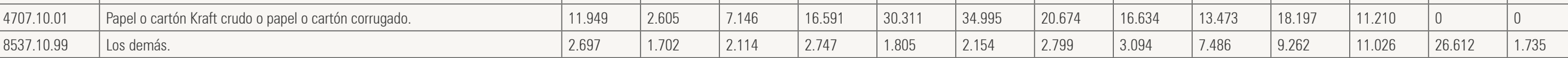

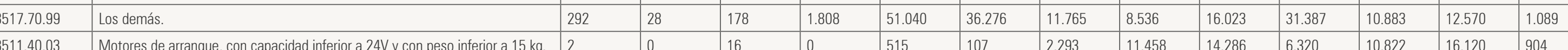

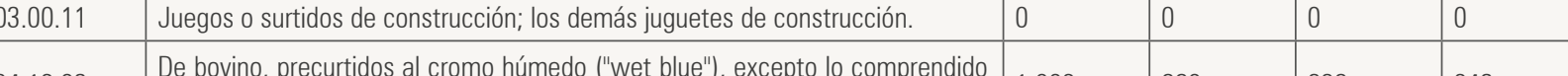

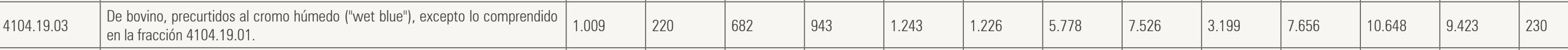

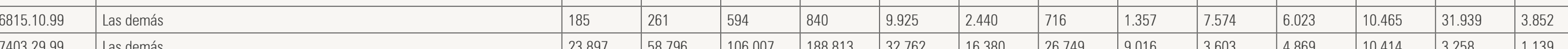

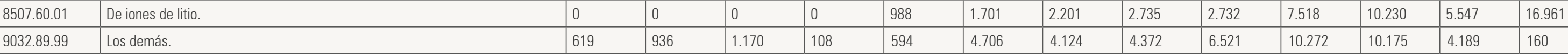

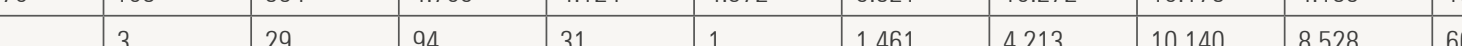

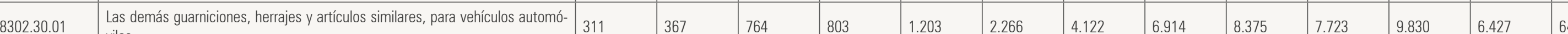

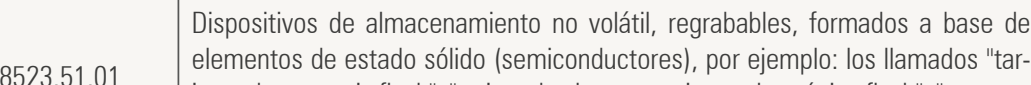

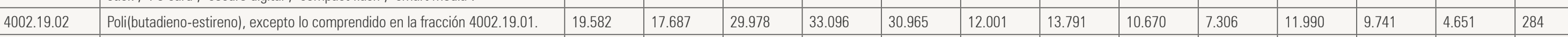

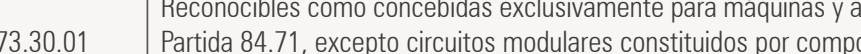

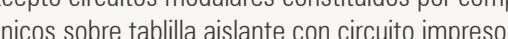

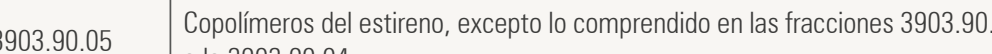

(1)

703.21.99 Los deng \begin{tabular}{|l|l|l|l|l|l|l|l|l|l|l|l|}
\hline & 3509 & 355 & 368 & 395 & 1.386 & 3.182 & 3.668 & 9.818 & 8.911 & 7.769 & 815 \\
\hline
\end{tabular} \begin{tabular}{|l|l|l|l|l|l|l|l|l|l|}
\hline & 32 & 390 & 1.402 & 6.183 & 8.998 & 9.452 & 8.716 & 6.340 & 514 \\
\hline
\end{tabular}

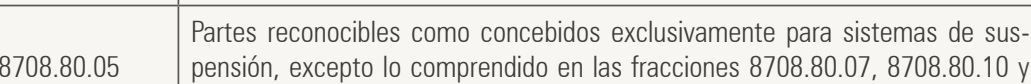

52010099 Los demás

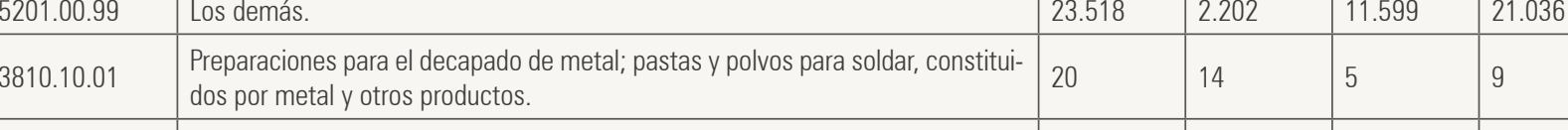

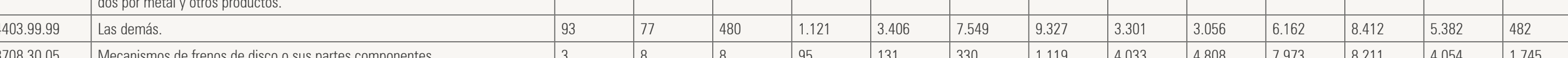
\begin{tabular}{lllllllllllll}
3.312 & 2.249 & 5.273 & 5.121 & 4.995 & 5.668 & 7.184 & 7.509 & 9.131 & 3.477 & 8.119 & 2.759 & 0 \\
\hline
\end{tabular}

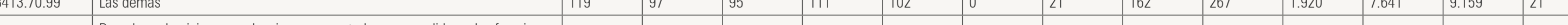

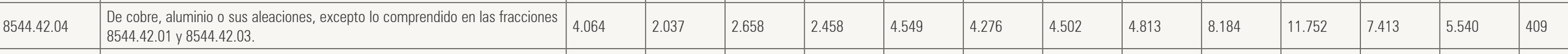

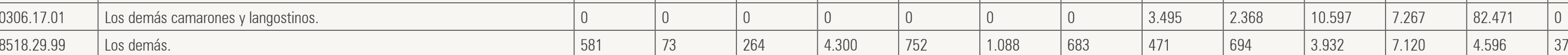

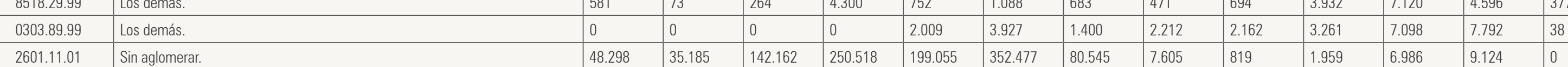




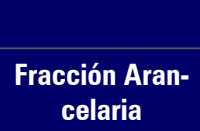

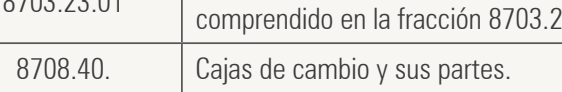

\begin{tabular}{|l|l|l}
\hline 8532.2499 & Los denmis. \\
\hline 850131.199 & Los denass. \\
\hline
\end{tabular}

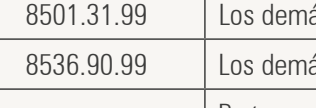

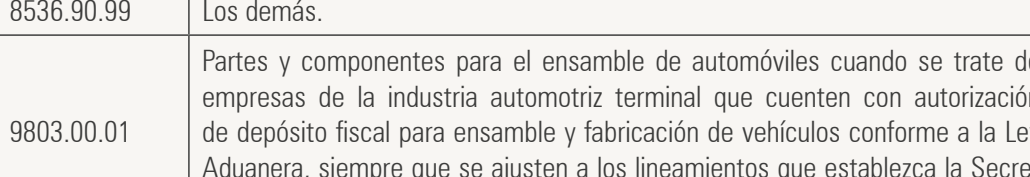

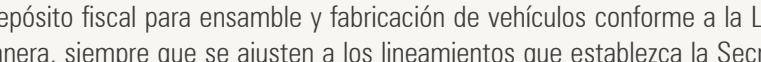
taria de Economia
Partes moldeadas.

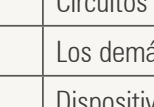

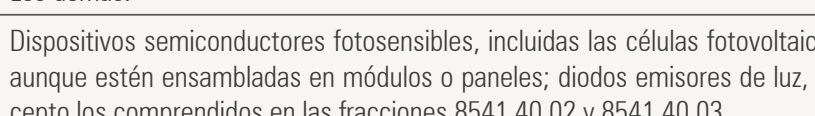
Los denás.

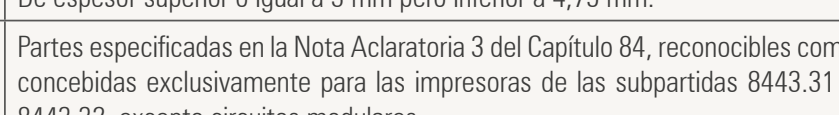

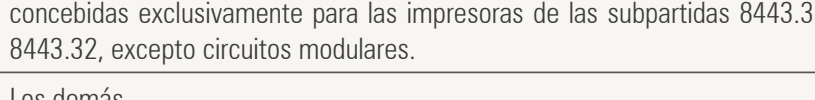

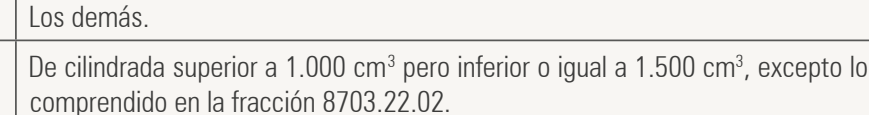

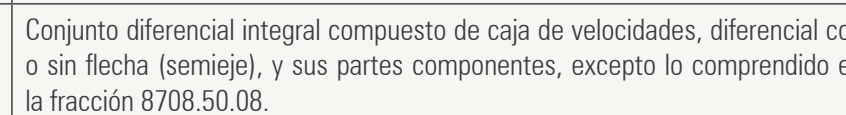
la faccioion 870.50 .08$.
Cajas de velocidades automáticas

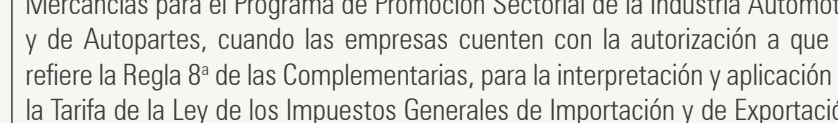

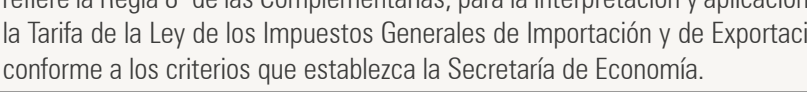

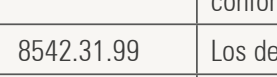

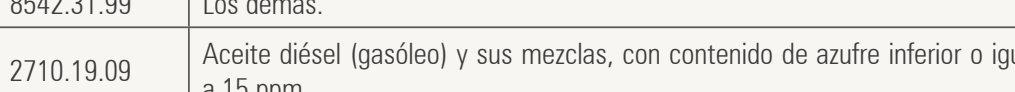

7326.90 .99 Las demás

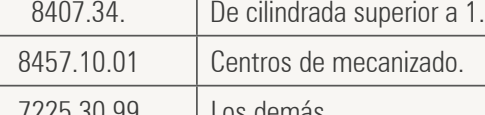

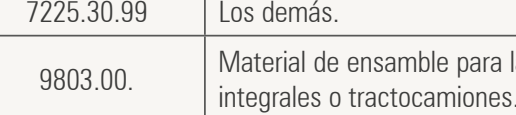

\begin{tabular}{|l|l|}
\hline 7225.50 .99 & Los demás. \\
\hline 8504.50 .99 & Las demás. \\
\hline
\end{tabular}

\begin{tabular}{|l|l|}
\hline 8537.10 .99 & Los denás \\
\hline 8708.29 .99 & Los denáas \\
\hline
\end{tabular}

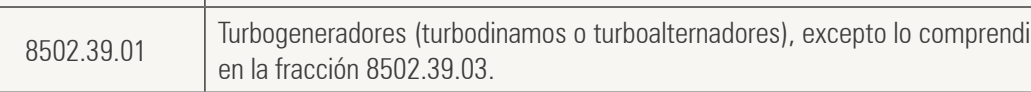

\begin{tabular}{|l|l|l}
8480.71 .99 & Los dents \\
\hline
\end{tabular}

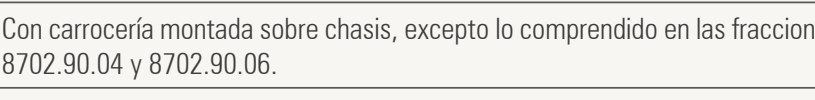

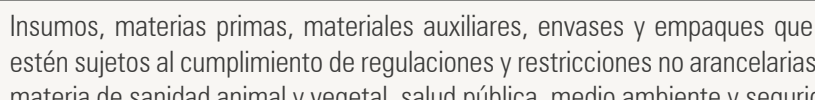

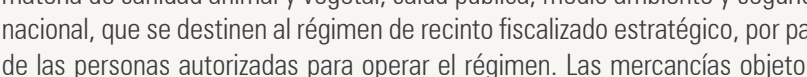

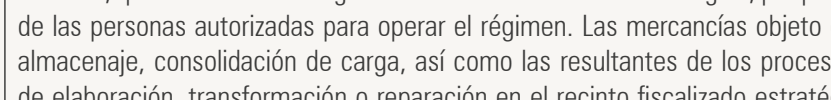

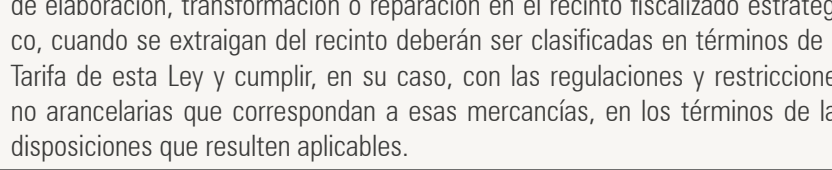

\begin{tabular}{|l|l|}
\hline 3926.90 .99 & Las demás \\
\hline 9031.80 .99 & Los demás \\
\hline
\end{tabular}

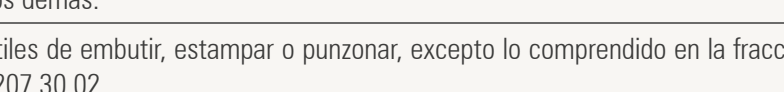

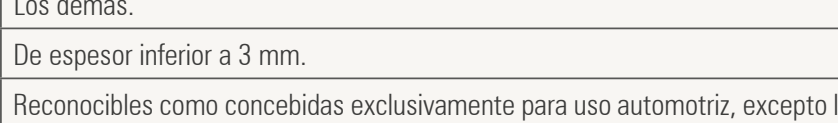

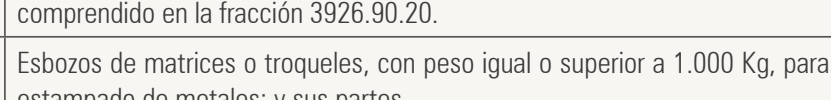

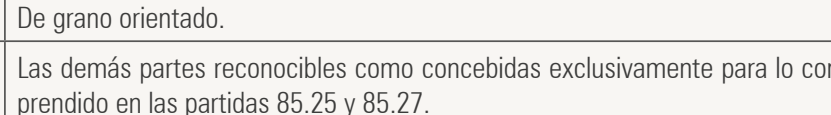

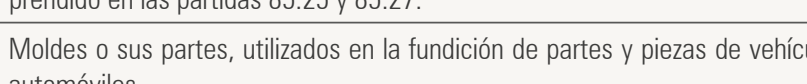
Los demás.

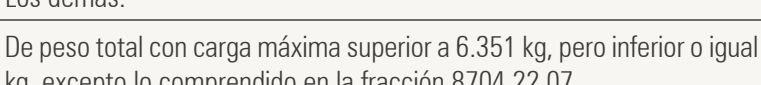

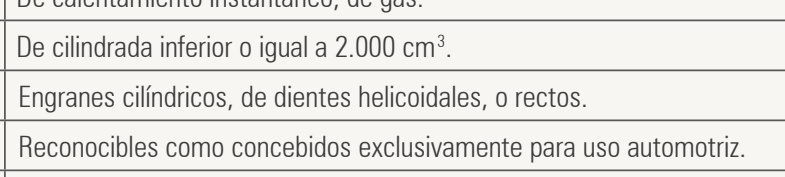

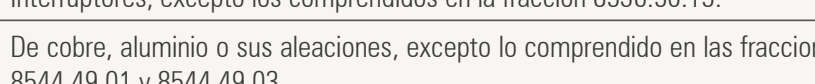

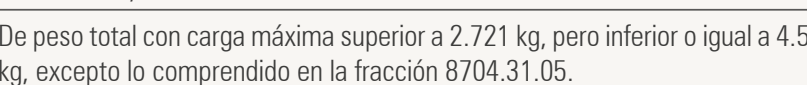

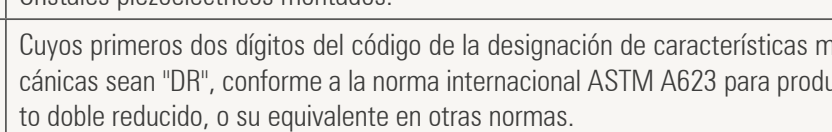

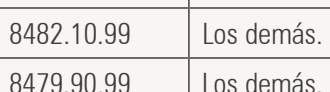

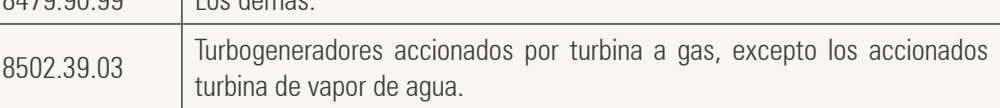

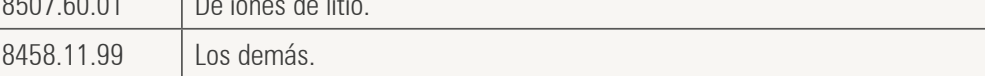

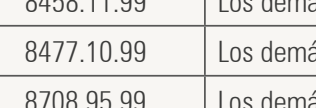

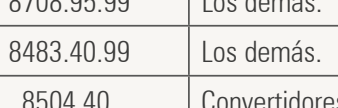

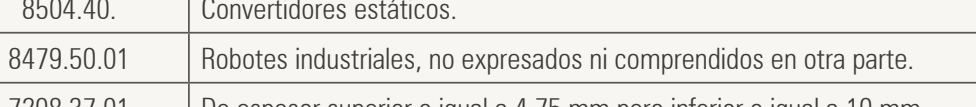

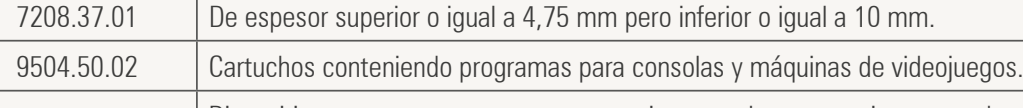

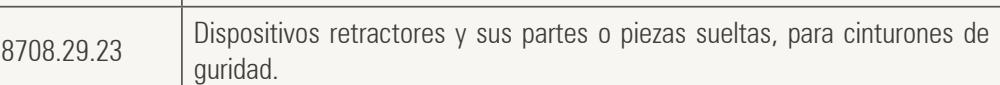

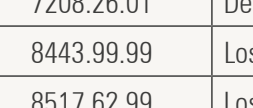

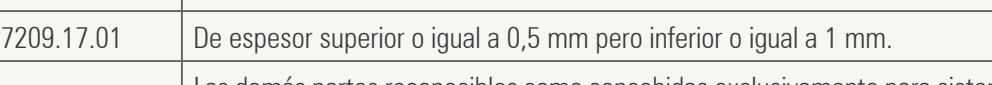

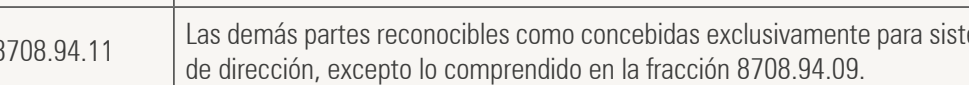

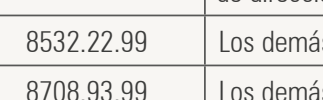

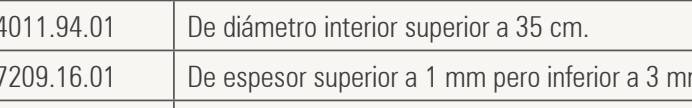

152323.9.03 Cintas montines sing

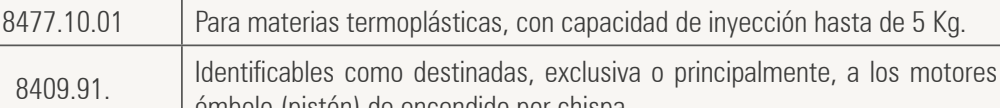

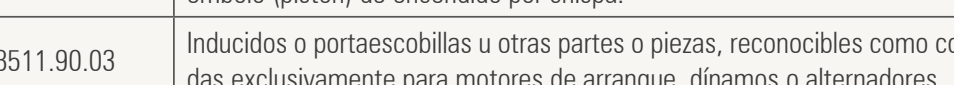

9032.89 .999 Los demás.

\begin{tabular}{|l|l|}
\hline 8462.10.99 & Los demás. \\
\hline 8466.94 .99 & Las demás. \\
\hline
\end{tabular}

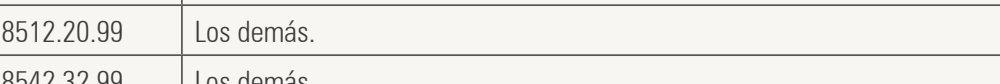

851521.01 Paras oddata metales por costuras o p provección.

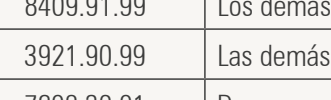

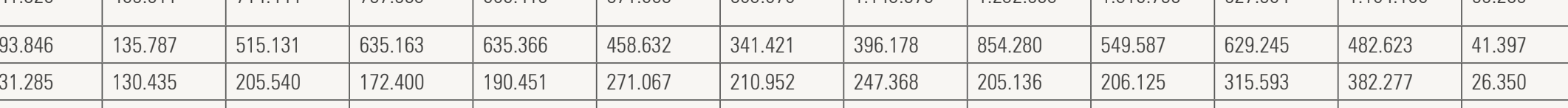

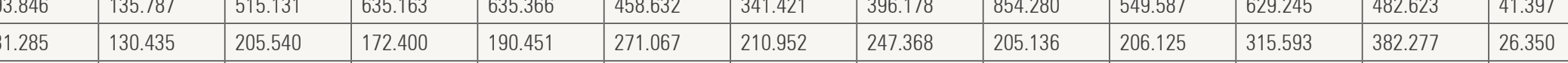

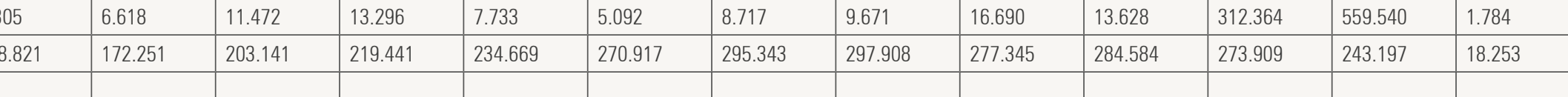

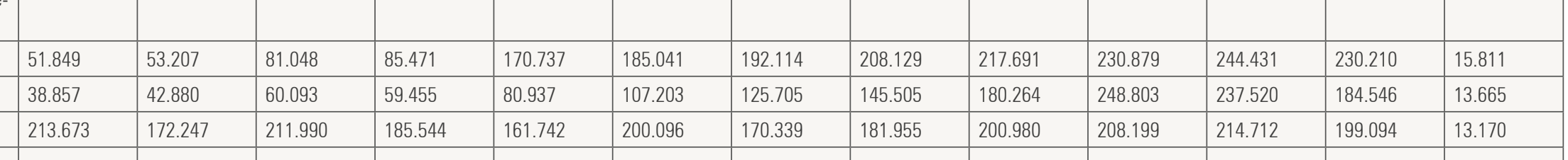

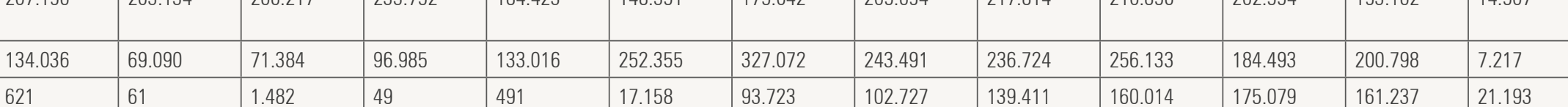

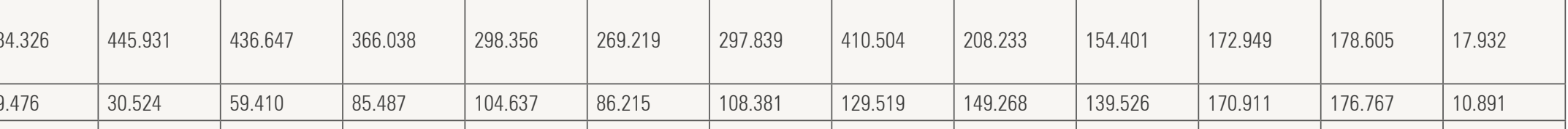

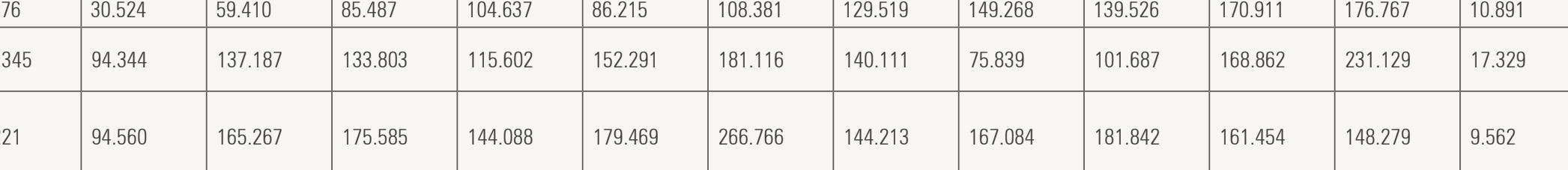

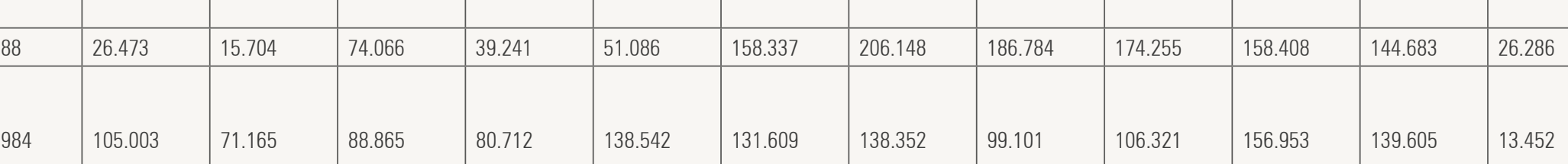

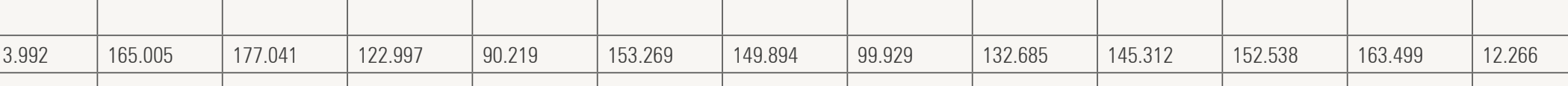

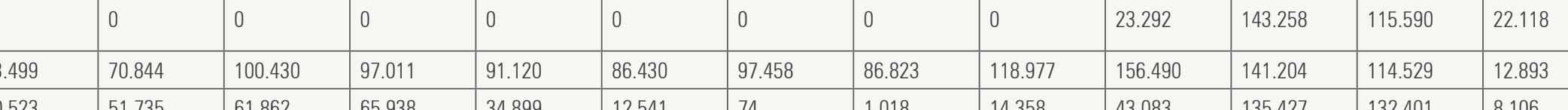

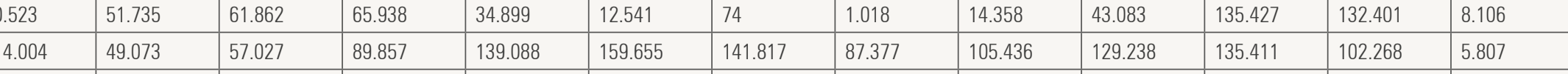

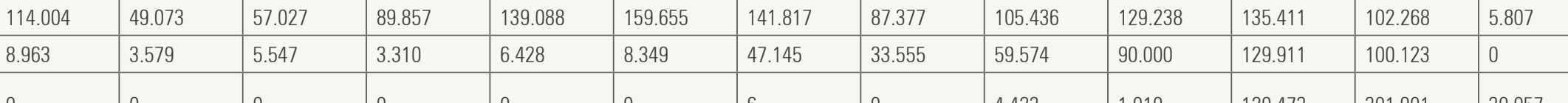

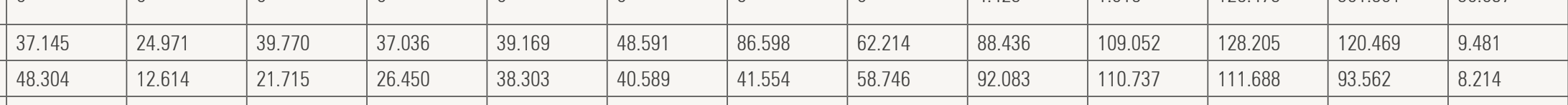

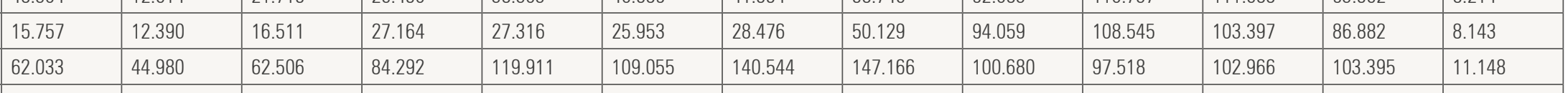
\begin{tabular}{|l|l|l|l|l|l|l|l|l|l|l|l|l|}
\hline 4406 & 3 & 0 & 1 & 68 & 2.941 & 42.475 & 14.209 & 194 & 66.039 & 10.557 & 5 & 0 \\
\hline 5052 & 47.255 & 33.329 & 36.55 & 46.359 & 75.957 & 65.911 & 45.367 & 51.252 & 54.258 & 98.991 & 81.079 & 4.139 \\
\hline
\end{tabular}

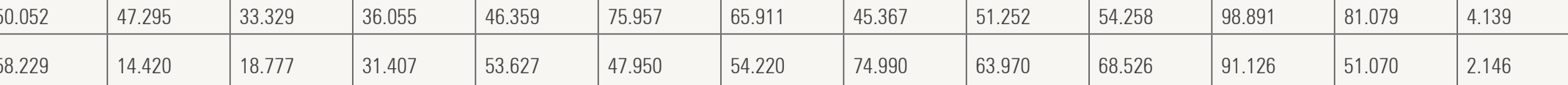
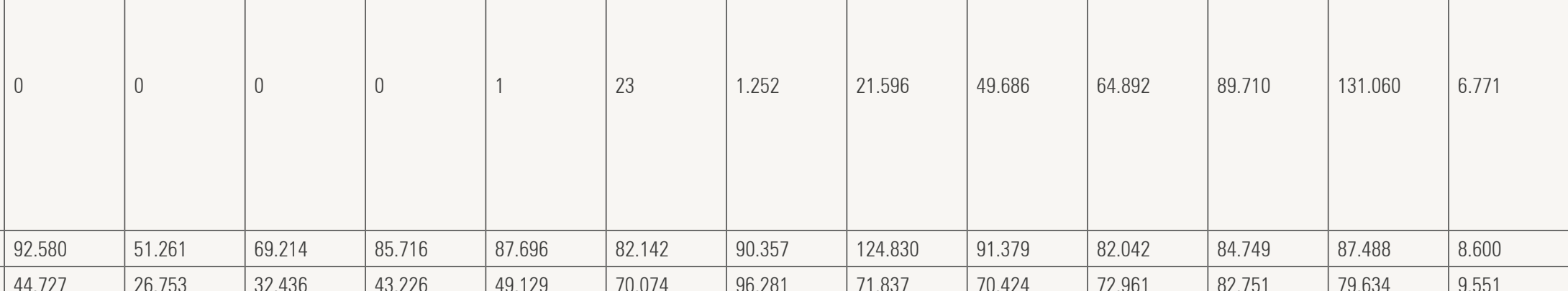

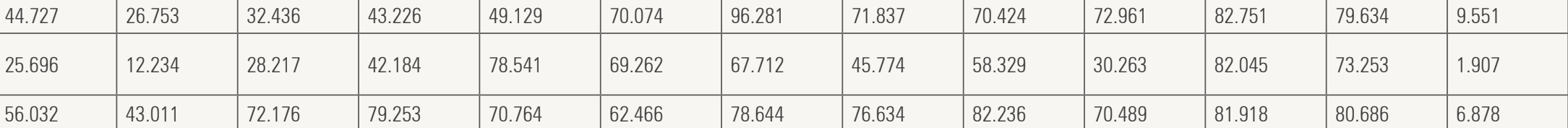

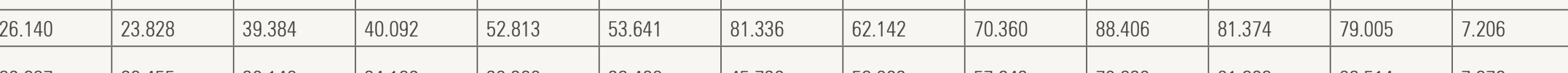
\begin{tabular}{|l|l|l|l|l|l|l|l|l|l|l|l|l|}
\hline 104 & 43 & 5.155 & 3.6 .617 & 24.730 & 50.707 & 49.468 & 2.0831 & 31.428 & 48.642 & 80.051 & 56.848 & 3.210 \\
\hline
\end{tabular}

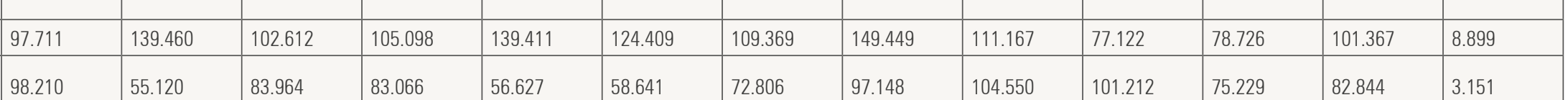

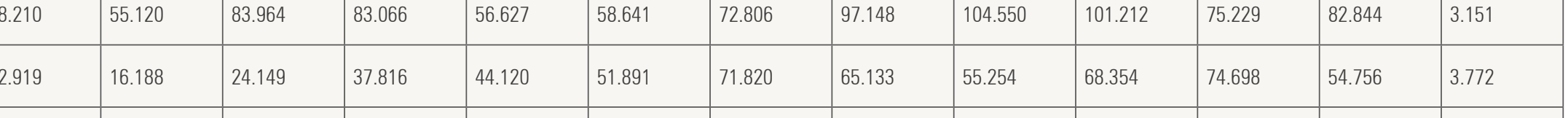

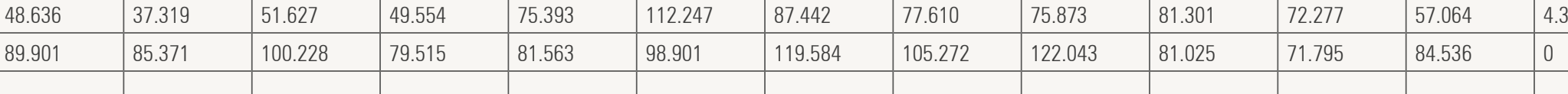

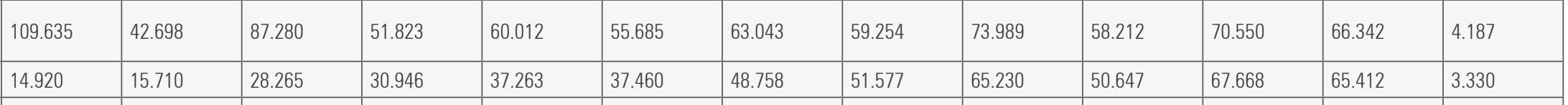

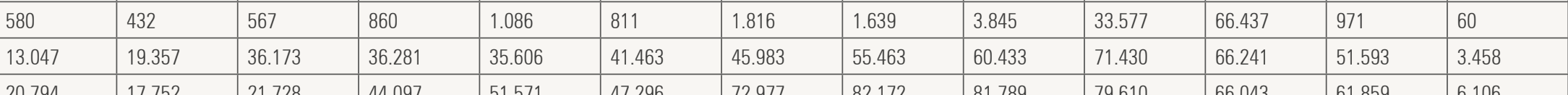

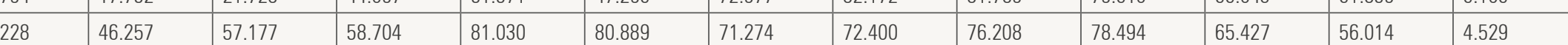
\begin{tabular}{|l|l|l|l|l|l|l|l|l|l|l|l|l|l|l|}
\hline 37.720 & 15.746 & 19.376 & 32.72 .99 & 33.940 & 39.503 & 41.235 & 32.782 & 52.262 & 54.169 & 63.554 & 59.311 & 7.459 \\
\hline
\end{tabular}

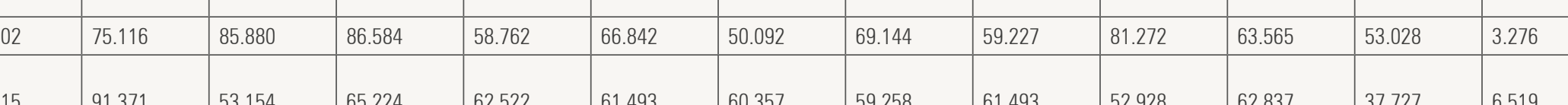

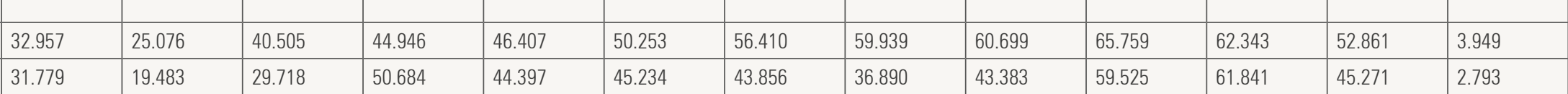
\begin{tabular}{|l|l|l|l|l|l|l|l|l|l|l|l|l|}
\hline 0 & 0 & 0 & 15.002 & 2 & 2 & 44.573 & 344 & 4.996 & 77.150 & 61.231 & 0 & 0 \\
\hline 18.126 & 11.678 & 18.322 & 16.148 & 18.414 & 54.215 & 62.104 & 71.814 & 76.822 & 59.665 & 61.25 & 77.389 & 5.663 \\
\hline
\end{tabular}

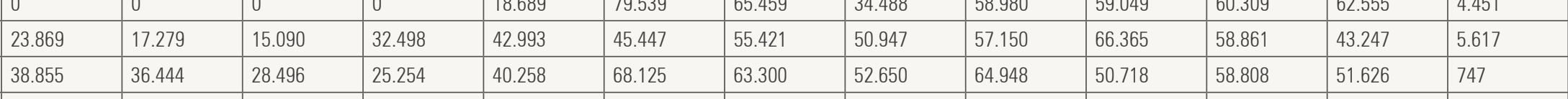

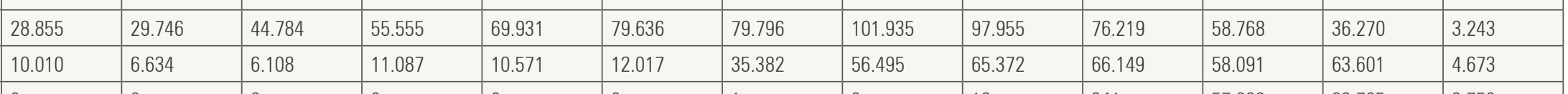

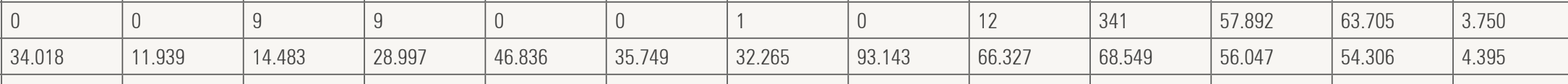

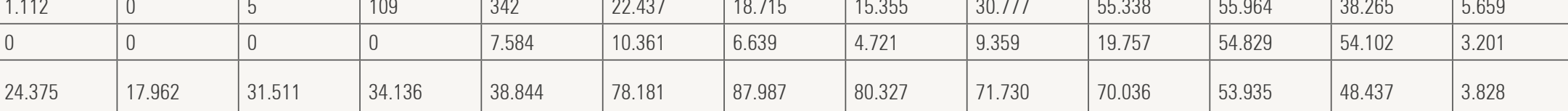

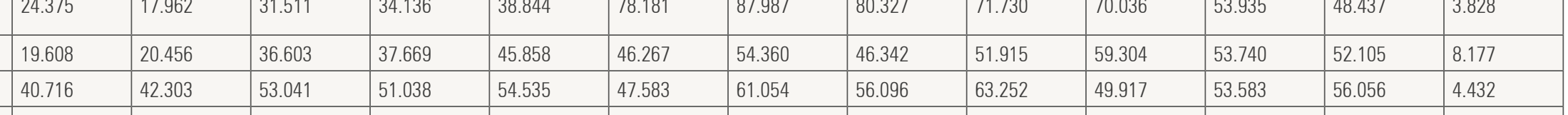

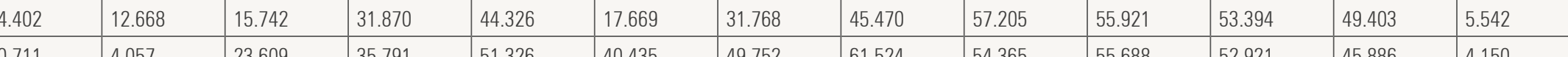

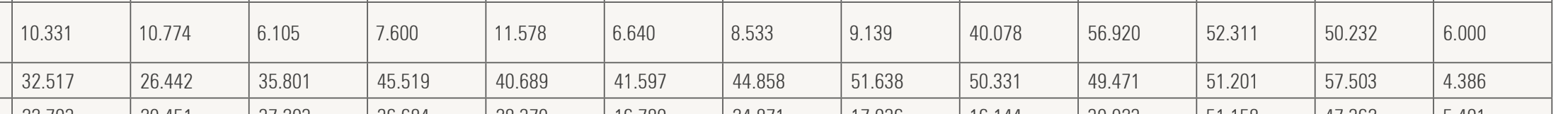

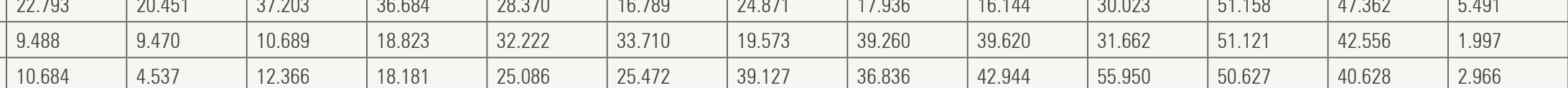

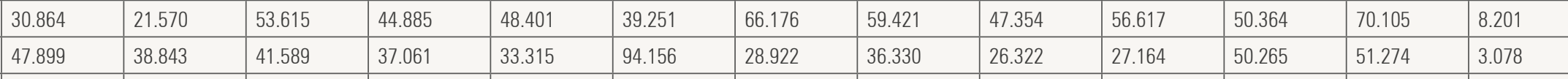

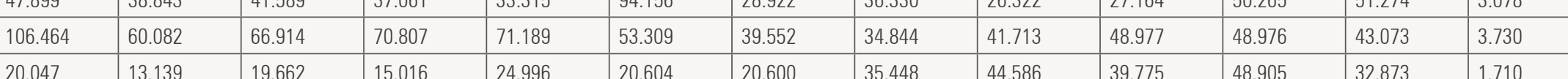

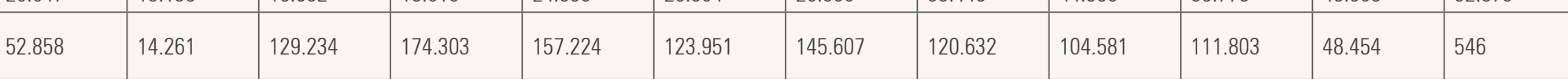

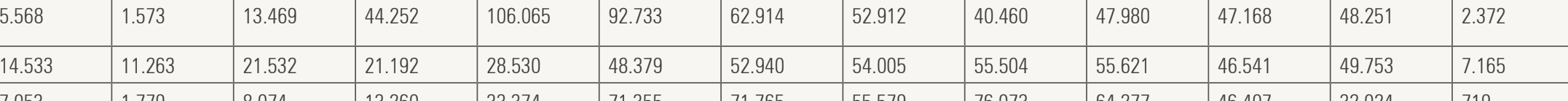

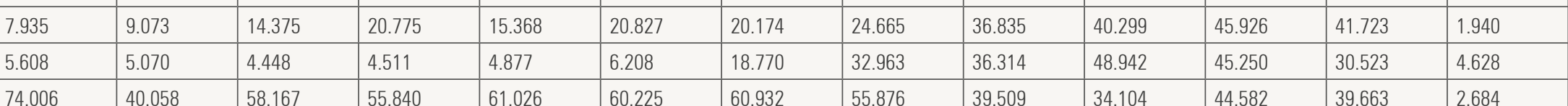

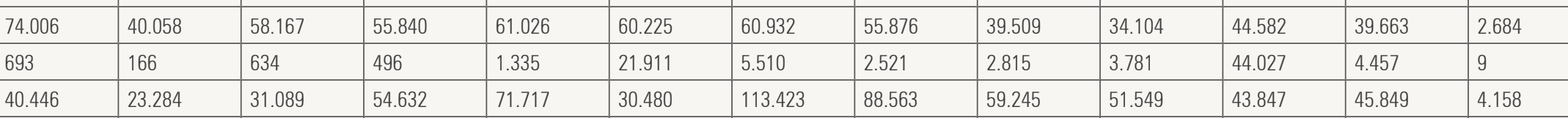

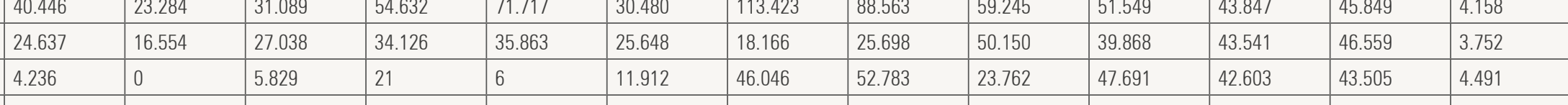




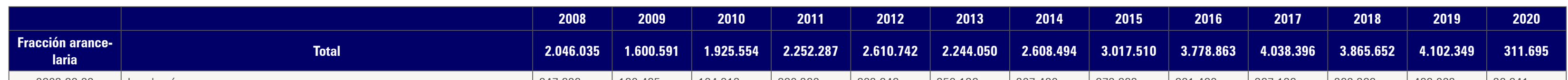

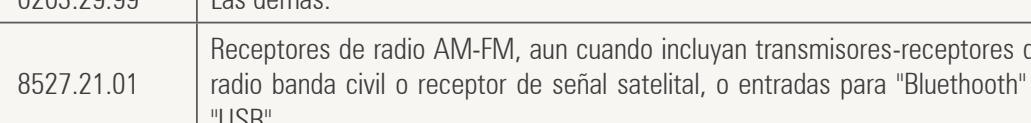

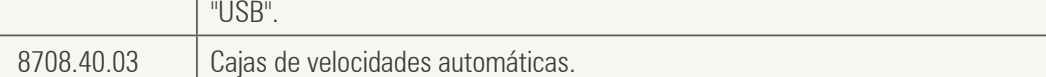

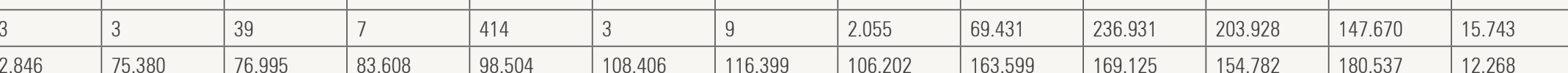

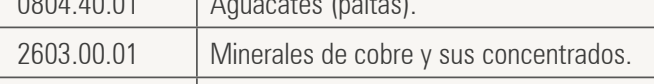

\begin{tabular}{|l|l|l|l}
\hline 8517.62 .99 & Los demás. \\
\hline 2008.00 .01 & Minerales de cinc y sus concentrados \\
\hline
\end{tabular}

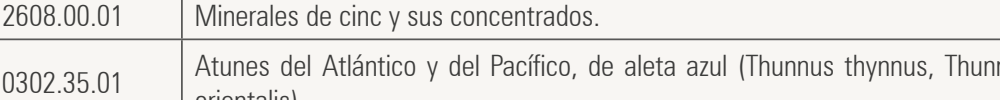

\begin{tabular}{l|l}
7106.91 .01 & En bruto. \\
\hline 8708.0099 & Las demás \\
\hline
\end{tabular}

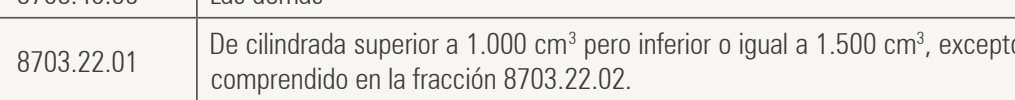

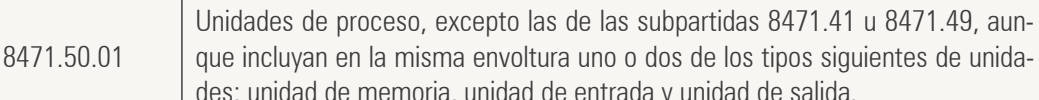

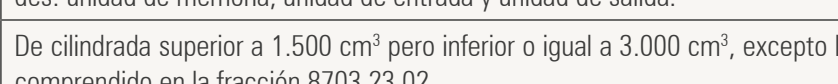

8471.7.0.1 Unidades de memori

\begin{tabular}{|l|l|}
\hline 2501.00 .99 & Las demas. \\
\hline 0203.19 .99 & Las demás. \\
\hline 84099199 & Los demás \\
\hline
\end{tabular}

\begin{tabular}{|l|l|}
\hline 8409.91 .99 & Los demás. \\
\hline 02023001 & Deshuesada. \\
\hline
\end{tabular}

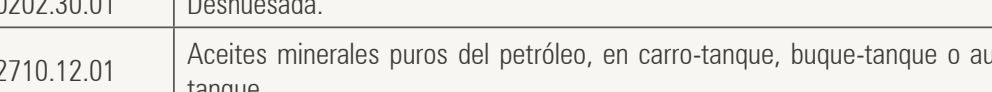

\begin{tabular}{l|l}
8501.131 .01 & Generatodres \\
\hline 2613001 & Tosades \\
\hline
\end{tabular}

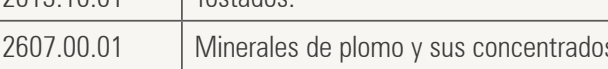

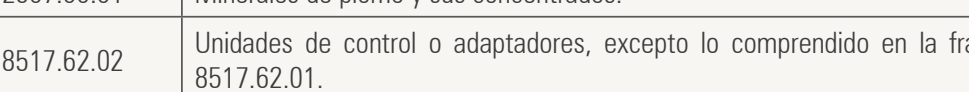

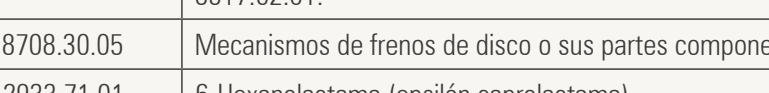

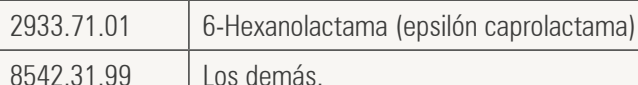

\begin{tabular}{|l|l|}
\hline 7326.90 .99 & Las demás \\
\hline 020130.01 & Deshuesada \\
\hline
\end{tabular}

200911.109 Congelado.

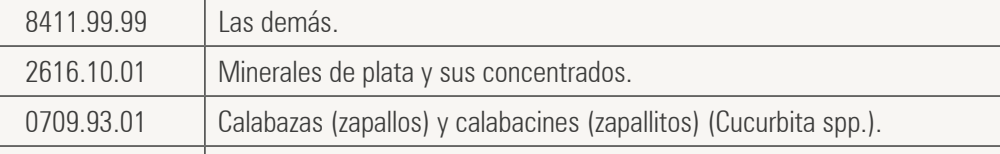

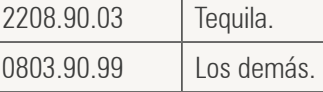

\begin{tabular}{c|c}
770400.99 & Los demas. \\
\hline 130220.01 & Pectinas. \\
\hline &
\end{tabular}

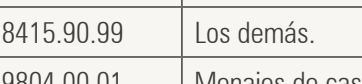

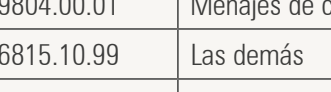

2903.92.01 Barcos de motor, excepto los de motor fuera de borde

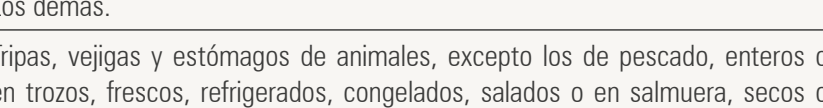

\begin{tabular}{|l|l|l}
\hline 4107.9 .101 & Plena Alor sin dividir. \\
\hline & &
\end{tabular}

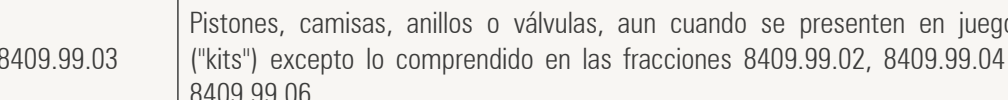

\begin{tabular}{lll}
0007.1999 & Los denás. \\
\hline
\end{tabular}

3923.50.01 Tapones, tapas, cápsulasy y demáas dispossitivos de cieire.

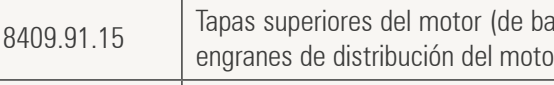

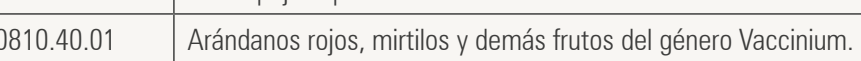

8471.80 .02 Unidades de controlo addaptados

\begin{tabular}{|l|l|l}
\hline 12066.17 .01 & Los demás camarones y langostinos \\
\hline
\end{tabular}

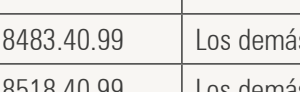

\begin{tabular}{|l|l|}
\hline 84113.30 .06 & Para aceite. \\
\hline 200929.99 & Los demás. \\
\hline
\end{tabular}

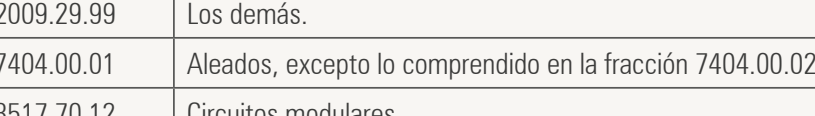

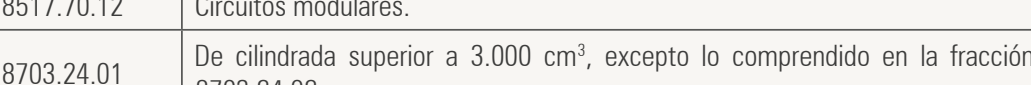

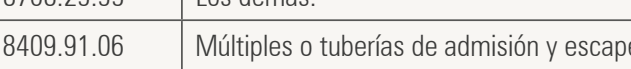

$\begin{array}{ll}2203000.01 & \text { Cenverade ne } \\ 1521.1099 & \text { Las demas. }\end{array}$

\begin{tabular}{|l|l|}
\hline 8708.80 .99 & Los denems. \\
\hline 8483.9099 & Los demsis. \\
\hline &
\end{tabular}

\begin{tabular}{c|c}
8708.99 .99 & Los demás. \\
\hline
\end{tabular}

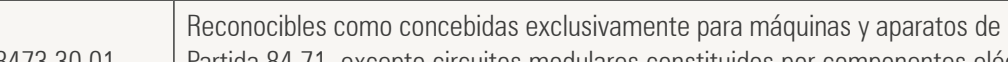

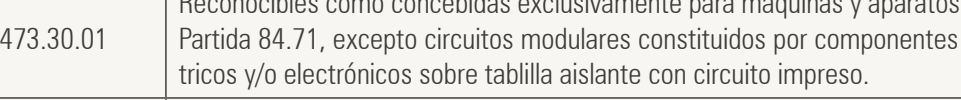

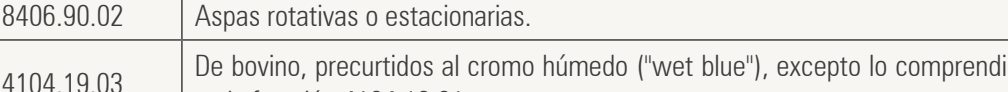

\begin{tabular}{|l|l}
3402.20 .99 & Los demas. \\
\hline 8708.9599 & Los demas. \\
\hline
\end{tabular}

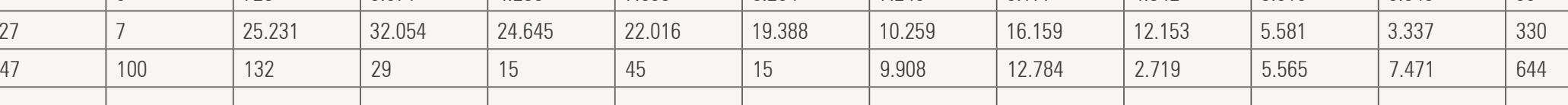

840991.03

1711 thol

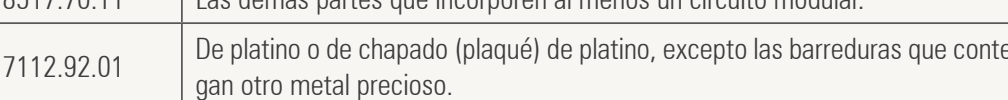

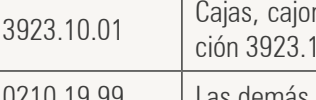

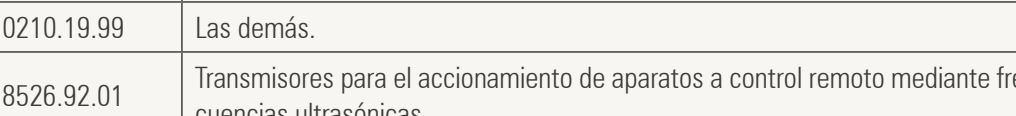

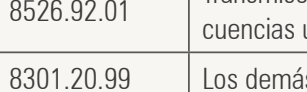

cinc suerior o igualal $199.99 \%$ en neso

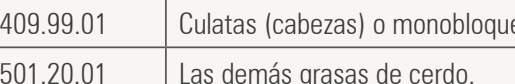

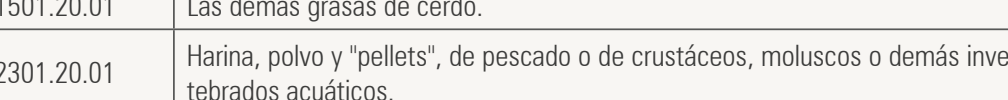

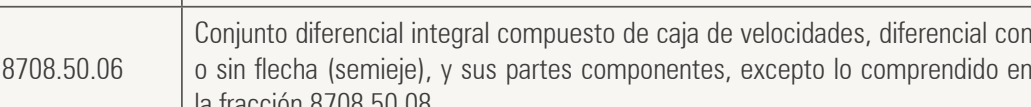

8421.139.99 $\quad$ Las demás

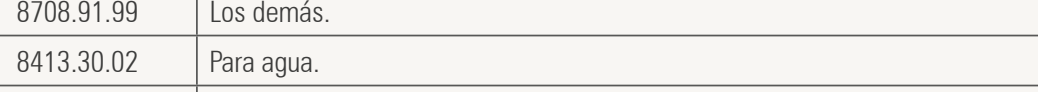

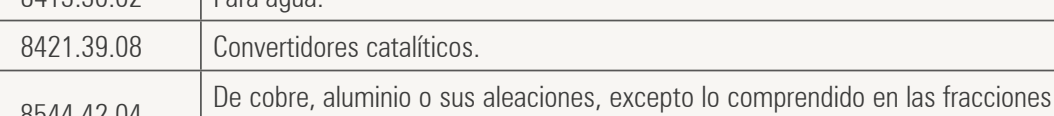

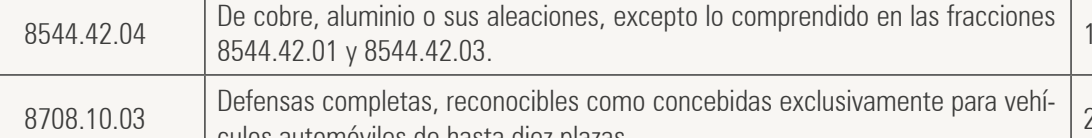

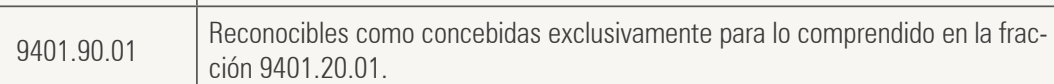

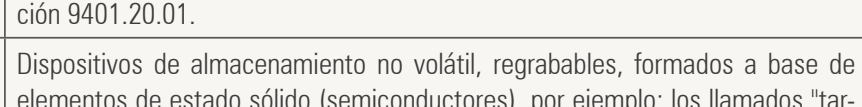

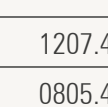

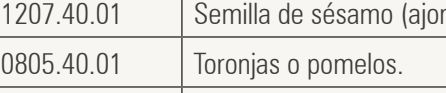

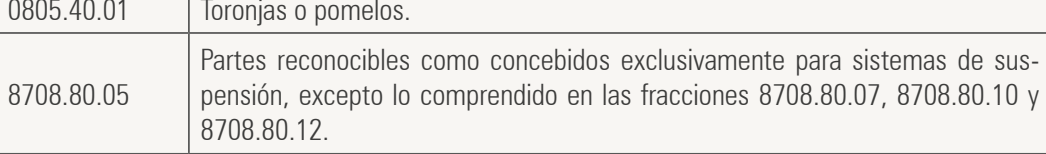
\begin{tabular}{|llllllll|l|l|l|l|}
\hline 34.370 & 33.201 & 33.087 & 31.454 & 32.455 & 50.911 & 45.951 & 45.577 & 46.748 & 46.603 & 43.519 & 3.326 \\
\hline
\end{tabular}

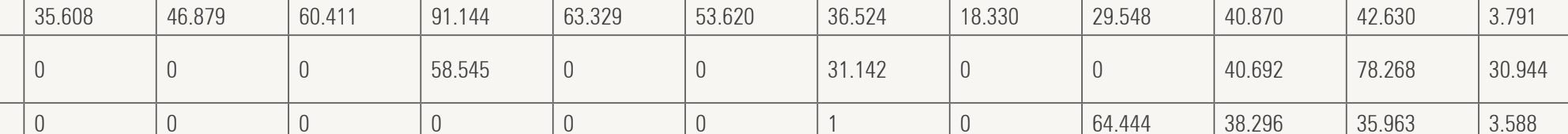

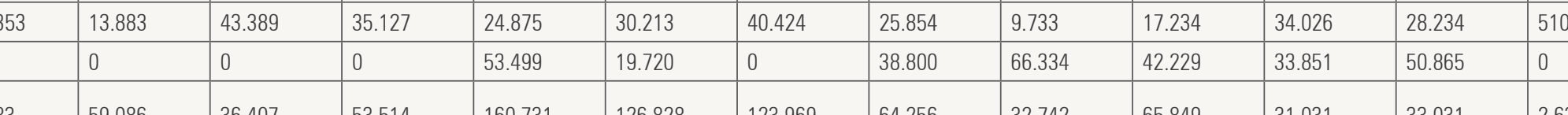
\begin{tabular}{|l|l|l|l|l|l|l|l|l|l|l|l|}
\hline 59.086 & 36.407 & 53.514 & 160.731 & 126.828 & 123.969 & 64.256 & 32.72 & 65.849 & 31.031 & 33.031 & 2.632 \\
\hline 3.914 & 1 & 13 & 31 & 7 & 11 & 1.205 & 17.251 & 31.471 & 30.644 & 11.711 & 555 \\
\hline
\end{tabular}

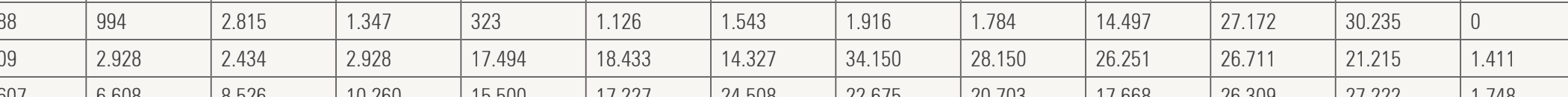

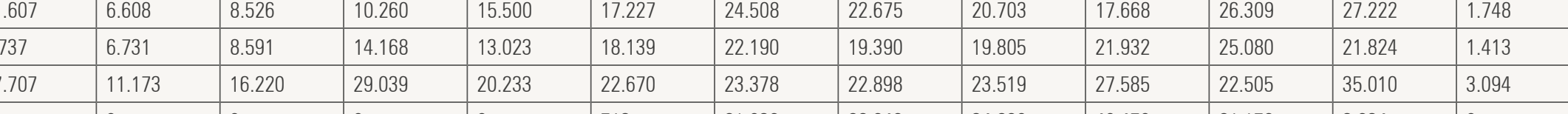

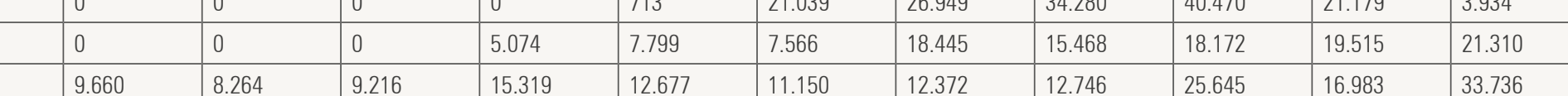

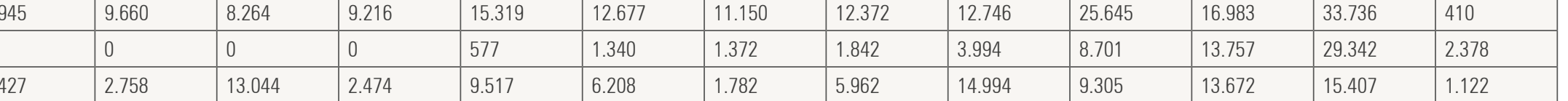

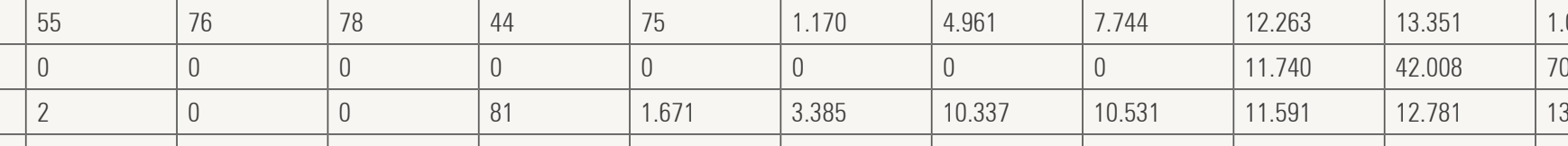

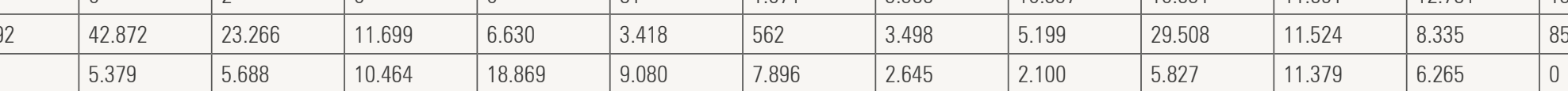
\begin{tabular}{|l|l|l|l|l|l|l|l|l|l|l|l|}
\hline 6.239 & 8.863 & 190.076 & 8.796 & 10.868 & 13.576 & 7.630 & 9.999 & 7.542 & 10.696 & 11.756 & 1.236 \\
\hline
\end{tabular}

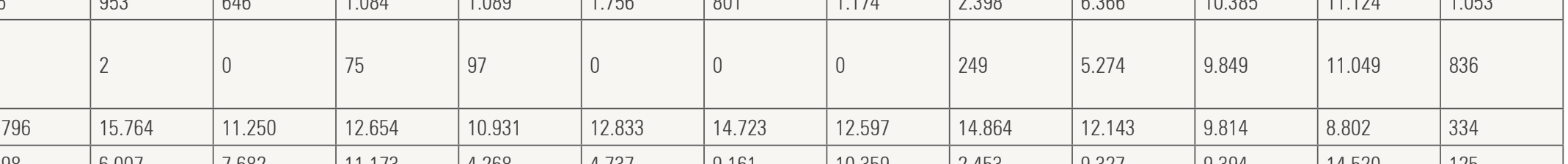

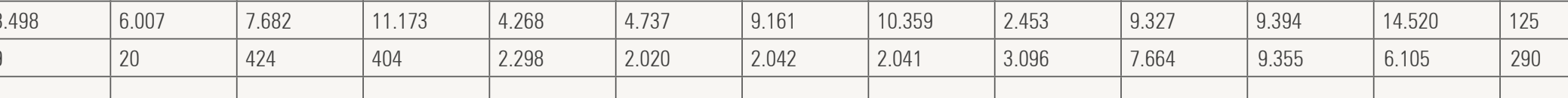

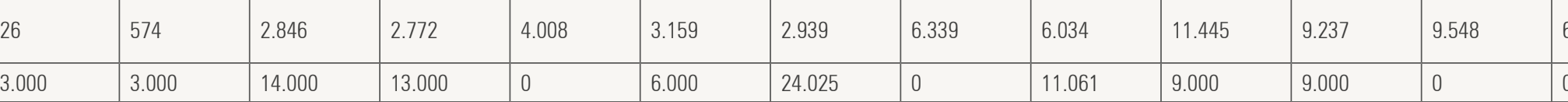

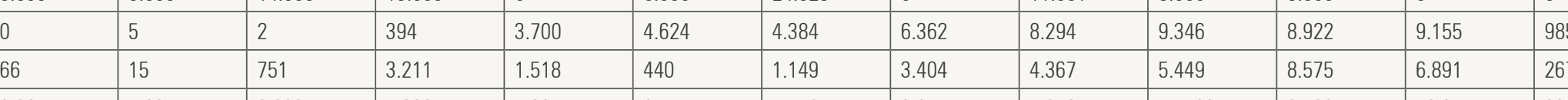

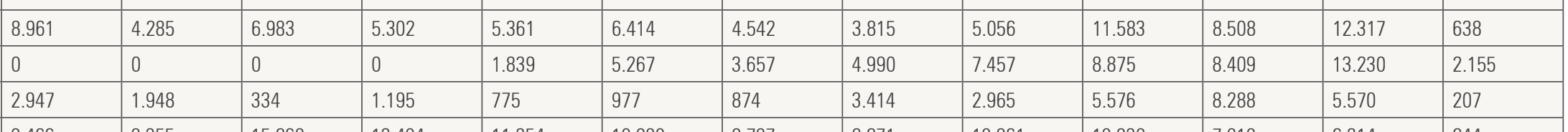

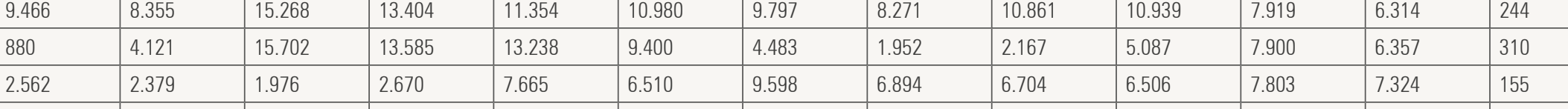

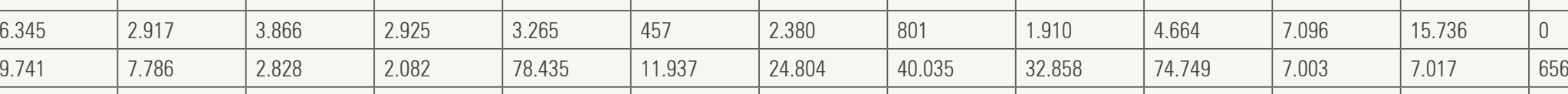

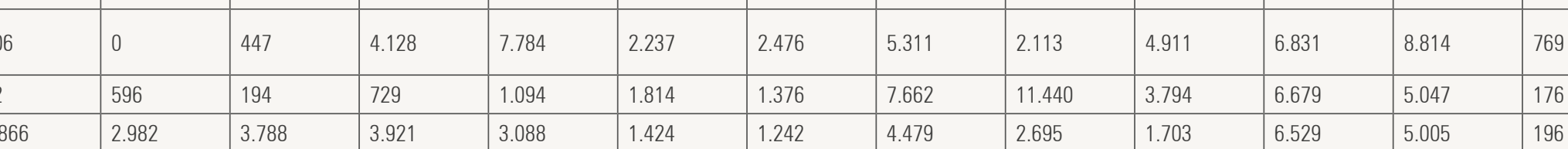

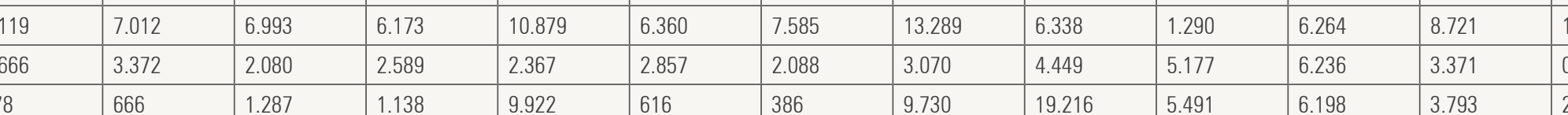

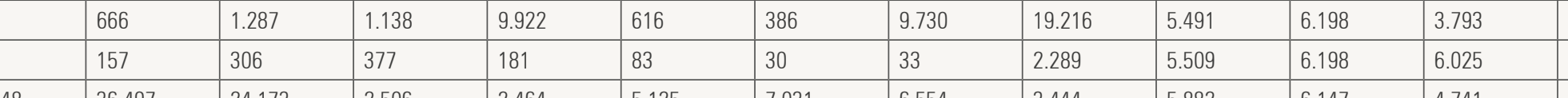

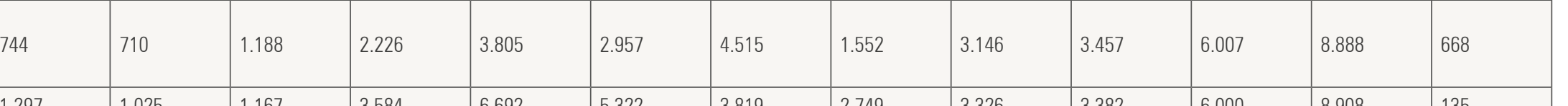

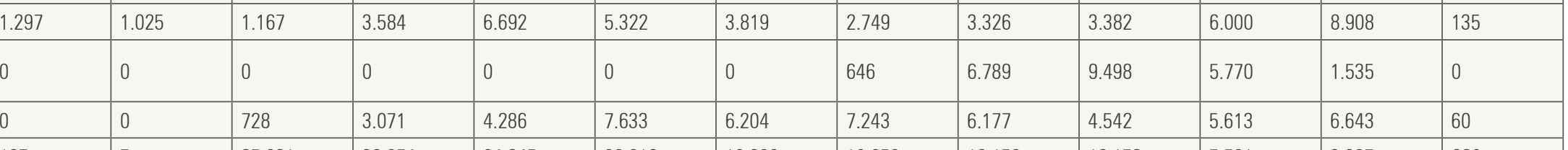

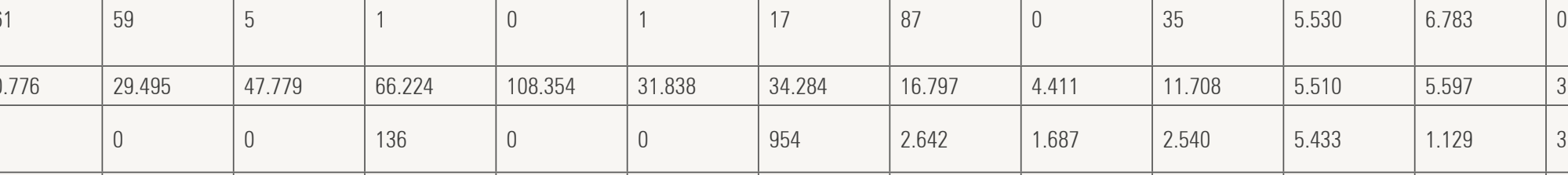
\begin{tabular}{|l|l|l|l|l|l|l|l|l|l|l|l|l|}
\hline 232 & 129 & 126 & 179 & 8.421 & 6.692 & 6.842 & 6.831 & 5.380 & 5.794 & 5.351 & 5.322 & 543 \\
\hline 1.892 & 0 & 0 & 0 & 0 & 1 & 0 & 0 & 5.930 & 13.762 & 5.268 & 0 & 0 \\
\hline
\end{tabular}

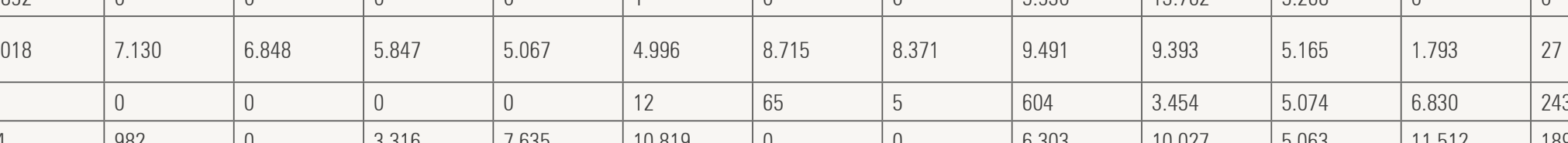

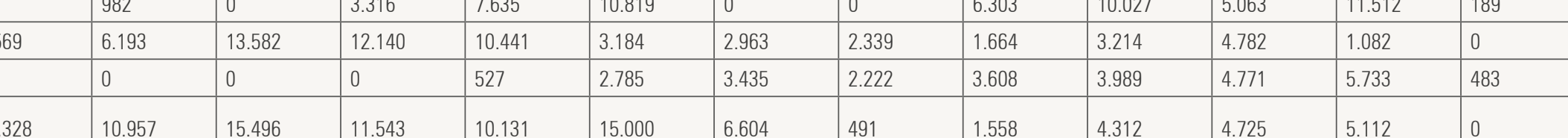

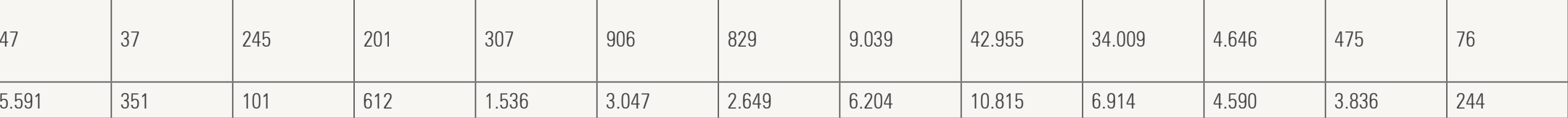

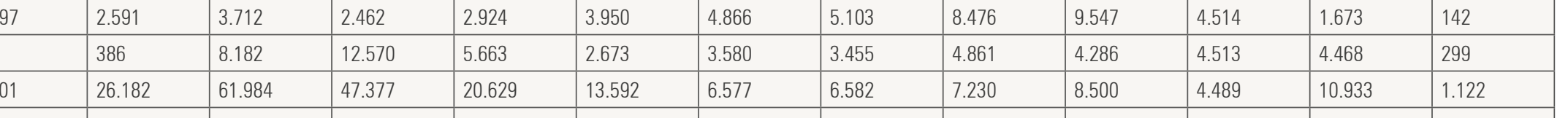

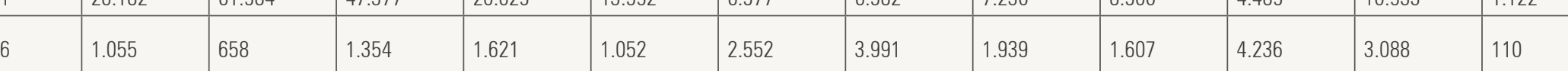
\begin{tabular}{|l|l|l|l|l|l|l|l|l|l|l|l|l|}
\hline & 80 & 91 & 116 & 40 & 42 & 1.917 & 2.812 & 3.385 & 4.121 & 3.005 & 287 \\
\hline 700 & 1.573 & 5.694 & 1.966 & 1.734 & 17.921 & 49.888 & 52.541 & 45.599 & 21.255 & 4.112 & 2205 & 179 \\
\hline
\end{tabular}

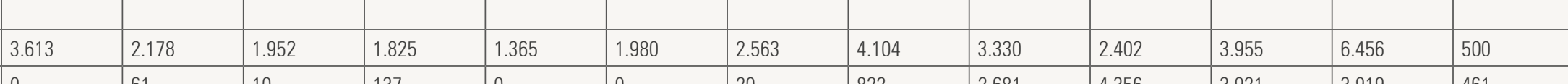
\begin{tabular}{|l|l|l|l|l|l|l|l|l|l|l|l|l|}
\hline 0 & 61 & 10 & 137 & 0 & 0 & 20 & 822 & 2.681 & 4.356 & 3.921 & 3.919 & 461 \\
\hline 2 & 33 & 61 & 52 & 98 & 382 & 946 & 1.634 & 4.906 & 1.874 & 3.907 & 11.74 & 1.509 \\
\hline
\end{tabular} 


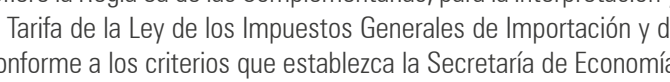

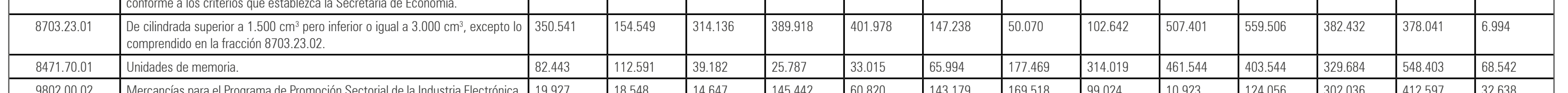

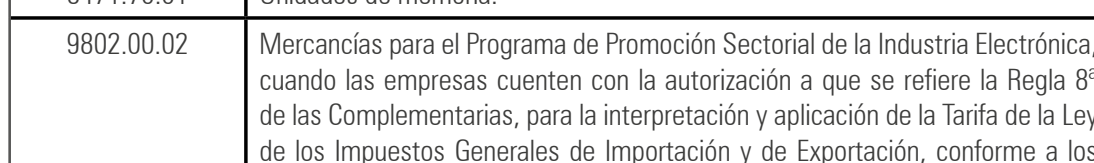

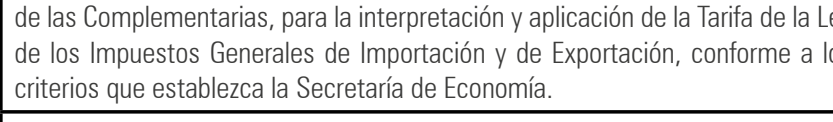

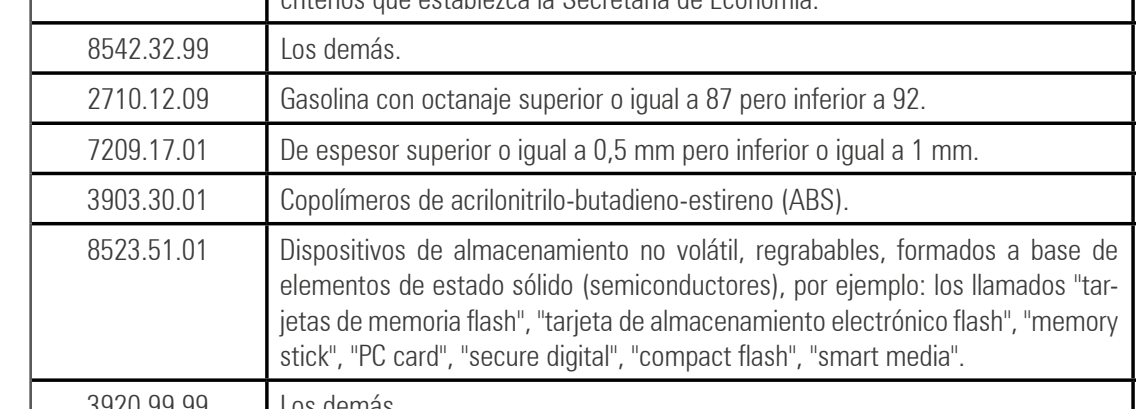

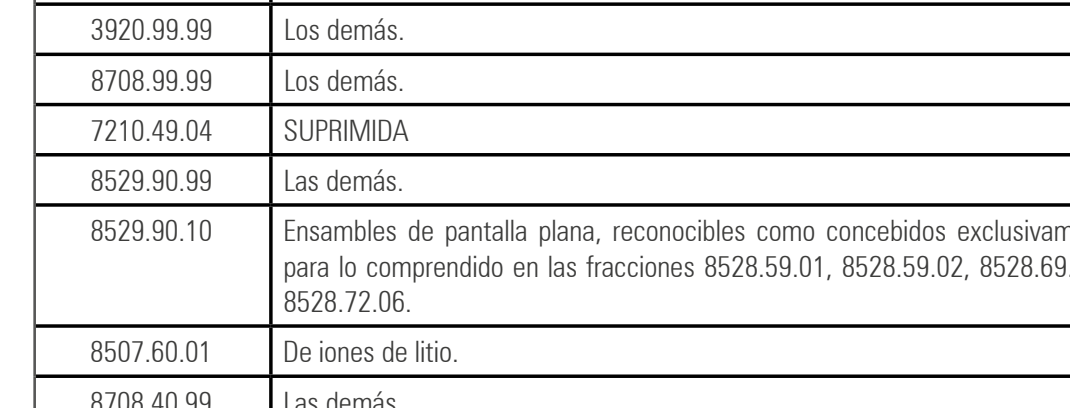

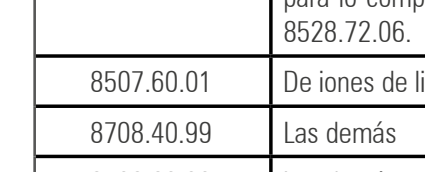

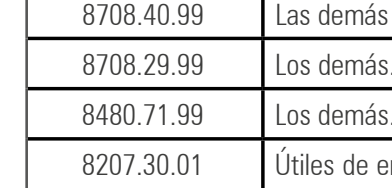

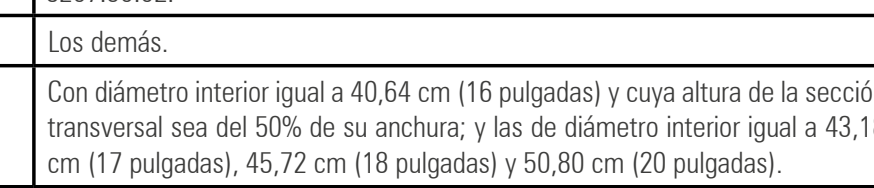

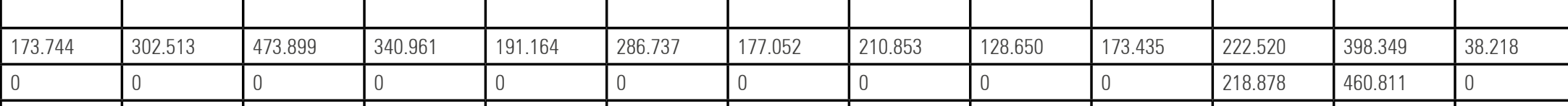

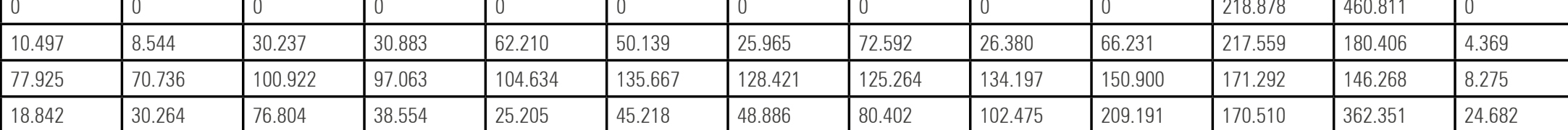

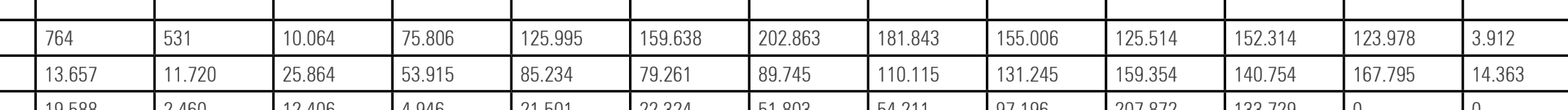

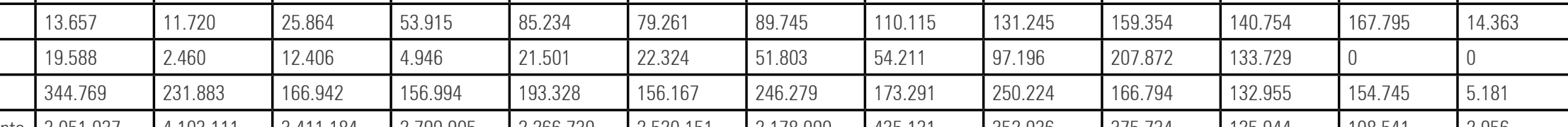

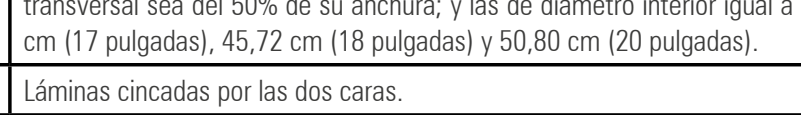

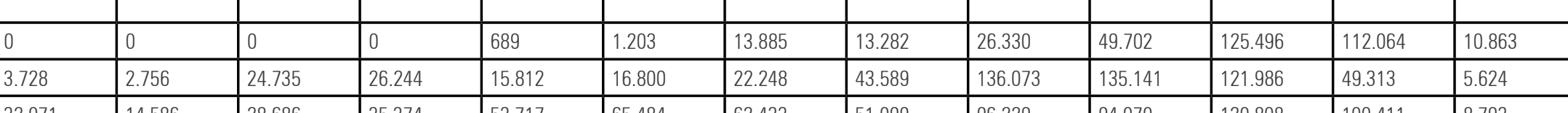

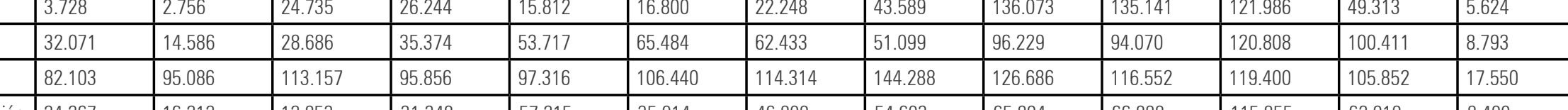

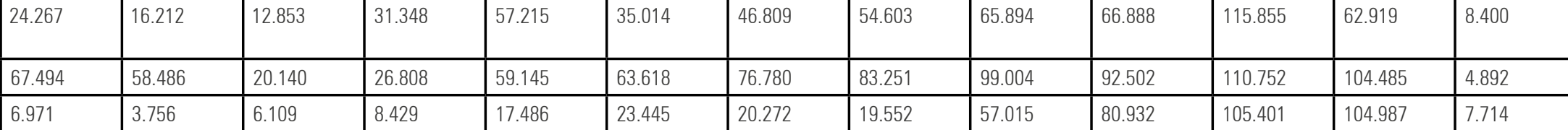

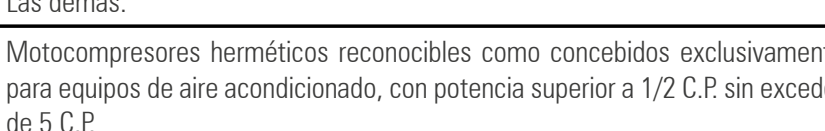

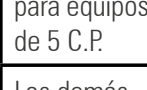

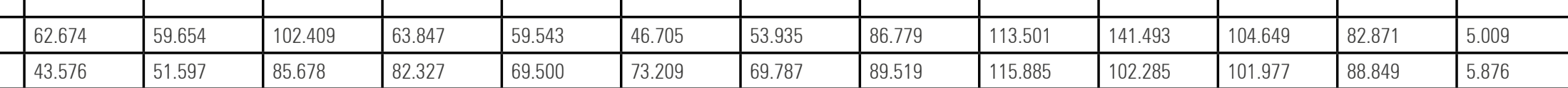

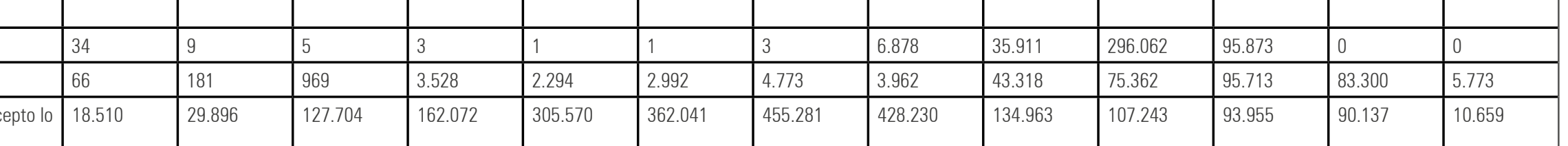

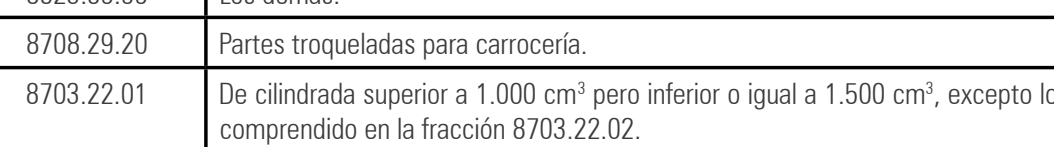

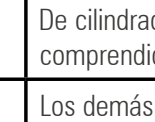

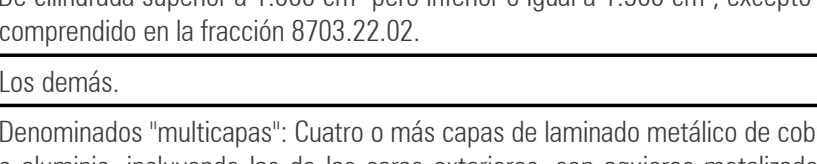

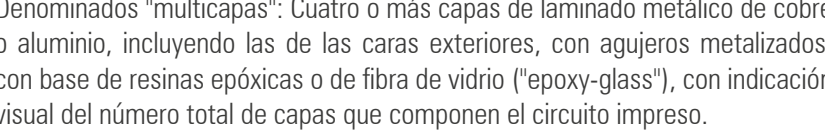

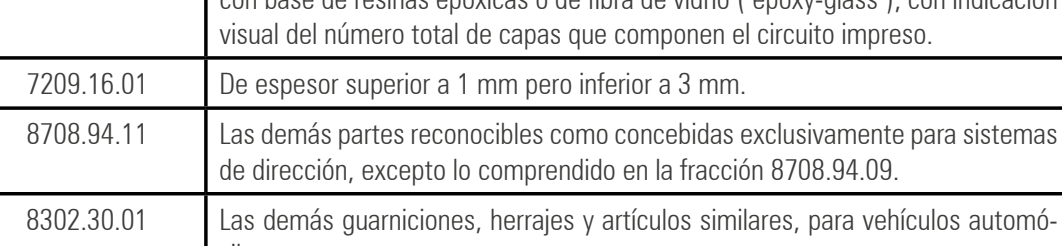

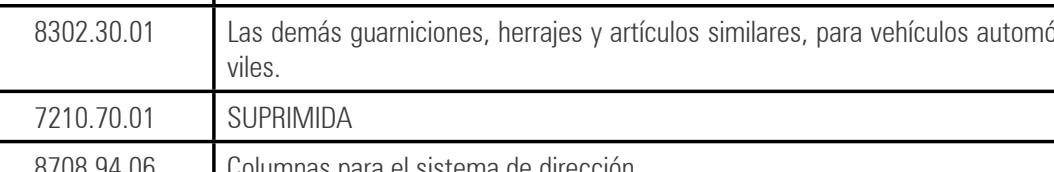

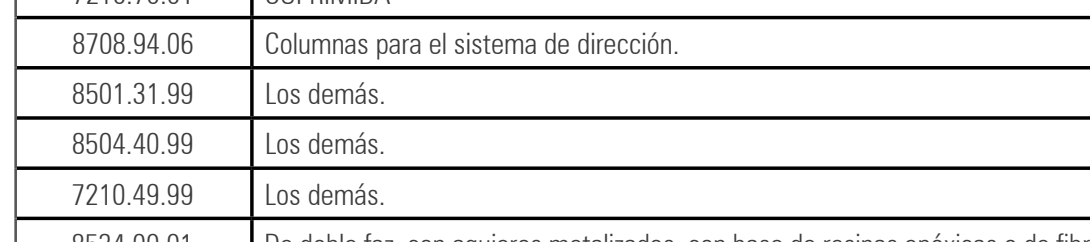

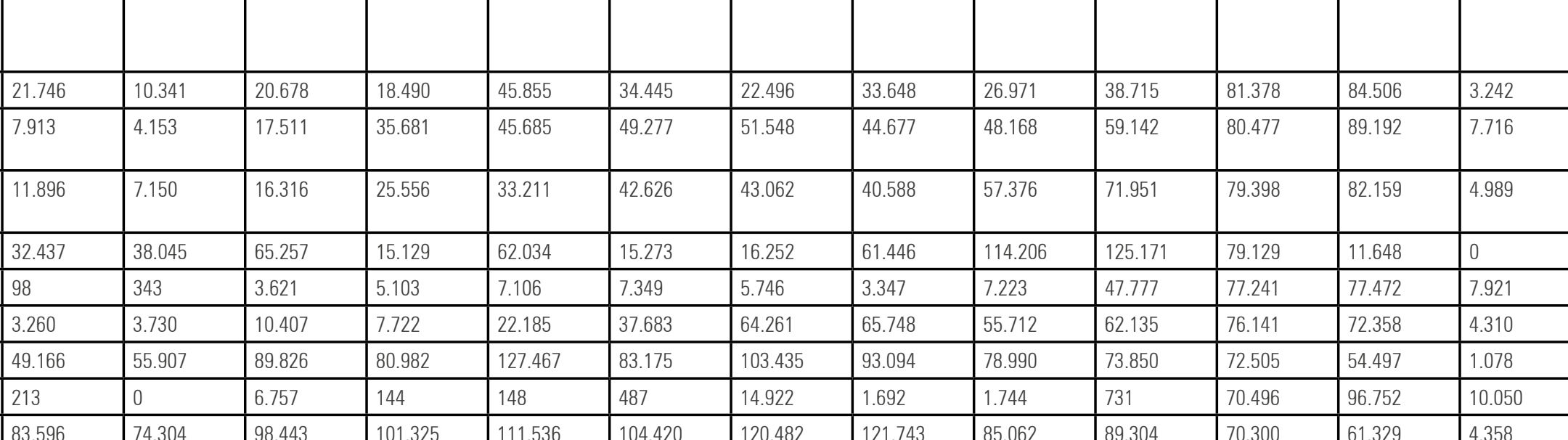

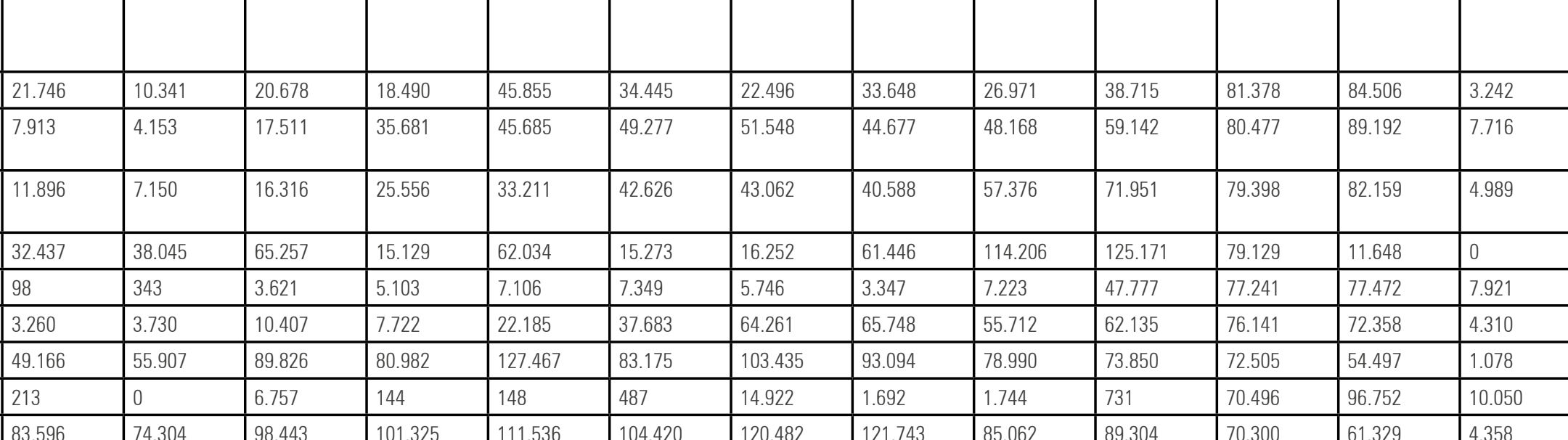

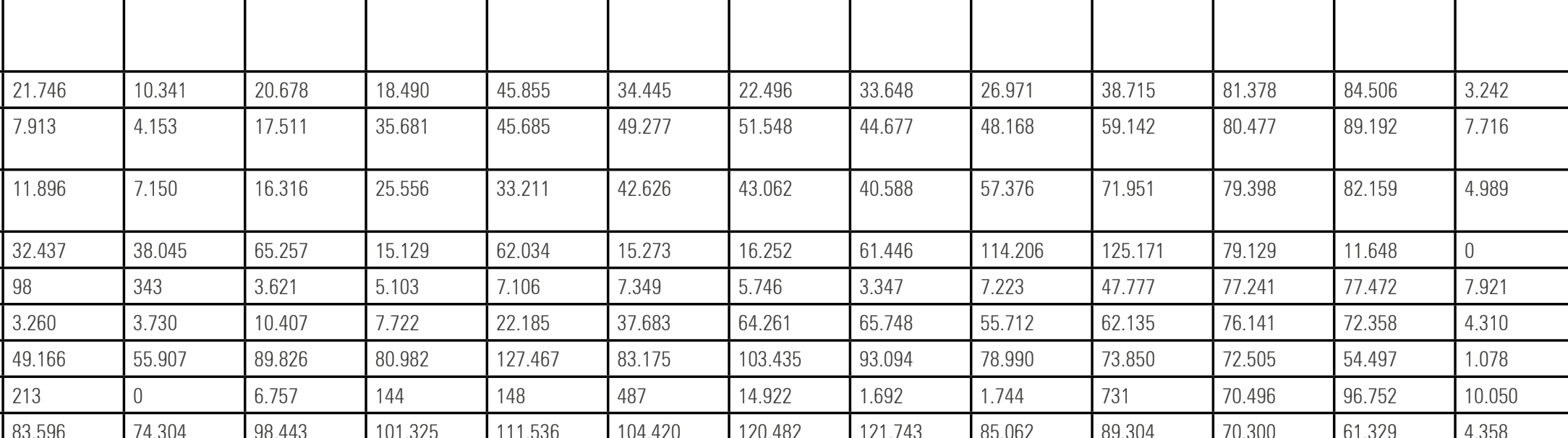

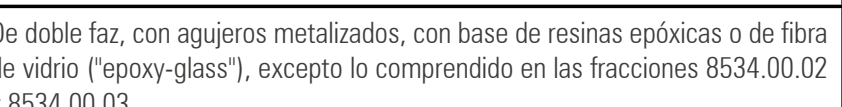

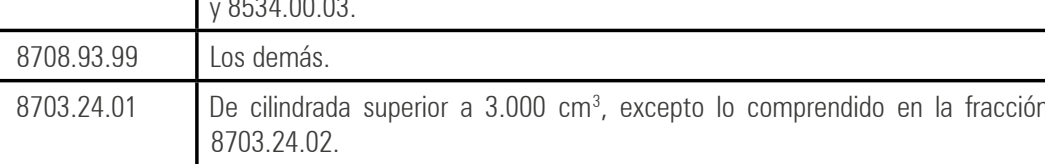

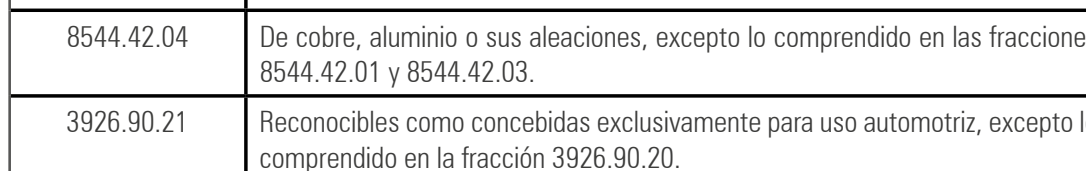

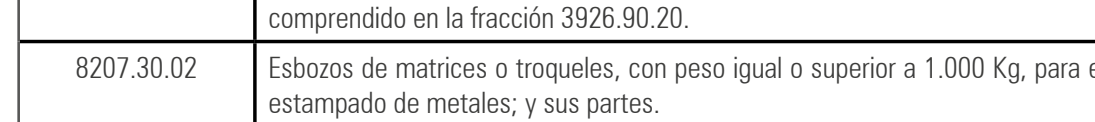

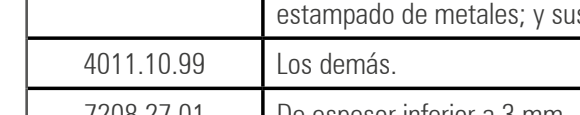

\begin{aligned} 40111.0 .99 \\ \hline 72027.01 \\ \hline 902020.15\end{aligned}

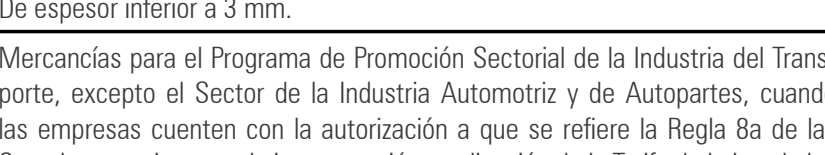

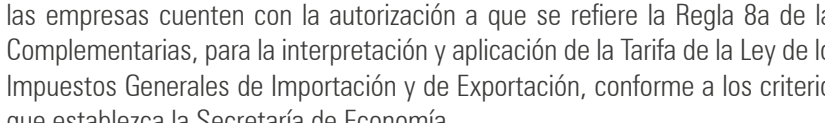

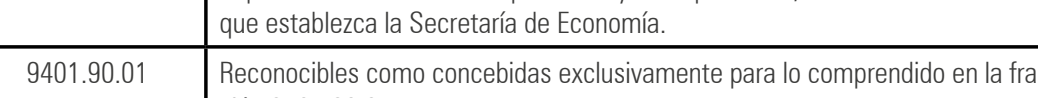

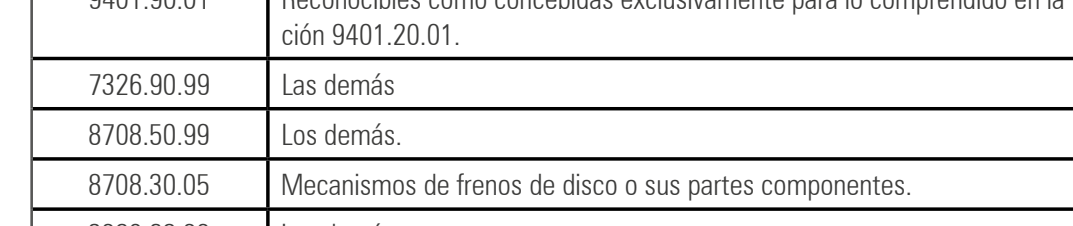

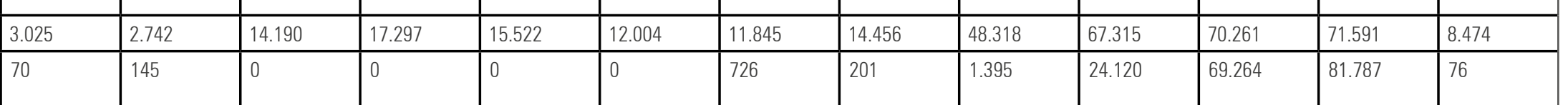

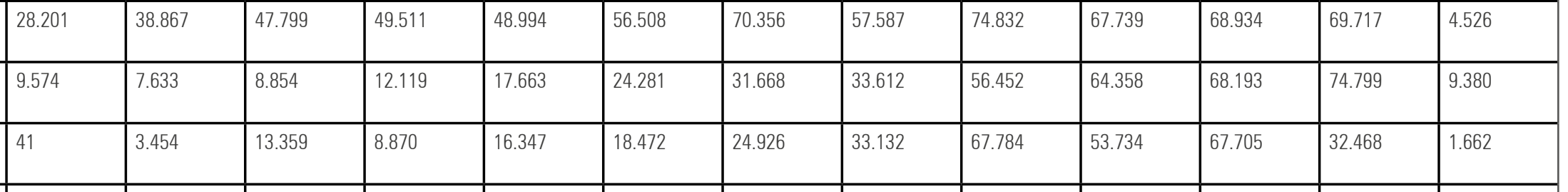

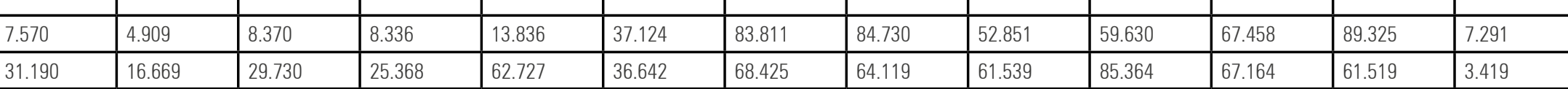

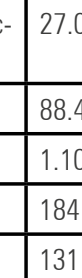

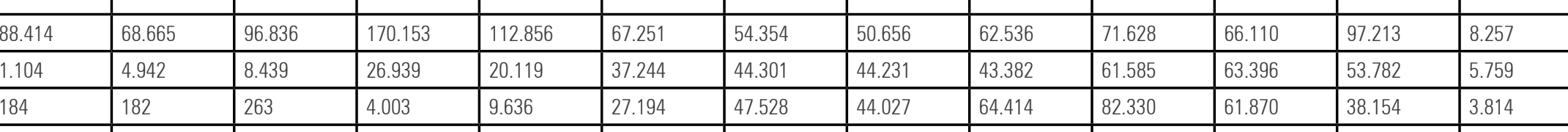

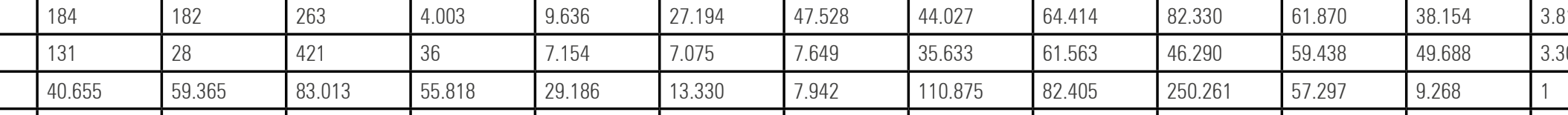

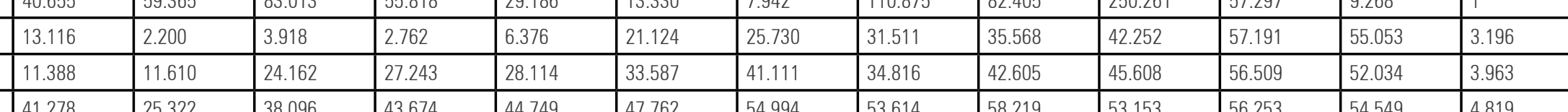

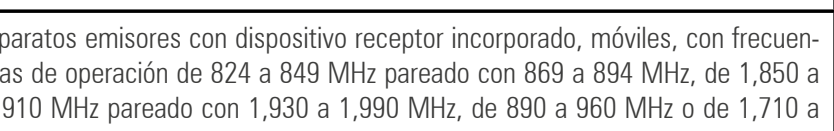

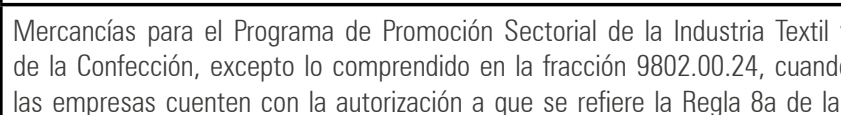

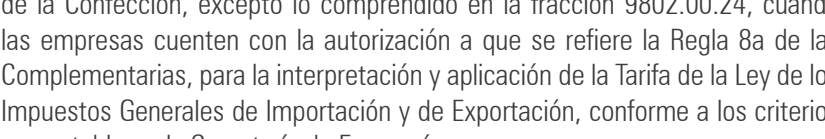

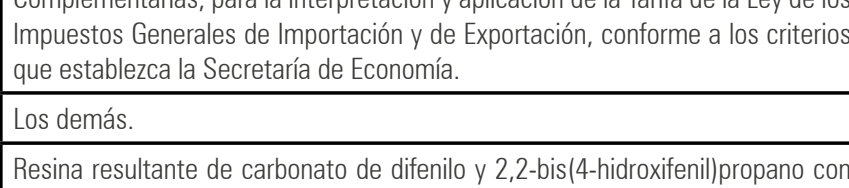

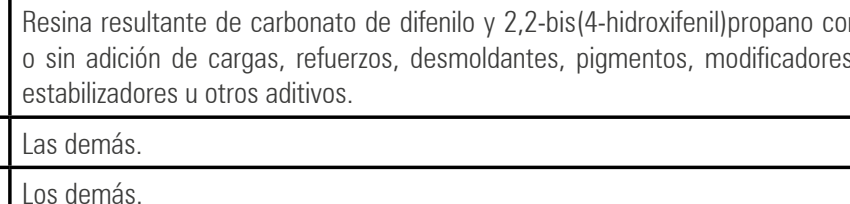

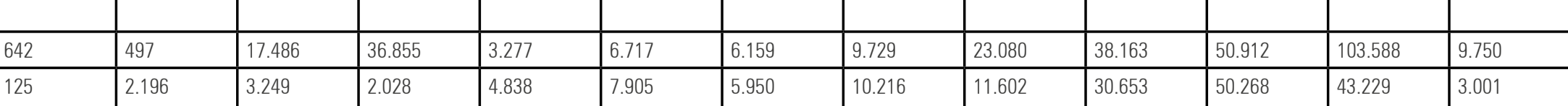

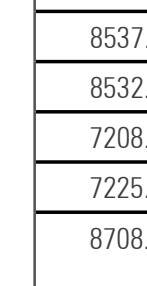

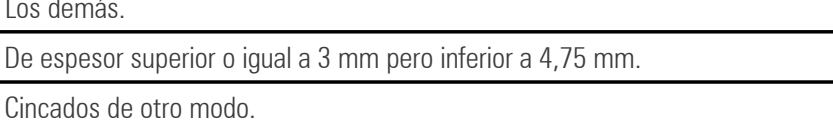

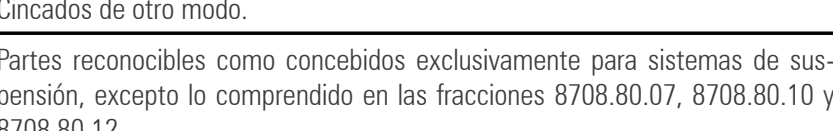

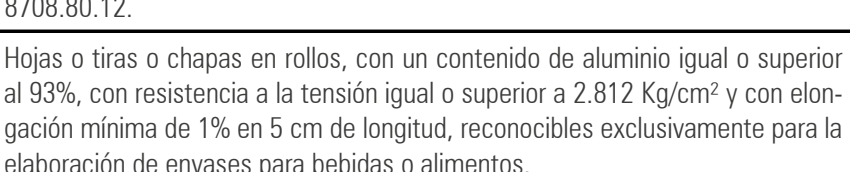

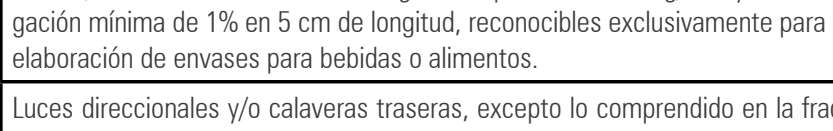

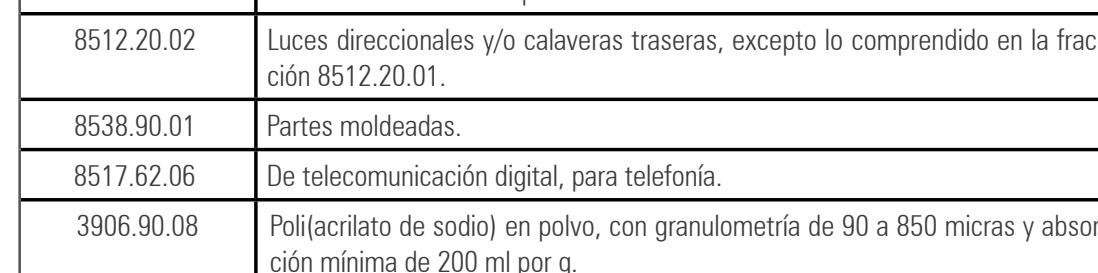

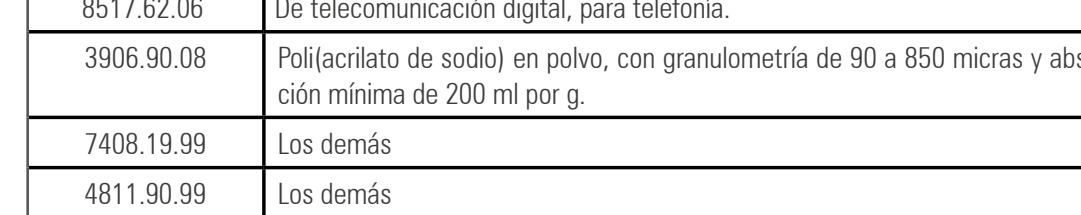

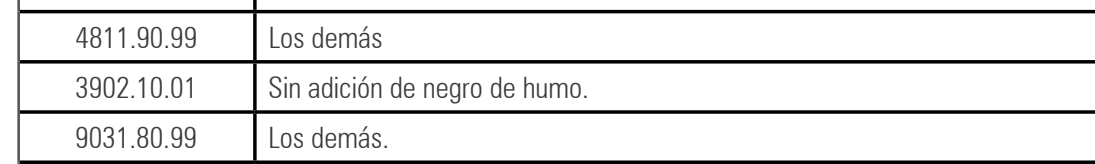

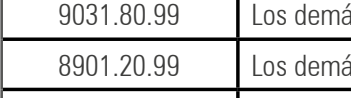

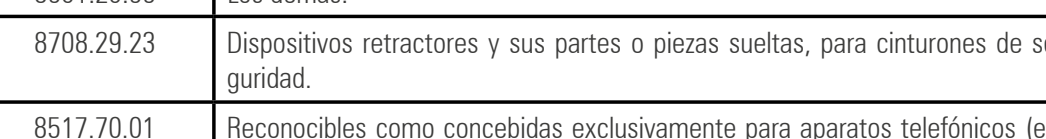

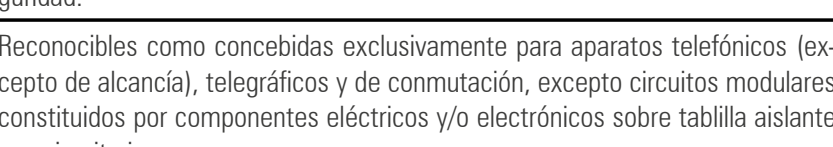

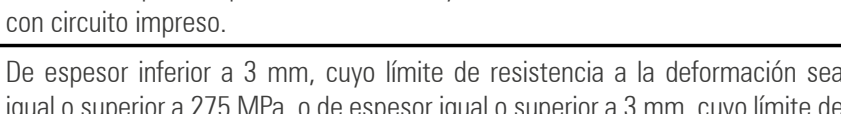

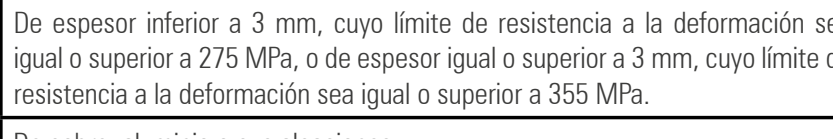

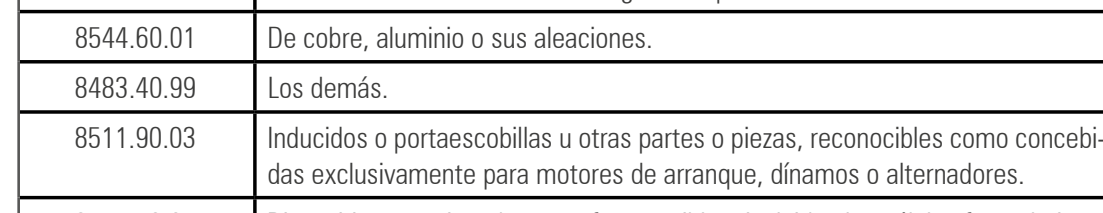

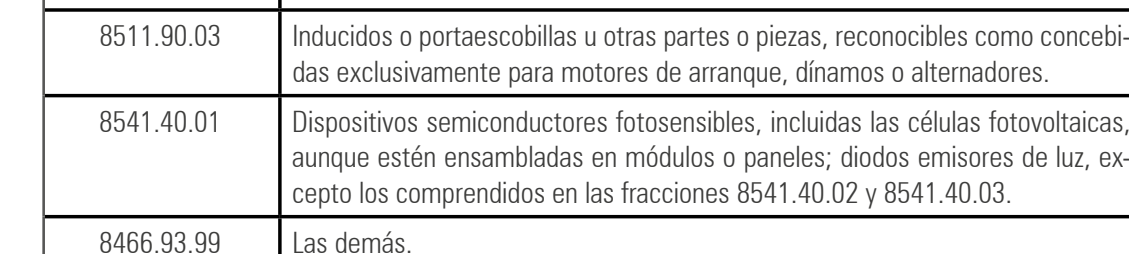

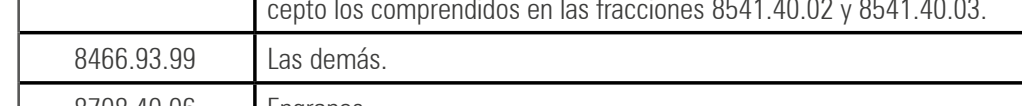

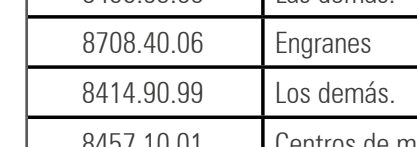

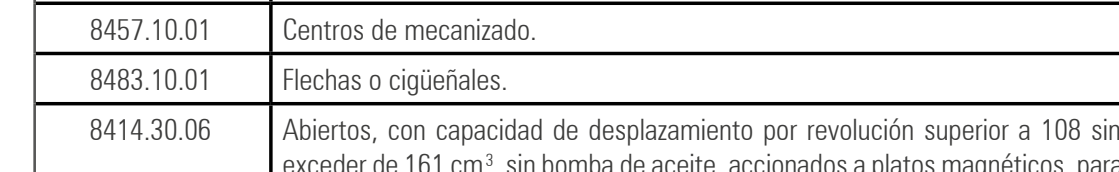

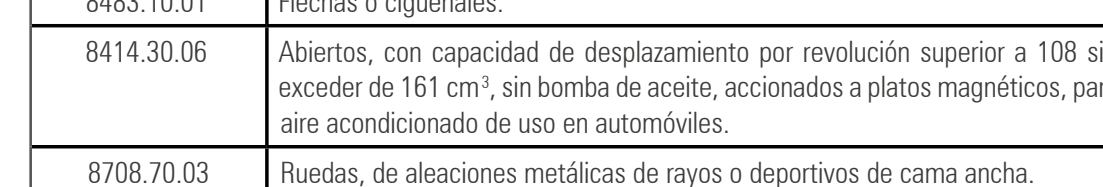

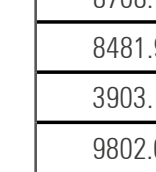

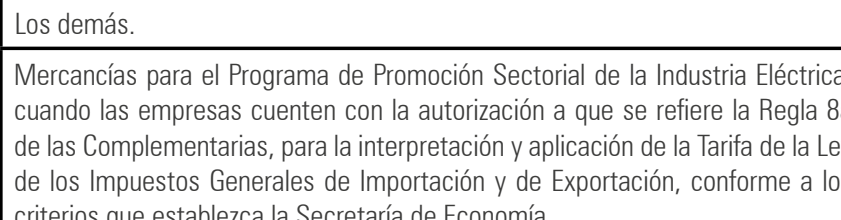

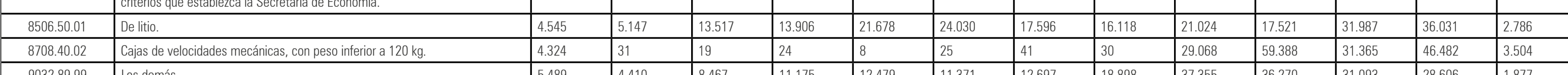




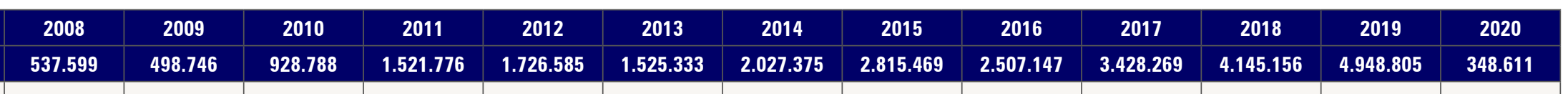

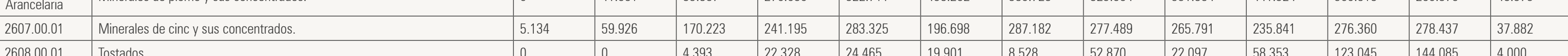

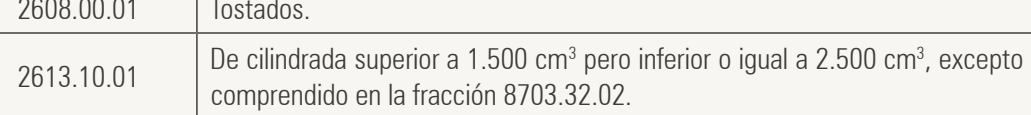

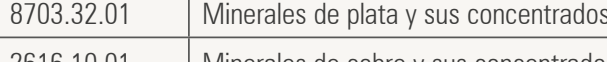

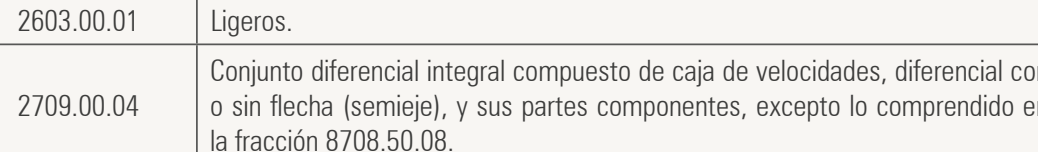

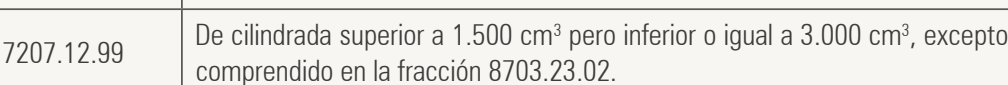

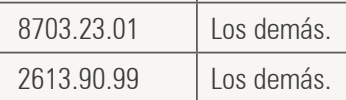

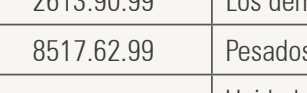

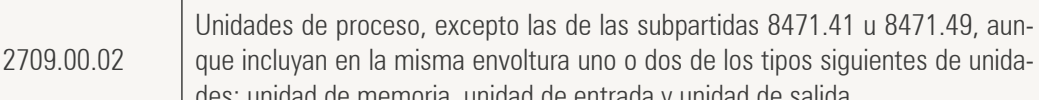

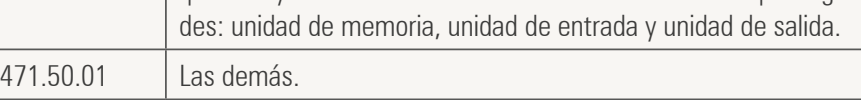

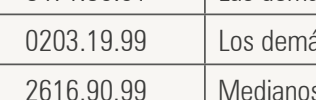

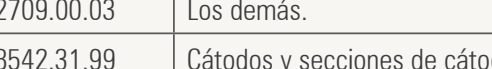

$700.11 .101 \quad$ Las demás

8471.70.01 Culatas (caberas) omonoblowues

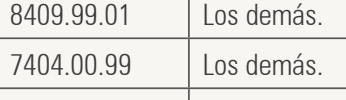

020230.01 Los demás.

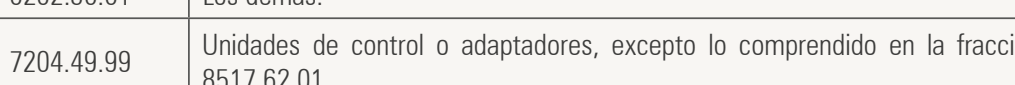

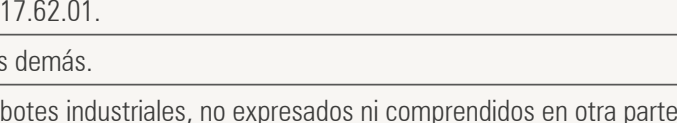

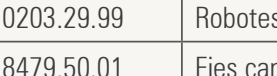

\begin{tabular}{|l|l|l|}
\hline 87005.50 .21 & Las demás. \\
\hline 25010099 & Los demass. \\
\hline
\end{tabular}

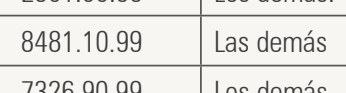

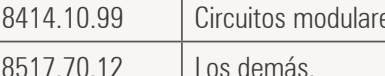

9026.20 .99 Cajas de velocidades automáticas.

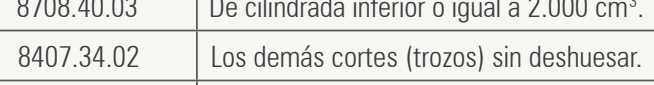

020220.999 De acero inoxidable

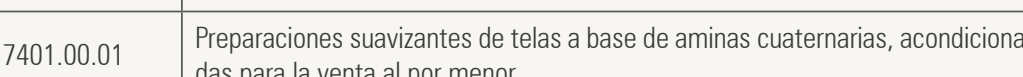

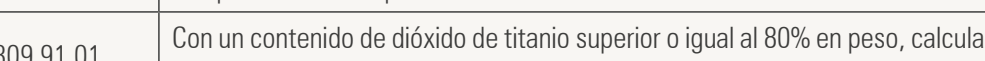

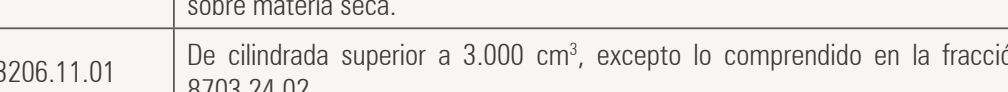

8703.24.01 Aguacates [pattas.

\begin{tabular}{|l|l|l|}
\hline 080440.01 & Los demasas \\
\hline 8537.10 .99 & Los demás \\
\hline
\end{tabular}

\begin{tabular}{|c|c|c|}
\hline 83012.20 .99 & Los demás \\
\hline 90292.209 & Los demis \\
\hline
\end{tabular}

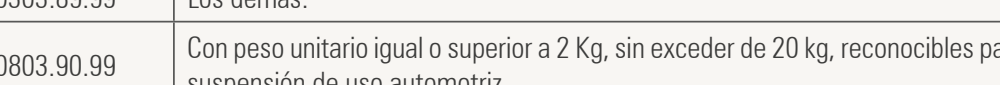

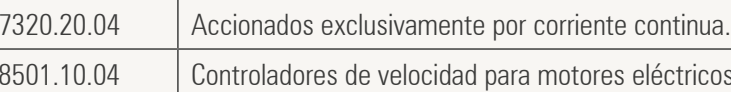

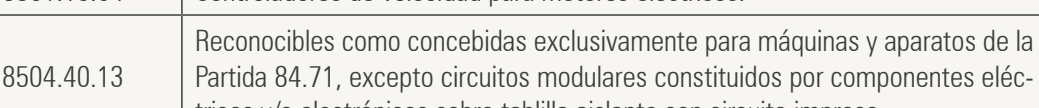

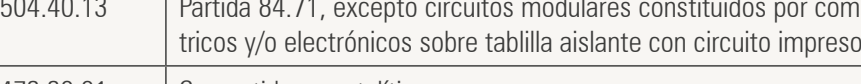

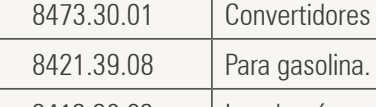

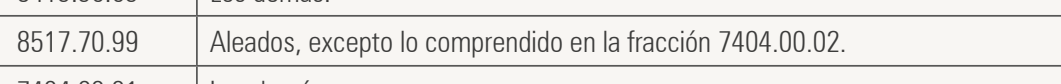

\begin{tabular}{l|l}
$7704-0.0 .01$ & Los denmas. \\
\hline
\end{tabular}

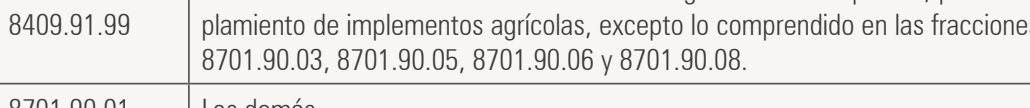

\begin{tabular}{|l|l|}
\hline 870190.01 & Los denás. \\
\hline 8528.51 .99 & Matas de gat \\
\hline
\end{tabular}

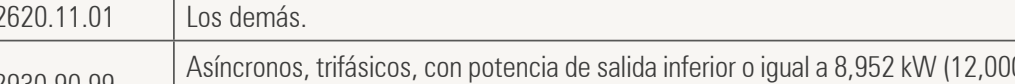

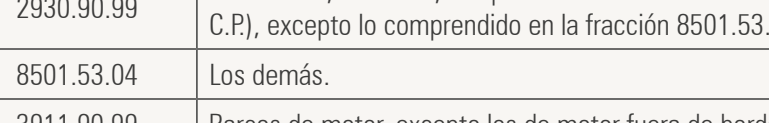

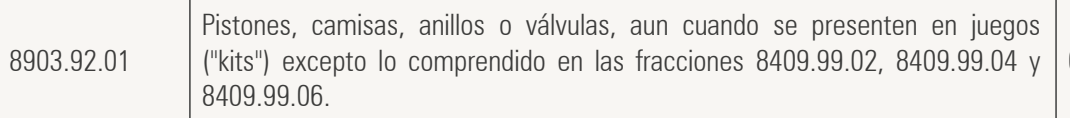

\begin{tabular}{|l|l|}
\hline 840999.03 & Tequila. \\
\hline 2208.90 .03 & Los dem \\
\hline
\end{tabular}

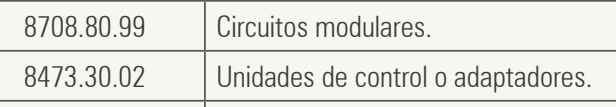

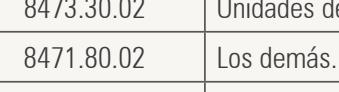

\begin{tabular}{|l|l|l|l}
\hline 1515.50 .99 & Las demás \\
\hline 6810.1999 & Los demás. \\
\hline
\end{tabular}

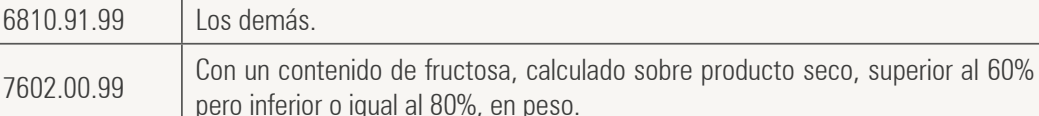

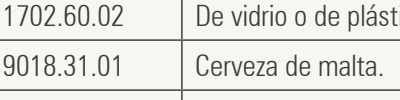

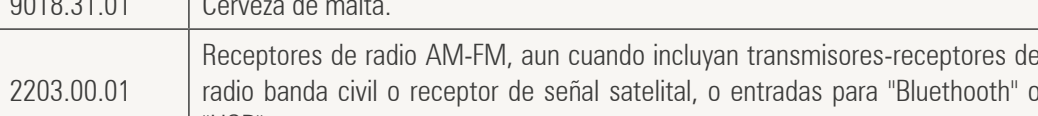

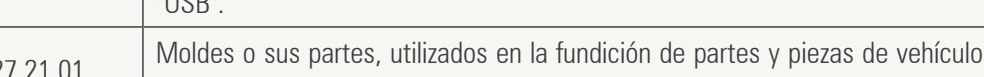

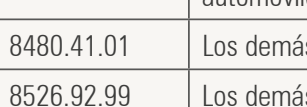

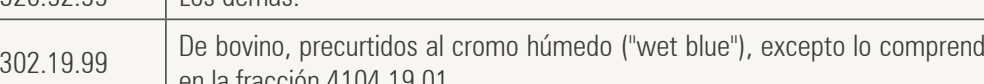

4104.1903 Los denás.

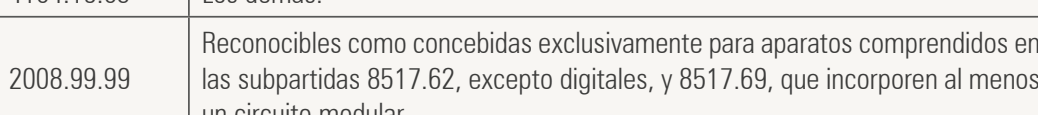

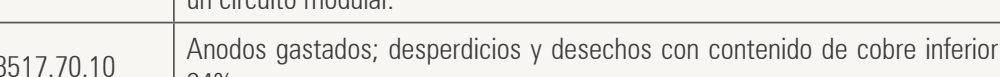

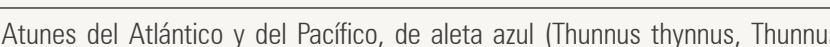

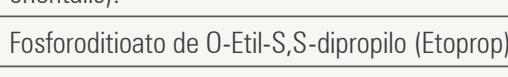

$293090.45 \quad$ Los dem

2934.99.99

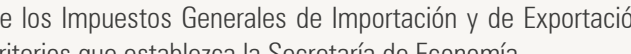

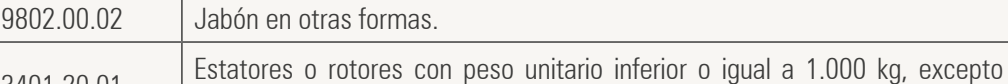

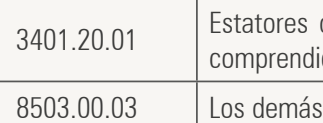

\begin{tabular}{|l|l|l}
85030.0 .03 & Los demas \\
\hline 8414.59 .99 & Los demas \\
\hline
\end{tabular}

3203.0 .099 Carbonato de

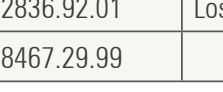

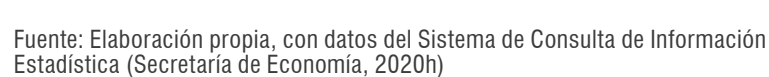

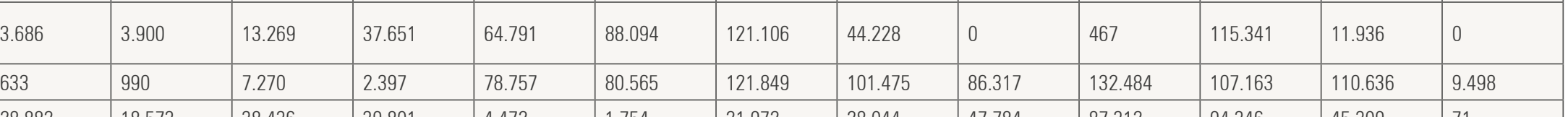

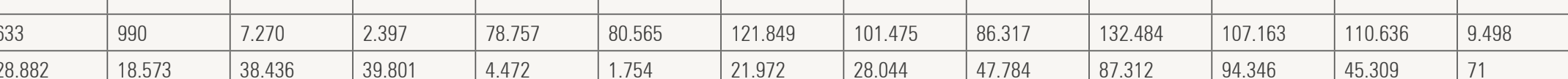

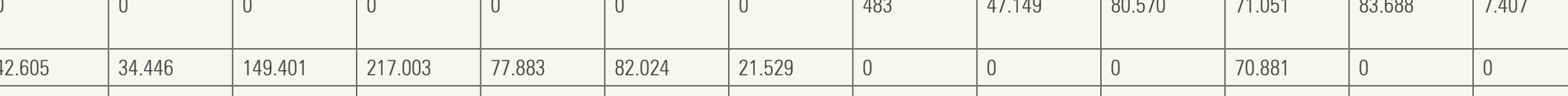
\begin{tabular}{|l|l|l|l|l|l|l|l|l|l|l|l|}
\hline 2.021 & 4.857 & 44.670 & 11.056 & 68 & 1.732 & 7.811 & 17.403 & 28.199 & 63.568 & 82.650 & 2.512 \\
\hline
\end{tabular} \begin{tabular}{|l|l|l|l|l|l|l|l|l|l|l|l|}
\hline 379 & 3639 & 362 & 7.546 & 17.862 & 5.167 & 8.010 & 15.142 & 4.759 & 57.415 & 52.812 & 3.227 \\
\hline 0 & 0 & 0 & 0 & 0 & 0 & 0 & 0 & 205.357 & 52.432 & 0 & 0 \\
\hline
\end{tabular}

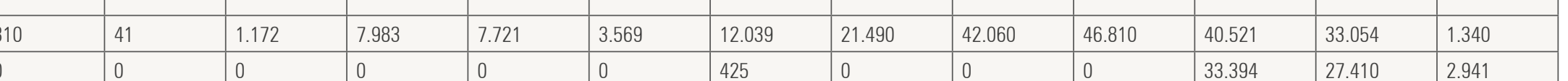

